University of San Diego

Digital USD

2012-05-01

\title{
Tobacco-Use Promotional Environment and Intrapersonal Environment: Predictors of Smoking Intention Among Young Southern California Thai-American Adolescents
}

Arpakorn Magkunthod PhD, MSN, RN

University of San Diego

Follow this and additional works at: https://digital.sandiego.edu/dissertations

Part of the Nursing Commons

\section{Digital USD Citation}

Magkunthod, Arpakorn PhD, MSN, RN, "Tobacco-Use Promotional Environment and Intrapersonal Environment: Predictors of Smoking Intention Among Young Southern California Thai-American Adolescents" (2012). Dissertations. 422.

https://digital.sandiego.edu/dissertations/422

This Dissertation: Open Access is brought to you for free and open access by the Theses and Dissertations at Digital USD. It has been accepted for inclusion in Dissertations by an authorized administrator of Digital USD. For more information, please contact digital@sandiego.edu. 


\title{
UNIVERSITY OF SAN DIEGO
}

Hahn School of Nursing and Health Science

DOCTOR OF PHILOSOHPY IN NURISNG

TOBACCO-USE PROMOTIONAL ENVIROMENT AND INTRAPERSONAL ENVIRONMENT: PREDICTORS OF SMOKING INTENTION AMONG YOUNG SOUTHERN CALIFORNIA THAI-AMERICAN ADOLESCENTS

by

Arpakorn Magkunthod, MSN, RN

A dissertation presented to the

FACULTY OF THE HAHN SCHOOL OF NURSING AND HEALTH SCIENCE

UNIVERSITY OF SAN DIEGO

\author{
In partial fulfillment of the \\ requirements for the degree \\ DOCTOR OF PHILOSOPHY IN NURSING
}

May/2012

Dissertation Committee

Cynthia D. Connelly, PhD, RN, FAAN, Chairperson

Jane M. Georges, $\mathrm{PhD}, \mathrm{RN}$

Kathy S. James, DNSC, FNP-BC 
Tobacco-Use Promotional Environment and Intrapersonal Environment:

Predictors of Smoking Intention among

Young Southern California Thai-American Adolescents

\begin{abstract}
This study explores tobacco-use related environment, intrapersonal factors, and smoking initiation in Thai-American adolescents aged 10 to 16 living in Southern California.

A purposive sample of 217 youth was recruited from seven Thai-community centers located in four counties of Southern California: The sample was fairly evenly distributed by gender with female (54.5\%) and almost three quarters (70.9\%) were born in the United States (70.9\%). Age ranged from 10 to 16 years, with the mean age 12.71 years old $(S D=1.835) ; 27 \%$ reported age of 11 .

Data were collected using the 97 item Teen Tobacco-Use Questionnaire. Findings indicated 12 participants (6.3\%) reported ever trying a cigarette and $2(1.1 \%)$ reported smoking daily. Approximately half $(n=91,48.9 \%)$ of the sample had been exposed to family smoking, 34 (18\%) reported having at least one closet friend who smoked and 15 (7.93\%) having friends who used chewing tobacco, snuff, of dip. 167 (88.4\%) were exposed to smoking advertisings at least some of the time from at least one source. Interpersonal factors included self-esteem subscales of self, family, school, and sensation seeking. Slightly more than half of the sample reported a high level of family self-esteem, but a low level of other self-esteem subscales and sensation seeking. Gender, age group,
\end{abstract}


and school grade level were statistically significant different in exposure to tobacco-use related environment and intrapersonal environment.

Exposure to tobacco-use related environment was positively correlated with belief and attitude toward smoking, intention to smoke, and smoking initiation. Family, school, and friend self-esteem subscales were inversely correlated with intention to smoke and smoking initiation, in contrast sensation seeking was positively correlated with intention to smoke and smoking initiation. Intention to smoke was statistically significantly predictive on smoking initiation. Belief and attitude toward smoking increased the odds while school self-esteem subscale decreased the odds of intention to smoke.

Findings suggested tobacco-use promotional environment influence intention of smoking and smoking initiation. On the other hand, intrapersonal environment play a role as a protective factor among the adolescents in this study. 
(C)2012

Arpakorn Magkunthod 


\section{DEDICATION}

This work is dedicated to my loving parents,

Boonmee and Noopon Rattanatrisree

who defined me:

"Accomplishment is always possible for ones who never give up seeking for it" 


\section{ACKNOWLEDGEMENT}

The completion of this dissertation could not be deeply appreciated without extending my heartfelt gratitude to the following persons who have supported me in many ways.

My Chair Committee, Dr. Cynthia D Connelly and my dissertation committee Dr. Jane Georges and Dr. Kathy James who always advocated time, intelligence, and guide for the best in my dissertation and words of encouragement whenever they were needed. Thank you for exemplifying me scholarly nursing research leaderships. You all are so awesome!

Ministry of Public Health, Thai Government for the Royal Thai Government Scholarship to study aboard. Without this support, I will never have an opportunity to study in the most wonderful university on earth.

Thai Buddhist temples, participants, and the parents who participated in this study and made data collection possible.

Office of Educational Affair, Royal Thai Embassy in Washington DC who took care of all my financial requests. Without your help make my staying aboard will never be this sweet.

Praboromarajchanok Institute for Health Workforce Development who allowed time for me to study aboard, kept my employment, and processed all documents for the scholarship.

Borromarajonnany College of Nursing Udonthani, Thailand who provided the instrumental site for the Computer-Based Questionnaire which made Survey Monkey for iii 
this study possible.

Chia-Yen Lin, assistant director of Office of International Center who processed all legal documents for my residency in the United States and made my stay hospitality.

All faculties and staffs at Hahn School of Nursing and Health Science who provided me a warm, welcome, and scholarly learning climate. Thank you for all your advocates to nursing study and research.

My classmates who energized me and advocated in growing our scholarly knowledge.

All of my friends who always cheered me up and provided helps when they are needed during this research process.

Last but not least, I like to heartedly thank my loving husband, Saner Magkunthod and my beloved daughter, Kantawa Magkunthod who always support in all possible ways for achievement in my PhD study and dissertation and make my day-to-day pleasant and warm. 


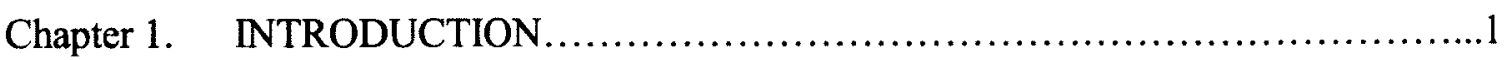

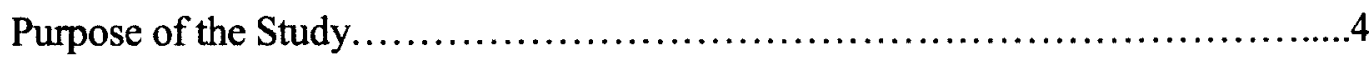

Associated Assumptions......................................................

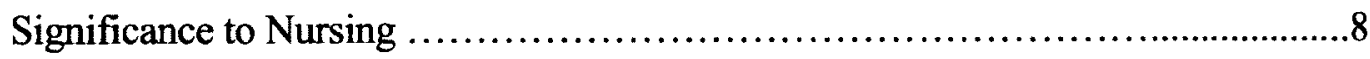

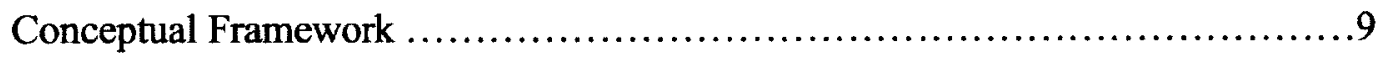

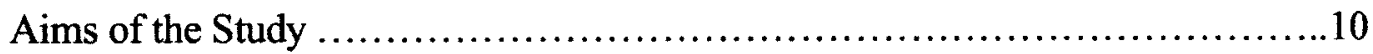

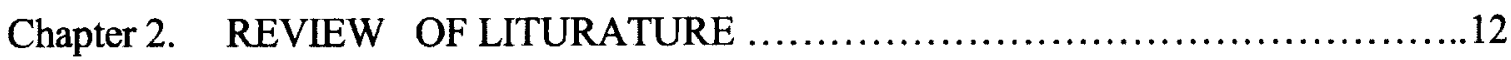

Health Consequence Education............................................17

Gender Related Smoking.................................................23

Home Smoking and Peer Smoking ........................................28

Tobacco-Industry Promoted Images and Perceptions............................34

Socioeconomic Factor .....................................................40

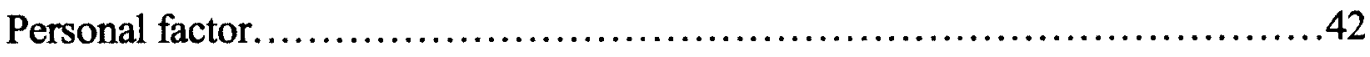

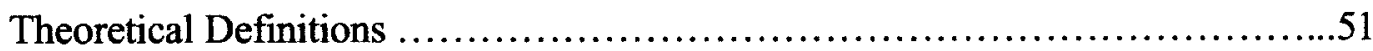

Smoking Behavior Absorption...........................................................51

The Smoking Behavior Adoption .....................................65

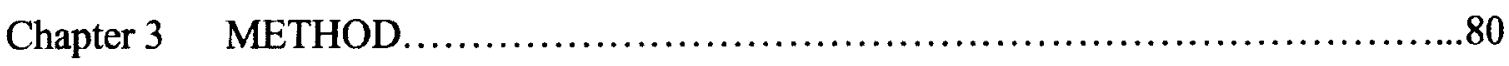

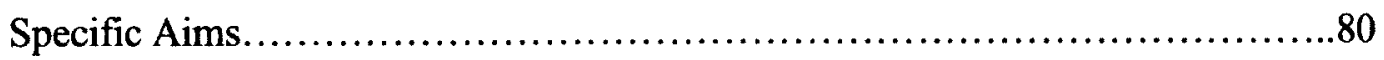

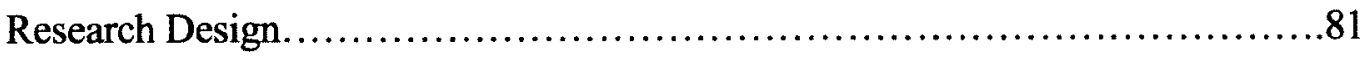


Power, Effect, and Sample Size............................................. 83

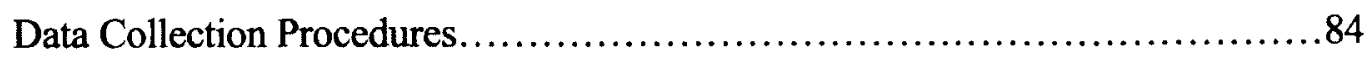

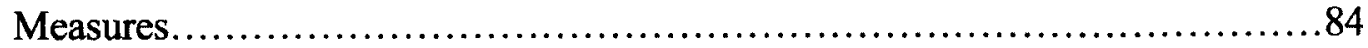

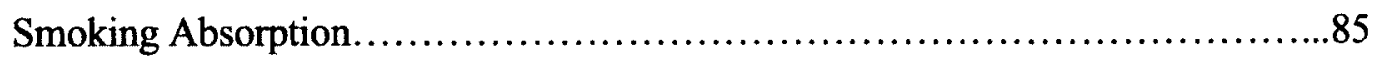

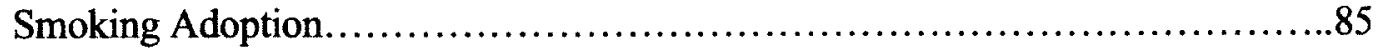

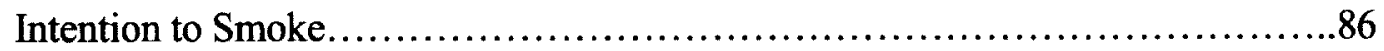

Demographic and Tobacco Use ........................................... 87

Validity and Reliability of the Instruments.................................95

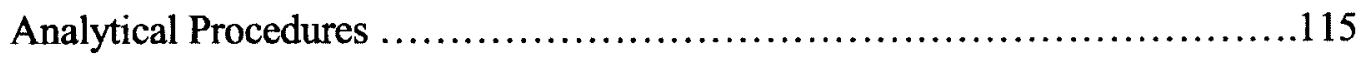

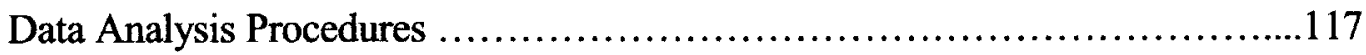

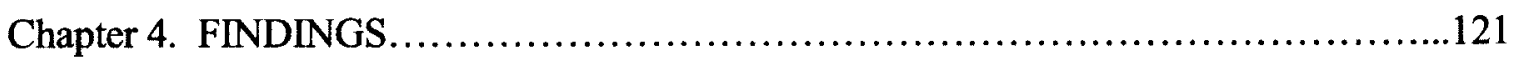

Descriptive of Sample ...................................................

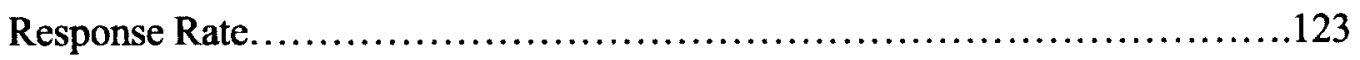

Statistical Analysis.......................................................... 124

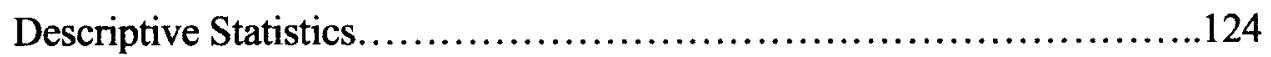

Smoking Initiation.........................................125

Tobacco-Use related Environment...........................131

Belief and Attitude toward Smoking............................133

Intention to Smoke.......................................133

Recalled Antismoking Messages..............................135

Self Esteem.............................................. 140 
Sensation Seeking...........................................141

Inferential Statistics............................................ 142

Differences between and among Groups.......................142

Relationships between Variables...........................147

Odds Ratio and Predictors.....................................151

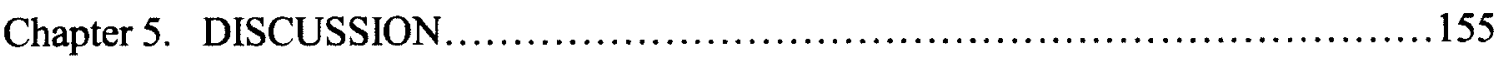

Discussion of Results....................................................

Differential Analysis Results.....................................160

Correlation Analysis Results....................................162

Logistic Regression Analysis Results............................165

Limitation............................................................ 166

Implication for Nursing Practice.......................................169

Implication for Future Research .......................................170

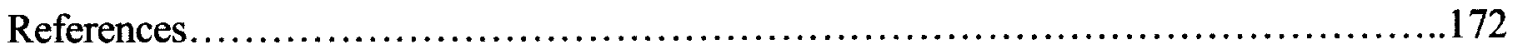


List of Tables

Page

Table 4.1 Demographic Characteristics of Study Sample

Table 4.2 Descriptive Statistics for Smoking Initiation and Tobacco-Use

Related Environment.

Table 4.3 Descriptive Statistics for Belief and Attitude and Intention

to Smoke.

Table 4.4 Descriptive Statistics for Antismoking Messages, Self-Esteem

and Sensation Seeking.

Table 4.5 Belief and Attitude, Intention to Smoke, Self-Esteem, and

Sensation Seeking.

Table 4.6 Differences between and among Groups...............................145

Table 4,7 Correlations between Variables Related to Smoking Initiation.............148

Table 4.8 Differences between Intention and Non-Intention to Smoke.............151

Table 4.9 Summary of Logistic Regression Analysis for Variables

Predicting Smoking Initiation.

Table 4.10 Summary of Logistic Regression Analysis for Variables Predicting Intention to Smoking. 


\section{List of Figures.}

\section{Page}

Figure 1. Conceptual Model and Theoretical framework $\ldots \ldots \ldots \ldots \ldots \ldots \ldots \ldots \ldots \ldots . . . \ldots$ 


\section{List of Appendices}

Appendix A. Institutional Review Board Approval...................................187

Appendix B. Teen Tobacco Use Questionnaire....................................188

Appendix C. The 2005 Middle School Youth Risk Behavior Survey....................214

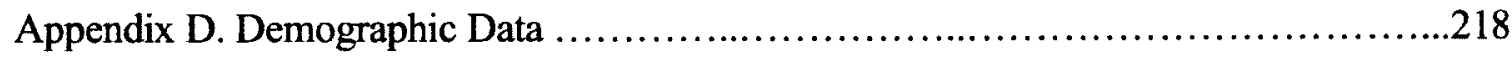

Appendix E. The National Youth Tobacco Use Survey.........................................219

Appendix F. The Indiana Youth Tobacco Use Survey...............................228

Appendix G. The Assessment of Prototypes and Subjective Normative

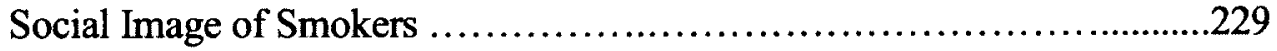

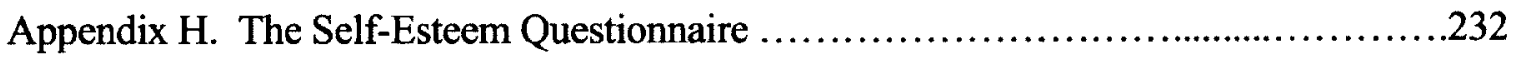

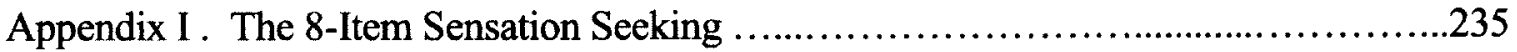




\section{CHAPTER I}

\section{INTRODUCTION}

Statement of the Problem

Smoking cessation is a Global Health Priority (WHO, 2008c). Globally, tobacco use- related diseases account for 5.4 million deaths or one seventh of total deaths caused by non-communicable diseases in 2005 (Mathers \& Loncar, 2006; WHO). Current trends show that by the year 2020/2030, tobacco is likely to be the world's leading cause of death and disability; killing more than 10 million people annually $(70 \%$ of these deaths occurring in developing countries). According to WHO estimates, there are approximately 1.1 billion smokers in the world, about one third of the global population aged 15 years and over.

Empirical findings have found similar smoker characteristics worldwide. Current global reports indicate about 1 billion men smoke with the majority living in developing countries. Approximately 250 million women are daily smokers, (American Cancer Society, 2008) and it is projected to increase to 532 million by 2025 (WHO, 2001). Although in general, boys are more likely to smoke than girls, according to the Global Youth Tobacco Survey (GYTS) boys and girls smoking is almost equal; in fact the trend 
for girls, smoking is increasing and in European and South American countries girls are smoking more than boys (American Cancer Society, 2008). Findings indicate almost all boys who currently smoke began using tobacco before they reach adulthood, notably; about one quarter of young smokers had their first cigarette as early as ten years of age. Most of the girls who currently smoke begin smoking before they reach adulthood (American Cancer Society). The most alarming point is that the vast majority of current smokers, both boys and girls experiment with cigarettes as early as 10-11 years of age (WHO, 2001).

There is an increasing trend in adolescent smoking. Among teens aged 13 to 15 , globally about one in five smokes (WHO, 2002a). Between 80,000 and 100,000 children start smoking everyday, approximately half of whom live in Asia (WHO). About half of those who start smoking in adolescent years continue smoking for 15 to 20 years (WHO). Notably, most teen smokers become addicted to nicotine by the time they reach adulthood (WHO, 2002b). Interestingly, the increase of youth smoking is similar among developed countries and developing countries (WHO, 2002a). These findings suggest smoking initiation problems among Thai adolescents, an example of adolescents in developing countries, do not differ from American adolescents, an example of adolescents in developed countries. However, very few studies have particularly addressed smoking initiation problems among American adolescents who are originally from developing countries, and none have been conducted among Thai adolescents who live in the United States. 
Since 1962, the studying of smoking and tobacco-use related diseases has resulted in over seven thousand publications. Many educational programs have been implemented to educate risk groups; and "quit line" counseling, as well as other remedies have been offered to smokers who want to quit (CDC, 2007). The United States Congress has passed many laws including: the Federal Cigarette Labeling and Advertising Act, the Public Health Cigarette Smoking Act, the Little Cigar Act, and the Comprehensive Smoking Education Act (CDC). These laws, respectively, require tobacco industries to provide health warnings on all cigarette packages, ban cigarette advertising on television and radio, provide an annual report on the health consequences of smoking, and require health warnings, not only on cigarette packages but also on advertisements (CDC). However, data show the consumption of tobacco products is still high.

Numerous studies have been conducted and findings indicate the fight against tobacco-use using educational programs do not appear to be as effective as the temptation created by tobacco-advertisings. Program messages appear too weak to alert adolescents of harmful effects and have failed to make it obvious to the adolescents that tobaccorelated diseases and illness do affect their lives. In fact, some of educational programs had reverse effects; rather they appeared to cause susceptibility to smoking rather than warnings of smoking health risks.

Previous research has identified factors that lead to smoking initiation and continuation among adolescents. Such factors include age, gender, ethnicity, family size, parent smoking, peer smoking, socioeconomic status, tobacco industrial advertising, 
smoking related background, education, belief and attitude toward smoking, and selfesteem. Unfortunately, none of these studies have been able to connect these factors into a complete picture of smoking initiation and continuation within the context of adolescence. This failure causes an inability to create essential interventions to fight against the initiation of tobacco-use and continuation of the use among adolescents.

Purpose of the Study

The present study purposes to construct a picture of smoking and tobacco-use within the Thai adolescent context and examine what factors influence Thai youths smoking patterns.

Associated Assumptions

Previous research has examined adolescent background, knowledge of unethical practice of tobacco companies, smoking advertisings, beliefs and attitudes toward smoking, socio-economic status (SES), parent smoking, peer smoking, motivation, parenting style, and adolescent smoking.

The adolescents' background includes sensation seeking, body self-esteem, family self-esteem, and school self-esteem. Sensation seeking has influences on whether or not the adolescents are receptive to messages of anti-smoking education or smoking advertising, the selection of anti-smoking learning environments, and whether or not attitudes toward smoking (negative or positive) perpetrated by social norms can affect 
pre-existing attitudes toward smoking, and how well one can resist smoking. Positive attitudes, beliefs, and social norms of smoking; specifically parents smoking and peer smoking have significant influences on smoking initiation and continuation. These influences are even stronger among adolescents who are raised with high levels of "strictcontrol" parenting and "psychological-control" parenting. The interaction between parent smoking and peer smoking both directly and indirectly leads to smoking initiation. Finally, low self-efficacy, low family self-esteem, low school self-esteem, and low selfimage and body image allow channels for these factors to motivate adolescents to smoke.

Various models have revealed significant factors for smoking initiation among early and middle adolescents across all genders and ethnicities including sociodemographic, socio-cultural, and personal factors. The most consistent components in each model include socio-demographic factor: age; socio-cultural factors: parents smoking, and family members smoking, peer smoking, and tobacco advertising; and finally, personal factors: positive beliefs and attitudes toward smoking, low self-efficacy to resist smoking, low school self-esteem, low family self-esteem, low body-image selfesteem, and low self-image.

These components lead to the assumption that smoking initiation and continuation among adolescents are bound within a specific developmental context from childhood toward adulthood which links the adolescents to smoking. The age factor indicates that the older the adolescents grow, the more likely they are to smoke. Therefore, there must be something in the development from childhood to early adolescence, early adolescence 
to middle adolescence, and so forth until the child reaches adulthood that leads the adolescents to smoking. Findings also show that the older the adolescent becomes the lower one's self-esteem, the more self-dependent, and peer interdependent they become (Kawabata, Cross, Nishioka, \& Shimai, 1999; Wolman, 1998).

Research studies show children learn from their environment via interaction with people.-Parent smoking, peer smoking, and tobacco advertising significantly influence attitudes and beliefs toward smoking and peer smoking; these factors illustrate the social smoking learning context. As the adolescent matures; the older adolescent becomes more self-dependent and peer interdependent which may support why peer smoking becomes the most crucial key in smoking initiation and continuation.

\section{Smoking Behavior Absorption}

This investigator proposes that to initiate smoking adolescents must have resided in the specific environmental context and must have gone through two processes: a) smoking behavior absorption and b) smoking behavior adoption. The smoking behavior absorption refers to the process of introducing the adolescents to smoking, how they absorb messages, beliefs, and attitudes toward smoking from their environment, until they develop their own beliefs and attitudes toward smoking. For adolescents to initiate smoking, one must have developed "desirability" toward smoking. The smoking behavior adoption refers to the process when "absorption" initiated youths accept smoking activities in addition to their developmental activities, or to replace some of 
developmental activities which are unlikely to be achieved in order to fulfill the sense of development toward adulthood.

To find an explanation for the smoking behavior absorption, the investigator hypothesizes that before an adolescent starts smoking, she/he must get to know about it first. An individual gets to know about smoking, cigarettes, or tobacco products through his/her sensation receivers, such as by seeing, watching, or even smelling. Through the process of getting to know, the feelings toward the atmosphere of smoking emerge. These emerging feelings are mostly positive for those who are likely to absorb the behavior; feelings gradually transform to cognitive responses, then attitudes and beliefs emerge. When repeatedly submerged in a smoking scene, the individual's attitudes or beliefs toward smoking become stronger and stronger until he/she develops intention to smoke, and is encouraged enough to try smoking. Some adolescents may initiate smoking alone; however, it is most likely that when the adolescents who already have intention to smoke get together they are encouraged by each other to smoke. The youth may try his/her first puff and may stop or repeat his/her experiment with smoking until he/she realizes whether he/she likes or dislikes it, and then he/she may decide to continue or quit. This process goes through the cognition-intention and intention-behavior links. Prior to reaching the intention point, the youth must pass through the smoking adoption.

\section{Smoking Behavior Adoption}

In the smoking behavior adoption, the investigator hypothesizes that an individual 
accepts smoking activities into his/her practices. The adolescent perceives such activities are acceptable amongst his/her social setting; for some adolescents smoking activities may also serve as fulfillment for the sense of self when they sense threats to the development toward adulthood caused by unlikely-to-achieve developmental activities or when they sense the developmental gap is too wide. The investigator believes that the former condition is most likely to happen among adolescents who were raised in the specific smoking environmental context where anti-smoking education is deficient or ineffective. The investigator believes that the latter condition is a stronger link to smoking than the former; the adoption of smoking behavior still occurs unless antismoking education campaigns are sufficient, effective, matched to the adolescents' background and desirability, and endued in a perfect timing.

Adolescents value and prioritize daily activities based on their developmental interest and situations they are facing. They learn to do so via the interaction with their significant others. The individual will put his/her greatest effort practicing the behavior he/she highest values and prioritizes until his/her desire is fulfilled or until he/she realizes that it is impossible to fulfill the desire or his/her interest has shifted.

\section{Significance to Nursing}

This study is important for several reasons. First, it will provide a picture of smoking initiation and tobacco use among Thai-American adolescents living in Southern California; concurrently it may provide information on the causes of initiation, smoking absorption, smoking adoption, or both. Being able to address the point where the 
adolescents initiate smoking and the causes of smoking initiation has the potential to improve educational and early intervention efforts directed toward smoking cessation. A clearer understanding of the role of smoking absorption and smoking adoption will help guide nursing in clinical practice, education, and research.

\section{Conceptual Framework}

The conceptual framework for the proposed study is derived from the literature and is depicted in the following model (see figure 1).

Figure 1. Conceptual Model and Theoretical Framework

\section{Smoking Adoption}

\section{Smoking Absorption}

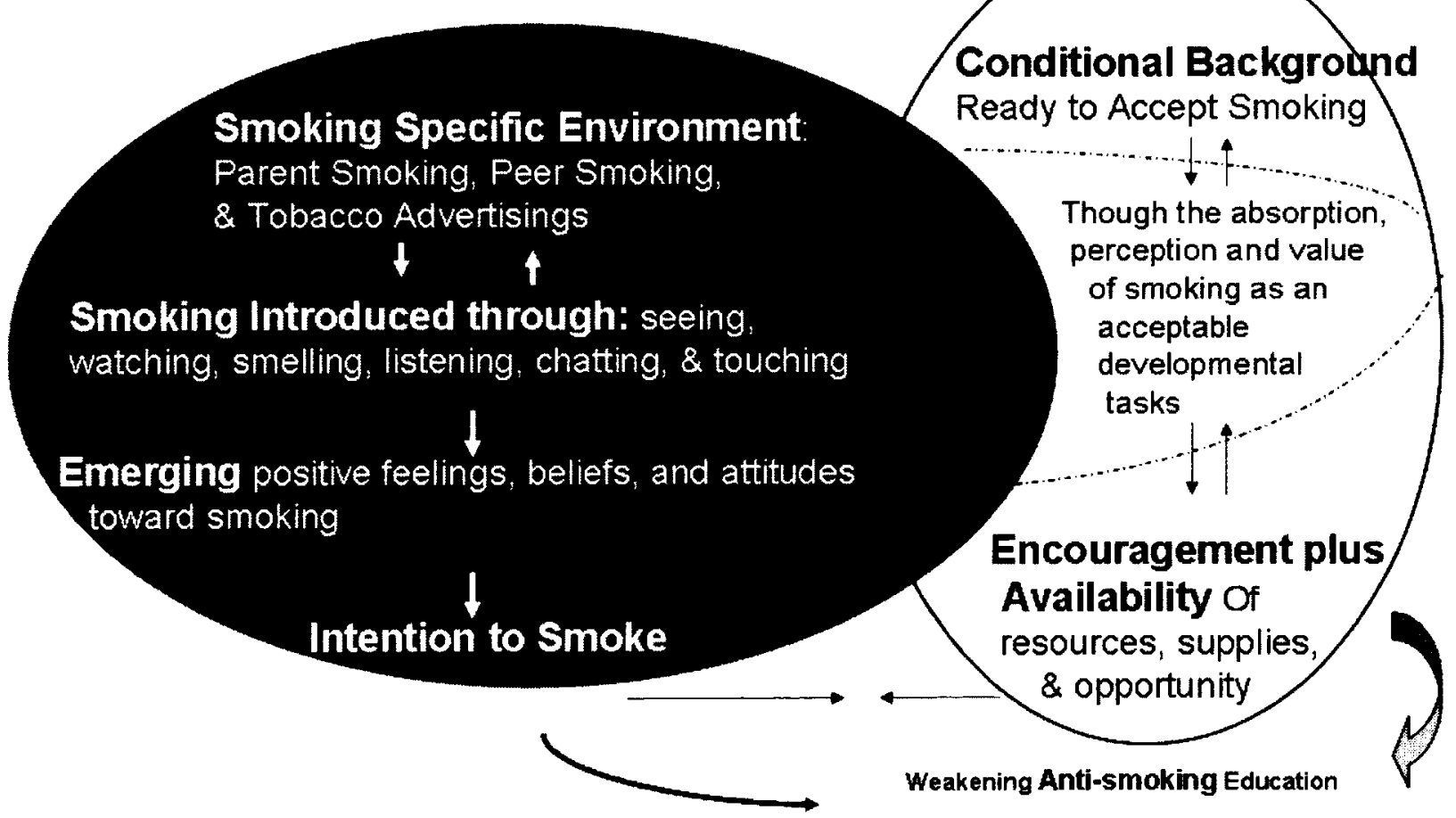

The smoking environment includes parent smoking, peer smoking, and tobacco 
advertisings. The smoking absorption includes receiving messages of smoking through one or more receivers--seeing tobacco products and advertisings or watching the scene of smoking, chatting to friends about smoking or listening to people in the smoking scene, smelling the smoke, and touching tobacco products--, then develops feelings, beliefs, and attitudes toward smoking, and finally develop intention to smoke. The smoking adoption includes the adolescents' background ready to accept smoking, the adolescents valuing smoking as an acceptable developmental task, encouragement to smoke, and smoking initiation.

The adolescents' background ready to accept smoking includes one or more of the following aspects: high sensation seeking, low body-image or self-image, low family self-esteem, low school self-esteem, and low self-efficacy to resist smoking. As the two diagrams are moving closer toward each other, the greater the chance the adolescents who have these conditions, the smoking absorption and smoking adoption, will initiate smoking. One never imagines that human behaviors will obviously become a new significant health-threat.

\section{Aims of the Study}

The aims of this study are:

Aim 1: Characterize smoking absorption and smoking adoption among ThaiAmerican youth.

Aim 2: Examine the relationships between the domains of smoking specific 
environment, smoking introductions, smoking believes, intentions to smoke, and smoking adoption among a group of Thai American adolescents.

Aim 3. Examine which domains (smoking specific environment, smoking introductions, smoking believes, intentions to smoke) increase the risk for smoking adoption among a group of Thai American adolescents living in Southern California. 


\section{CHAPTER II}

\section{REVIEW OF THE LITERATURE}

Historically, health care providers targeted infectious diseases to promote health and well-being. As a result diseases and deaths caused by microorganisms or communicable diseases are decreasing; in contrast diseases and deaths due to human behavior, or non-communicable diseases are rapidly increasing. In 2002, noncommunicable diseases caused nearly half of the global disease for all ages (Mathers et al., 2004). For the age group of 15 years and over, non-communicable diseases account for $85 \%$ of disease in developed countries, over $70 \%$ in middle-income countries, almost $50 \%$ in high mortality regions, including many developing countries (Mathers et al., 2004), resulting in increased number of deaths, which are constantly increasing each year.

Among non-communicable diseases, the highest proportion of death presents in coronary heart disease. In 2005, globally, deaths caused by cardiovascular disease alone accounted for thirty percent of deaths of all causes, equaling to a combined number of those caused by communicable diseases, maternal and perinatal conditions, and 
Nutritional deficiencies (WHO, 2006). Empirical studies have shown relationships of the disease as well as some other non-communicable diseases to tobacco use. Tobacco-userelated diseases account for 5.4 million deaths, or one seventh of total deaths caused by non-communicable diseases in 2005 (Mathers \& Loncar, 2006; WHO, 2008c).

Tobacco use, including smoking is linked with many kinds of deadly chronic diseases (WHO, 2007). Empirical studies found thousands of toxic chemicals in tobaccosmoke including acetone, ammonia, arsenic, butane, cadmium, carbon monoxide, DDT, hydrogen cyanide, methanol, naphthalene, toluene, and vinyl chloride (WHO, 2002). Interestingly these are used in manufacturing following products, respectively: paint stripper, floor cleaner, ant poison, lighter fuel, car batteries, car exhaust fumes, insecticide, gas chambers, fuel, moth balls, industrial solvent, and plastics (WHO). Studies also illustrate that some of these chemicals are primary factors that induce heart disease, stroke, and chronic lung disease. Some cause cancer of the lungs, larynx, esophagus, mouth, and bladder. In addition, some also contribute to cancer of the cervix, pancreas, and kidneys (WHO).

Smoking causes many serious health problems not only to smokers but also second hand smokers. In direct smoking alone, the Surgeon General's Report (CDC, 2004) - various diseases and adverse health effects caused by smoking. Diseases include cancer of bladder, cervix, esophagus, kidneys, larynx, lungs, oral cavity, pancreases, and stomach, leukemia, cardiovascular diseases, respiratory diseases, and other health defects. Cardiovascular disease includes abdominal aortic aneurysm, atherosclerosis, 
cerebrovascular disease, and coronary heart disease. Respiratory disease includes chronic obstructive pulmonary disease, pneumonia, respiratory effects to fetus, respiratory effects in childhood and adolescence, and respiratory effects in adulthood. Additional health defects include fetal death, stillbirths, infertility, low birth weight, pregnancy complications, cataract, diminished health status, morbidity, hip fractures, low bone density, and peptic ulcer in persons who are Helicobacter pylori positive (CDC).

Second-hand smokers are also susceptible to tobacco-related diseases. Those who never smoke, but happen to be exposed to environmental tobacco smoke are at increased risks of smoking-related diseases. Based on epidemiological studies, "involuntary smoking" can lead to coronary heart diseases, chronic respiratory symptoms, having fullterm infants weighing 200 gram less than those born from non-exposure of smoking pregnant, and obtaining higher concentrations of carcinogens placing second-hand smokers at higher risks of cancer for several sites of the body. In addition, second hand smokers are found to have cotinine, a parent compound of nicotine (WHO, 2002a).

Extant studies have reported the consequences of second-hand smoking; in children, involuntary smoking can cause middle ear disease, respiratory symptoms, impaired lung function, sudden infant death syndrome (SIDS), and lower respiratory illness. Evidence also suggests that brain tumors, lymphoma, asthma, and leukemia are more likely to occur in children exposed to tobacco-smoke. In adults, evidence supports second-hand smoking can cause nasal irritation, coronary heart disease, lung cancer, and poor reproductive outcomes in women, such as low-birth weight. Finally, evidence also 
suggests that exposure to tobacco smoke may cause stroke, nasal sinus cancer, breast cancer, atherosclerosis, chronic obstructive pulmonary disease (COPD), chronic respiratory symptoms, asthma, impaired lung function, and preterm delivery (CDC, 2006). Sadly, most smokers and second-hand smokers are unaware of such health consequences. The unawareness results in continuous use and/or exposure, which boosts gradual health impairment. Unfortunately, such consequences are hardly noticeable. It takes time for the smoker and second-hand smoker to become suspicious about his/her health and when he/she realizes the compromised health, it is often too late.

The information discussed above marks tobacco use as a significant health-risk factor. In fact, it is the single largest cause of preventable death globally (WHO, 2008d). Among eight leading causes of death, tobacco-use is a risk factor for six leading causes of death; including ischemic heart disease, cerebrovascular disease, lower respiratory infections, chronic obstructive pulmonary disease (COPD), tuberculosis, and tracheabronchus-lung disease (WHO, 2008 e). In 2002, among fifteen leading causes of death, ischemic heart disease, cerebrovascular disease, lower respiratory infection, COPD, tuberculosis, trachea-bronchus-lung disease, hypertensive heart disease, and stomach cancer are ranked first, second, third, fourth, eighth, ninth, thirteenth, and fifteenth (Mathers \& Loncar, 2006). If current smoking patterns continue, in 2030, these causes of death will still be in top rankings. Several may even move up in rank: COPD moves up to the fourth, Trachea-bronchus-lung cancer moves up to the sixth, hypertensive heart disease moves up to eleventh, and stomach cancer moves up to the tenth. Lower 
respiratory infection may move down to the fifth and tuberculosis down to the twentythird because of interventions to achieve the Millennium Development Goal for tuberculosis (Mathers \& Loncar).

These diseases lead to life and economic losses. Mathers and Loncar (2006) predict that tobacco-related diseases will cause 6.4 million deaths in 2015 , which is $50 \%$ more deaths than HIV/AIDS, and responsible for $10 \%$ of all deaths globally. Such losses will be continually increasing and reach 8.3 million by 2030 (Mathers \& Loncar). Currently, tobacco-use costs the world hundreds of billions of dollars each year (WHO, 2008e). The economic losses due to tobacco-related deaths in the United States are estimated at 92 billion dollars a year, and annual tobacco-related health-care costs are as high as 81 billion dollars (WHO). Second-hand smoking is also costly. Health-care expenses for second-hand smokers alone in the United States account for 5 billion dollars on direct costs and more than 5 billion dollars on indirect costs (WHO). In 1998, tobaccorelated diseases cost Hong Kong 532 million dollars for active smoking and 156 million dollars for passive smoking (McGhee et al., 2006). Globally, tobacco-use causes tremendous losses. Howard Barnum, World Bank economist, estimated that worldwide expenses due to health-care and economic losses caused by smoking-related diseases are approximately 200 billion dollars a year in global net social cost (Lemieux, 2001; WHO, 2007).

In spite of serious consequences and great loss of life and increased healthcare expenses, people are still practicing the habit of smoking and other methods of tobacco 
use. The number of global cigarette consumption recorded in 1880 revealed only 10 billions of "sticks". Thirty years later, in 1910, the consumption rose to 100 billion of "sticks" (WHO, 2004). After tobacco companies had successfully improved the operation of the cigarette machine; global cigarette consumption dramatically increased (Robert, 2007). Ten years later, the number of consumption was tripled to 300 billion of sticks, and increased to 600 billion in 1930 and 1,000 billion in 1940. Fifty years later, in 1990, the consumption exponentially rose to 5,419 billion "sticks" (WHO, 2004a). By 2000, consumption was pretty much stabilized, at 5,500 billion "sticks". The increase was only 81 billion of sticks from 1990 (WHO). However, when considering the percentage of increased consumption, in 120 years consumption increased 55,000 percent.

Ideally, when people realize health-consequences of tobacco-use, the use should decrease, but it hasn't. Several questions are raised based on this startling information. Why do people continue to risk their health with known untoward consequences? Were all at risk populations educated?

\section{Health Consequence Education}

Warnings of the health consequences of smoking aren't new. Early warnings were present during 1600s. A China philosopher, Fang Yizhi, reported" long years of smoking sear smoker's lung" (WHO, 2004b). In 1604, King James of England wrote an article about smoking titled "A counterblast to tobacco" followed by an article: "Turkey death penalty for smoking" in 1633 . The first study of effects of tobacco was conducted in 
England in 1761 (WHO). Thereafter, many reports regarding health-consequences of smoking were presented: Germany in 1795, United Kingdom in 1950 and 1962, and the United States in 1939 and 1953. In the United States, although effects of smoking had been debated for decades, the first Surgeon General's report was officially released in 1964. The report revealed that smoking causes lung cancer in men (Borio, 2003; WHO). The Surgeon General's report on health consequences of smoking was released annually from 1960s to 1980s; with 28 reports of the Surgeon General released to the public (Borio; University of Minnesota Libraries, 2008) and since 1962 a number of over seven thousand articles related to tobacco-use and diseases have been publicly published (CDC, 2007).

After the release of the first Surgeon General's report, a few states requested smoke-free airlines and banned cigarette advertising on television, similar to the United Kingdom. In the United States, health warning on the side of cigarette packs began in 1966. In 1968, the Action on Smoking and Health was formed to promote prevention of smoking in the community (Borio). Three years later, in 1967, the first world conference on tobacco was held. Since then, the world conference on tobacco has been held every four years (WHO, 2004). In 1970, the WHO publicly stood against cigarette smoking (Borio, 2003); Singapore in 1970, banned smoking in cinemas, theaters, and busses; the United States held and promoted "Smoke-out Day", smoke-free airlines; in 1977 Canada established; the first national Non-Smoking Week; and in 1978, Japan formed the first tobacco control group, followed by Australia in 1979, Taiwan in 1984, and Iceland in 
1985 (Borio). In 1988, after the $20^{\text {th }}$ Surgeon General's report was released, the World No-Tobacco Day sponsored by World Health Organization was held. Its slogan was "tobacco or health: the choice is yours" (Borio). Since then, World No Tobacco Day is held every May $31^{\text {st }}$ to call public attention to the health consequences, and to discourage tobacco-use (Borio; WHO).

Following the global movement against smoking, smoking restrictions increased. "Ban of Smoking" in restaurants began in 1987, followed by tobacco control in China in 1994, Italy banned smoking in any public places in 1995, and Turkey banned smoking in most enclosed places in 1996 (Borio, 2003). Health education about tobacco use was also implemented in the nations to promote awareness of its harmful effects (WHO, 2004). Annual themes from 1988 to 2002 respectively include: tobacco or health: the choice is yours choose health, women and tobacco: at added risk, growing up without tobacco: children and youth without tobacco, tobacco in public places and on public transportation: better be tobacco free; tobacco at the workplaces: safer and healthier, health services including health personnel, against tobacco: our window to a tobacco-free world, the media against tobacco: getting the health message across the economics to tobacco: tobacco costs more than you think, sports and arts without tobacco: play it tobacco-free- the United Nations and specialized agencies against tobacco: United for a tobacco-free world, growing up without tobacco cessation: leave the pack behind, the entertainment industry, secondhand smoke kills, let's clear the air, and tobacco free sports: play it clean (Borio; WHO). 
The anti-tobacco movement increased in intensity. May 2003, the WHO World Health Assembly adopted the WHO Framework Convention on Tobacco Control to provoke action at the global and country level against tobacco use (WHO, 2008e). Based upon the framework, many countries have adopted six policies to fight the tobacco epidemic. The six policies include: 1) monitoring tobacco use; 2) prevention policies; 3) protecting people from tobacco use; 4) warning about the dangers of tobacco; 5) enforcing bans on tobacco advertising, promotion, and sponsorship; and 6) lastly raising taxes on tobacco (WHO). Recommended indicators of monitoring systems include prevalence of tobacco use, impact of policy interventions, tobacco industry marketing, promotion, and lobbying. Protecting non-smokers from tobacco use includes smoke-free environments requesting no smoking in public places such as restaurants, workplaces, smoke-free laws enforcing complete prohibition of smoking in all indoor environments, clear penalties for violations, as well as enforcement policies. For smokers, helping to quit smoking includes tobacco cessation advice incorporated into primary health-care services, easily accessible free quit lines, and access to low-cost pharmacological therapy, as well as the support from government for the program. Warning about the dangers of tobacco includes anti-tobacco advertisements in order to change the image of tobacco and providing warnings on tobacco-product packs. Enforcing bans on tobacco advertising, promotion, and sponsorship include prohibition of any media of advertisements such as movies, televisions, radio, newspaper, magazines, billboards, and even the internet in order to protect current users and going-to-be users from false perception of tobacco 
produced by tobacco industries. Finally, taxation on tobacco directly increases the price of tobacco and results in reducing the consumption of tobacco (WHO).

Excise taxation of tobacco has been practiced worldwide for centuries (WHO, 2008e). Out of 193 member states of WHO, 86 countries have recently monitored tobacco-use and have nationally representative data for both adults and youths. One hundred seventy-nine countries and 1 territory have implemented smoke-free laws. However, only $5 \%$ or 16 countries have implemented comprehensive smoke-free laws that completely cover all public and enclosed places. Out of 173 member states reporting on tobacco dependence treatment, 151 states have help-to-quit programs. However, only 9 states have offered a full range of treatment and partial financial subsidies. For health warnings, 99 states have health warnings on tobacco packs. Out of these states, 23 countries require the warnings cover at least $30 \%$ of the surface of the package, and 5 states, such as Thailand adopted comprehensive pack warnings, require illustrative health warnings covering at least $50 \%$ surface of the package. One hundred twenty-three countries have bans on advertising, promotion, and sponsorship on any kind of activities. Out of these countries, 20 have adopted complete direct and indirect bans; 45 have at least four direct bans. Taxation seems to be implemented worldwide; all member countries, 152 that provide information of taxation have tobacco-excise tax. Out of these, 4 countries raised the tax up to $75 \%$ of the retail price, 55 to $51-75 \%$ of retail price, 58 to $25-50 \%$ of retail price, and the rest (35) have less than $25 \%$ of retail price (WHO).

In spite of massive global movement against smoking, cigarettes consumption 
still increases. Ten years after the nation members of WHO publicly declared war on smoking in 1970, 1980 cigarette consumption increased from 3,112 billion sticks to 4,388 billion sticks or about 41 percent (American Cancer Society, 2008; Bario, 2003). In order to provide a greater impact on smoking, in 1988, WHO established World No-Tobacco Day held every year ever since. However, in 1990 the consumption still increased to 5,419 billion sticks or about a 74\% increase from 1970 (American Cancer Society; Bario). After 30 years the anti-smoking movement had minimal effect, although the consumption appears to be progressing at a slower rate; the percentage of increase was 77.99 percent and 80.07 percent respectively from 1970 (American Cancer Society; Bario). WHO established WHO Framework Convention on Tobacco in 2003, yet, consumption continues to increase. Based on the current trends, the consumption of cigarettes is projected to reach 9000 billion sticks annually by 2025 (American Cancer Society). This projection is corresponding to the world demand of tobacco leaves estimated by FAO. In 2010, it is estimated that the demand will reach 7.1 million in dry weight; $8 \%$ more than 1998 demand (FAO, 2003). In addition, about $80 \%$ of tobacco leaf is used in from of cigarettes and about $20 \%$ of the leaves are consumed in the other forms including bides and chewing tobacco (FAO). In addition, in producing cigarettes, tobacco companies use less and less tobacco leaf per cigarette. While about 2.28 pound of tobacco leaf was used to produce 1,000 cigarettes in 1960 , only 0.91 pound of tobacco leaf was used in 2000 (WHO, 2004). An increased demand of tobacco leaf accompanied with less and less tobacco leaf use in producing cigarettes undoubtedly raises cigarette 
production. Tobacco companies are producing 5.6 trillion cigarettes per year, an average of 900 cigarettes for every single man, woman, and child of the world population (American Cancer Society, 2008). It is estimated that by 2030 there will be at least another 2 billion people who smoke (American Cancer Society). Even though, smoking prevalence in some countries is decreasing, the total number of global smokers is increasing due to expansion of the world population and tobacco marketing influences (American Cancer Society). Correspondingly, cumulative deaths globally due to tobaccouse related diseases continue to rise and are projected to increase to nearly 180 million deaths by 2030 .

\section{Gender Related Smoking}

The number of male smokers is declining in extremely slow rates. Currently, about 1 billion men smoke globally, the majority in developing countries. Approximately, 250 million women are daily smokers. In contrast to male smoking, the majority of female smokers are in developed countries, and the prevalence is even higher than male smoking in some countries (American Cancer Society, 2008). It is projected by 2025 global female smokers will rise to 532 million (WHO, 2001). Boys are more likely than girls to smoke. However, in the Global Youth Tobacco Survey (GYTS), gender differences in cigarette smoking are significantly minimal (WHO, 2002a). Almost all boys who smoke began using tobacco before they reach adulthood, about one quarter of young smokers had their first cigarette before the age of ten. There is an increasing trend 
in girls smoking (WHO). In fact, in European and South American countries girls are smoking more than boys. Most of the girls who smoke begin using tobacco before they reach adulthood (American Cancer Society). Some girls even try their first cigarette as a child, and many girls experiment with cigarettes around the age of 10-14 year, on the other hand in some countries girls do not start smoking until after the age of 18-21 years (WHO, 2001).

The question arises what in tobacco marketing influences the habit and what factors enhance this influence? Although governments all over the world can collect more than 200 billion dollars in tobacco tax revenues, less than 1 percent of the revenues were spent on tobacco-control. Unsurprisingly, only about 5 percent of the world's population is protected by any one of key interventions: smoke-free environment, cessation support, pack warnings, and effective bans on advertising-promotion-sponsorship (WHO, 2008e). People are still smoking or using any other kinds of tobacco. The world share of cigarette production and consumption in developing countries rose to over sixty percent and is projected to increase to seventy percent by 2010 (WHO). Global marketing of cigarettes is continually high. Share of world cigarette production and consumption has shifted to developing countries. According to the shift, the majority of world cumulative deaths are projected to occur in developing countries (WHO).

What factors in the nature of tobacco use trigger initiation repeated use, transforming to a habit, and eventually becoming addicted to it, particularly among youth? Empirical studies show factors that influence tobacco initiation and maintenance 
of tobacco use among adolescents mainly occur in their community. Based on a large number of empirical studies, World Health Organization (WHO, 2001) has discussed such factors in its report entitled "Women and the tobacco epidemic: Challenges for the $21^{\text {st }}$ century". These factors include socio-demographic, socio-cultural, socioeconomic, and personal factors.

Socio-demographic factors: age, gender, ethnicity, acculturation, family size and structure were found to have relationships with teen smoking. Strong relationships were also found between smoking and socio-cultural factors which include parental and peer tobacco use, and image or perception promoted by tobacco industry. In some areas, socioeconomic factors which include parental socioeconomic statuses and individual backgrounds were also found to be significant with teen smoking. Finally, personal factors including four domains: knowledge, attitudes and beliefs, self-esteem, and selfimage were found to be significant among teens in general. In the next section, factors that influences the initiation and continuation of tobacco use will be discussed based on these four groups of factors.

Socio-Demographic Factors: Age, Gender, Ethnicity, and Family Structure or family Size Studies show that initiation and prevalence of tobacco use among adolescents typically start with increasing age and grade (WHO, 2001). In addition, those who begin smoking at a younger age were more likely to become regular smokers and less likely to quit smoking. Prevalence of tobacco use between genders is found significantly different 
in particular areas (WHO). During 1999 to 2004, the prevalence of girls' smoking aged 15 or older was higher than that of boys, among the European countries, of Finland, Sweden, Spain, Austria, Czech, and Slovenia (American Cancer Society, 2008). In contrast, among some countries, boy smoking was more prevalent than girl smoking including the United States, Russian Federation, Turkey, Mongolia, Philippines, Myanmar, Sudan, Kenya, and Mauritania (American Cancer Society). Yet, overall, at the global level, male and female smoking is equally prevalent (American Cancer Society).

It is not quite clear why in some areas males and females tend to equally smoke, where as some areas tend to be gendered: male smoking is higher than female smoking, or female smoking is higher than male smoking. Differences in gender may link to differences in preferences. Empirical studies showed that although males and females tend to equally smoke, their preferences of smoking are different. Women tend to consume fewer cigarettes than men, prefer filter-tipped, low-tar, low-nicotine cigarettes, do not prefer self-roll cigarettes, inhale less deeply, and leave more of the cigarette not smoked (American Cancer Society, 2008). This finding indicates that smoking initiation or smoking habit was adopted through a gateway of different preferences between genders.

Tobacco products that contain particular aspects which match teens' preference will be able to sell themselves to the teens. The issue that is not well known is what these aspects are: is it just only the design of the products or other elements? For 
example, in the study of ethnic differences in predictors of smoking onset found black boys more likely to smoke than black girls while white boys and white girls were equally likely to smoke (Robinson, Murray, Alfano, Zbikowski, Blitstein, \& Klesges, 2006). This finding suggests there must be some other factors that relate to gender, and we need to find out what are they if we wish to effectively provide deterrents to teens smoking. To review other factors may provide additional clues.

Ethnicity is a factor associated with teens smoking. In some countries, for example, the United States, show significantly lower levels of initiation and current smoking than Whites or Hispanics (WHO, 2001). The question arises, "why"? In a longitudinal study of ethnic differences in predictors of smoking onset, Robinson, Murray, Alfano, Zbikowski, Blitstein, and Klesges (2006) found some predictors were shared and some were totally unique among teens from different ethnicities. Among Blacks, higher prevalence of smoking, onset of weekly smoking, and daily smoking was found in those who were rebellious. Among Whites, those who had many best friends smoking were 131 times more likely to smoke than were those who did not. In contrast, having a few best friends smoking showed to be a predictor of smoking onset among Blacks. Living in a smoking household was a significant risk for both Blacks and Whites (Robinson et al.), and Mexican teens aged 11 to 13 (Bird, Moraros, Olsen, Coronadi, \& Thompson, 2006). How the factor of living within a smoking household can trigger smoking requires attention. Is it role modeling, accessibility, or something else? Examining family structure may provide some insight into this factor. 
Family structures show relationships with smoking initiation. Intact-two parent families are protective against smoking. In contrast, household size has various and unclear effects on smoking (WHO, 2001). Since this finding is inconsistent, it is possible it may be just a coincidence. However, we need to keep it in mind when looking at other factors.

Socio-Cultural Factor

Home smoking and peer smoking.

An overwhelming number of studies about home smoking parent or sibling smoking and peer smoking predicting smoking onset among early adolescents show significant results (Flay et al., 1994; Kemppainen et al., 2002; Kobus, 2003; Mowery et al., 2004; Ayatollahi, Mohammadpoorasl, Rajaeifard, 2005; Brook, Pahl, \&Ning, 2006; Geckova, Stewart, Dijk, Orosava, Groothoff, \& Post, 2006; Miller, Burgoon, Grandpre, \& Alvaro, 2006; Seo et al, 2009). Parent smoking is as strong as friends smoking in predicting smoking initiation among early adolescents. Both factors are considered the strongest influences and they are so strong that they can influence the initiation regardless of gender and ethnicities.

A cross-sectional study of smoking behavior between Russian $9^{\text {th }}$ graders and their Finland counterparts showed that although there was a difference in smoking prevalence, age of smoking experiment, and intention to smoke in future, their smoking situations were common (Kemppainen et al., 2002). The prevalence of "daily smoker" 
among Russian boys was as 1.5 times greater than Finnish boys and 4 times greater than Russian girls (Kemppainen et al.). The prevalence of "daily smokers" among Finnish girls was slightly higher than Finnish boys and 3 times greater than Russian girls (Kemppainen et al.). In both areas, boys experimented with smoking earlier than the girls. Russian $9^{\text {th }}$ graders had a slightly higher prevalence of smoking intentions than Finnish $9^{\text {th }}$ graders. However, Russian adolescents experimented with smoking later than Finnish adolescents (Kemppainen et al.). Interestingly, despite such differences, smoking situations between two samples were common; for example, smoking with a friend was usual among the adolescents. They also commonly smoked in their free time, outside their home, during school breaks, on their way home, or at home secretly from parents' knowledge (Kemppainen et al.). Findings from following studies among different nationalities or ethnic groups were quite similar to Kemppainen et al's regarding peer influences.

Geckova et al. (2005) studied the influence of socio-economic status, parents, and peers on smoking behavior among Slovak adolescents at an average age of 15 years. The researchers found that about three quarters of adolescents reported their friends smoking and over half of the samples reported their parent smoking (Geckova et al, 2005). The researchers also found that "friend smoking" was the strongest predictor of smoking among Slovak adolescents; the more number of friends smoking the adolescent has, the more likely he/she will smoke (Geckova et al.). Slightly different from peer influence, parent smoking had both direct and indirect influence on smoking. Adolescents 
who's either or both parents smoked were more likely to smoke than those whose parents did not smoke. The adolescents also tended to have more friends who smoked than did the adolescents whose parent did not smoke (Geckova et al.) Socio-economic status showed indirect influence and was significant only when parent and peer smoking were included in-the model (Geckova et al.). The findings by Kemppainen et al. (2002) and Geckova et al. (2005) were mostly representing the influence of parent smoking and peer smoking on smoking behavior among Whites. Interestingly, the studies of such influences on adolescents in different ethnic groups revealed quite the same results.

Brook et al. (2006) conducted a 12-year longitudinal study of peer and parent influence on smoking transition between African-American adolescents and their Puerto Rican counterparts, from age of 14 towards their young adulthood, to identify the difference between two ethnicities. The researchers found prevalence and onset of smoking different and influence on smoking common between two samples. Puerto Rican adolescents had a greater lifetime prevalence of tobacco use, started smoking at an earlier age, and engaged in daily-smoking onset earlier (Brook et al., 2006). The study failed to show significant differences in parent and peer smoking on smoking onset between two samples. The researchers also found that the adolescents who reported exposure to peers who smoked at age of 14 were twice as likely to be in the smoking group and continue smoking increasingly toward the age of 24 where the number of cigarettes meets it peak. Exposing to peer smoking at age of 14 also decreased the likelihood to become non-smokers, late-starting smokers--starting at age of 19 , or those 
who reported stop-smoking after age of 24 (Brook et al.). Parent smoking affected almost similarly. Adolescents who were exposed to parent smoking at age of 14 were 3 times more likely to be in a smoking group that started smoking at early age and continued smoking as well as increased levels of smoking till the number of smoking met its peek at age of 24 , compared to adolescents who reported non-smoking through period of study (Brook et al.). In addition, exposing to parent smoking at age of 14 also predicted late-smoking onset. The influence was twice the odds for late-smoking onset than on non-smoking. It also decreased the likelihood that the adolescents will become non-smoker (Brook et al.).

An examination of psychosocial predictors of smoking onset among Maryland $6^{\text {th }}$ graders revealed similar results (Simons-.Morton, \& Haynie, 2003). In a 12-month study, between time 1 and time 2, there was a significant likelihood that the sample will be in higher smoking stage, from non-smoker to Intender, Trier, Experimenter, and current Smokers respectively. The percentage of non-smokers also decreased significantly at time 2, compared to time 1 (Simons-Morton \& Haynie). Adolescents who were smokers at time 1 were more likely to continue smoking and advance to higher levels of smoking. Intenders at time 1--smoked 1-2times in lifetime but not in the past 30 days or 12 months-were as much as 2.48 times to become experimenters and 2.64 times to become current smokers at time 2 (Simons-Morton \& Haynie). The influences found positively associated with the advance to higher smoking stage include peer affiliation and perceived smoking prevalence. Adolescents who had closest friends smoking, drinking, 
cheating on test, bullying someone, acting disrespectfully, stealing, lying to parents, or damaging property and adolescents who perceived high percentage of their peers' smoking were more likely to advance to higher stage of smoking (Simons-Morton \& Haynie). Differences between gender and among ethnic groups were found significant only in the advance in smoking stage. Girls were 1.49 times more likely than boys to advance in smoking stage, and Whites were more likely than Blacks to advance in smoking stage (Simons-Morton \& Haynie). Mowery et al's (2004) study yields quite similar results.

Mowery and associates (2004) examined the progression to established smoking and factors correlating to the progression among the United States (US) adolescents. The researchers found the progression to established-smoking differed between gender and among ethnic groups. Males were more likely than females to progress to established smokers. According to Mowery et al., established smokers were those who smoked over 100 cigarettes in their lifetime and smoked at least on 20 days of past 30 days (Mowery et al). The prevalence of established smokers was highest among Whites and lowest among Blacks. The prevalence of "open to smoking" or "intention to smoke" was highest among Hispanics and lowest among Whites (Mowery et al.) It is noteworthy that Whites were lowest in open to smoking but highest in established smoking.

The study also revealed that among middle-school adolescents, number of closest friends' smoking influenced the open to smoking. The adolescents who reported their closest friends smoking reported intention to smoke in near future (Mowery et al., 
2004). Although exposing to smoking at home such as parent smoking failed to show significant influence on opening the adolescents to smoking, it was a factor leading the teens to established smokers, which was significant both in middle-school and highschool adolescents. The researchers also found a similar effect in tobacco-advertising influence. Susceptibility to tobacco industry advertising and promotion was significantly related to intention to smoke among middle-school adolescents and to establishedsmokers among both middle-school and high-school adolescents (Mowery et al.). A study of such influences among Iranian adolescents showed supportive results to those discussed above.

Ayatollahi et al (2005) examined factors predicting stages of smoking among Iranian male adolescents, age range of 14 to 19 . The study showed low prevalence of smoking among Iranian adolescents: of 1,116 participants, 16.9\% were experimenters smoked less than 100 cigarettes in their lifetime, and $2.5 \%$ were regular smokers-smoked more than 100 cigarettes in their lifetime (Ayatollahi et al., 2005). The findings indicated that friends' smoking was correlated to stages of smoking among the samples. The findings also indicated other factors related to intense smoking including attitude toward smoking, use of alcohol or illicit drugs, and self-esteem (Ayatollahi et al.).

Examining risk factors and stages or onset of smoking provides a greater understanding of the developmental and dynamic progression of smoking among adolescents. According to the findings discussed above, parent or family smoking and friends smoking -indeed open the door to smoking among adolescents exposed to either 
or both of these factors. Findings from some studies discussed above also revealed clues that may lead to an explanation of why such factors can lead the teens to smoking initiation and continuation. Some highlight other variables related to smoking, which include perceived prevalence of peer smoking, intention to smoke, attitudes toward smoking, and exposure to tobacco-industry advertising. It is generally accepted that once an individual has an intention to do something, he/she will do it if he/she has adequate resources or supports. Thus, the relationship between intention to smoke and smoking will be not discussed in this paper. Next the influence of tobacco-industry advertising will be presented.

\section{Tobacco-industry-promoted image or perception.}

Long before warnings regarding health problems linked to tobacco use were released, historical evidence indicates people had positive attitudes toward tobacco use. Tobacco gained more and more important roles in the national economy among countries that do tobacco trade. Yet, after harmful effects of tobacco use were released, people still debated the advantages and disadvantages of tobacco-use and most people seem unconvinced regarding its harmful effects. Positive perception of tobacco use has been growing more and more for centuries from unintentionally-formed image by pioneer users to conventionally created image by tobacco-industry companies (Borio, 2007). Constant positive perceptions of tobacco use gradually root-deeply into user's life style.

Before cigarettes were invented and introduced to the world, tobacco was 
consumed in many forms including smoking, chewing, snuffing, and even drinking as tea (Canada Tobacco, 2008). Historical studies found nicotine, an addictive substance in tobacco, in human remains. This evidence indicated humans learned to consume tobacco long before the century era. However, for the new world, the very first group of people to be observed to use tobacco was Arawak, a tribe of the West Indies, by Columbus in 1492 . Historically, pioneer users consumed tobacco for many useful purposes: religious, medical, hygienic, and recreational (WHO, 2001; Canada Tobacco, 2008). In Central America, Mayas, the earliest user of tobacco around the first century, smoked tobacco leaf in their sacred and religious ceremonies. Arawak adopted the smoking custom from Mayas. They believed that their god revealed himself in the rising smoke of tobacco (Borio, 2007). During Columbus' Discovery, tobacco was offered to Columbus and his crew as a gift. After tobacco was introduced to Europe, Europeans studied its medical properties and recognized tobacco as a remedy for all diseases (Borio). Tobacco was used in treatment including migraine, colic, nephritis, hysteria, hernia, and dysentery, toothache, falling fingernails, worms, halitosis, lockjaw, and even cancer. Tobacco was finally recorded in the US Pharmacopeias as an official government listing of drugs in 1890 (Borio). Such purposes of tobacco use reflect how positively people perceived tobacco at the time and how valuable the plant was (Canada Tobacco, 2008). Tobacco leaves became more and more valuable and were used as a monetary currency acceptable for paying debts and goods or even buying people. In 1619, each of women shipped to America from England was worth $120 \mathrm{lbs}$ of tobacco leaves (Borio). 
The demand for tobacco became so great many European countries began cultivation of tobacco and controlled tobacco trade. For examples, in Spain around 1606, the death penalty was punishment to those who sold tobacco to foreigners (Borio, 2007). By $17^{\text {th }}$ century, people primarily smoked for pleasure purpose (Canada Tobacco, 2008). Soon cigarettes were invented and introduced to the public as a new way of smoking. The successful invention of cigarette-making machines, Bonsack machine the first machine resulted in an dramatic increase of cigarettes production (Borio). After the invention of Bonsack machines in 1881 , tobacco consumption hit 20 billion sticks in 1890 , double amount of that in 1880 (American Cancer Society, 2008). The demand of tobacco combined with the ability to cultivation of tobacco and successful production of cigarettes speeded up the growth of tobacco business as well as tobacco-advertising business.

Tobacco advertising was an effective strategy tobacco companies used to increase the demand-for tobacco. Advertising of tobacco began in North America around 1606, an early initiation of conventional tobacco-use image (Borio, 2007). The earliest official advertising of tobacco came out in late $19^{\text {th }}$ century, around $1870 \mathrm{~s}-1890 \mathrm{~s}$. Trade cards were the primary form of advertising. The cards illustrated attractive printing of cigarette brand names, company manes, and series pictures of wildlife, film, theater, and sport stars (Wisconsin Historical Society, 2009). The printing was processed in a special way to encourage the customers to keep the cards as a collection (Wisconsin Historical Society). The content in the cards generally focused on introducing the cigarette brands 
and companies to the public so that their prospective customers knew and felt familiar with the products.

At the time the tobacco advertising business grew, countries all over the world began cultivating and trading tobacco, even in the countries that enacted death penalty for tobacco use, such as Russia and Mongolia (Borio, 2007). As a result, global consumption of cigarettes hit 50 billion sticks in 1900 increase of fivefold within ten years, 100 billion sticks or ten folds in 1910, and it continually increased until it hit 560 folds in 2002 which made up the amount of 5,604 billions of sticks (American Cancer Society, 2008).

After the invention of advanced technology of communication, advertising of tobacco products were even more active. Imaging was used to guide customers and prospective customers to accept the product, and think, imagine, and act like the images illustrated in the advertising. Many slogans were created and used in the advertisings to ease recognition to the customers and guide their behaviors. The earliest band that presented slogans with its product was Camel, in 1915. The first slogan was "They satisfy", followed by "I'd walk a mile for a Camel", "For digestion's sake-smoke Camels", "Experience is the best teacher...in choosing a cigarette", "Your T-zone will tell you why", "More doctors smoke Camels than any other cigarette", and "pleasure helps your disposition for more pure pleasure have a Camel" (Chickenhead, 2009; TV Acres, 2009). Other tobacco companies also adopted similar strategies-using persuasive and illusive positive terms and images-in order to attract customers to their products.

Lucky another cigarette brand-illustrated pictures of sexy girls and good 
looking boys accompanied with persuasive terms: "fine tobacco", "light-up time", "light up a Lucky", "taste better, cleaner, fresher, smoother", "reach for a Lucky instead of a sweet", "men who know tobacco best, pick Lucky's two to one", “everybody's doing it!", and "...smoke Luckies all day long with no harmful effects..." (Borio, 2007; TV Acres). Bull Durham in "Roll Your Own" advertising adopted pictures of two handsome gentlemen and encouraging terms: "greater opportunities", "wide experiences", "the trained taste to appreciate the best of everything in life", and "delicious freshness, incompatible mildness, and unique fragrance" (TV Acres, 2009).

Kool brand adopted diverse illustrations and influential terms: "Change to Kools", "a change for the better", "instant refreshment", "your throat and tongue stay cool and smooth, your mouth clean and fresh", "Keep Kool”, (Chickenhead Productions, Inc., 2009). Other cigarette brands also used similar strategies, for examples, Philip Morris: "Join the millions who...call for Philip Morris!", Chesterfield: "Everywhere you go, have a Chesterfield. They Satisfy!" and “...whenever folks having a good time”, Cigarillo: "I love to see a man smoke a Cigarillo", Pall Mall: "Reward yourself with the pleasure of smooth smoking", Kent: "your voice of wisdom says Smoke Kent!", and Winston: “...smoking should be fun”.

Marlboro was considered the best selling tobacco product and the most successful ad campaigns ever; Marlboro advertising used slightly different strategies (Crain Communication, Inc, 2005; TV acres, 2009). The advertising of Marlboro was created in 1995 by Loe Burnett Company (Crain Communication, Inc). It used only a few 
slogans: "Come to Marlboro country", "Come to where the flavor is", and "You get a lot to like with a Marlboro" (TV Acres). The most powerful strategy was not the slogans themselves. The advertising became significant influential when the slogans were put along with the masculine and natural western lifestyle illustrations; mainly western cowboys riding on handsome horses (Wang, 1998). In addition to such image, colors of the product package and scenery in the advertising were powerfully attractive. Tones of colors used in the product packages were red, yellow, and green. The tones of colors of scenery in the advertising were selected according to the color of the product package it was promoting, which effectively guided the customers' feelings (Wang). The advertising was selling the image of the product as natural, virile, and American symbols. The feature of Cowboys riding handsome horses in natural scenery in the advertising influences the audiences' initiation of positive illusions toward the products, which include the spirits of American pioneers, braveness, perseverance, and innocence (Wang; Crain Communication, Inc, 2005). Meanwhile, the slogans used in the advertising strongly persuade the audiences to become one of these images (Wang).

The story of tobacco illustrates the deep relationships mankind had with tobacco, over the generations. Tobacco itself without any purposely advertising represents its important roles to mankind, from holly herbs to important nation-economic goods, and from religious God communicated remedy to medical remedy toward pleasure regimen till huge profitable business. - Of concern is the intentional attempt to exaggerate the positive image of tobacco products. The literature reviewed above has portrayed 
males-targeted smoking as a masculine habit, health, happiness, fitness, wealth, power, and sexual success (American Cancer Society, 2008). Moreover, smoking advertising has also added false images of vigor, slimness, liberation, sophistication, and sexual allure in order to attract female customers to their products (American Cancer Society). Research findings discussed above suggest tobacco advertising is usually found significant along with parent and peer smoking. These factors also have similar effects on smoking onset among early adolescents. Many research studies have been conducted to investigate such effects. However, none have addressed such problems among Thai adolescents who reside in the United States.

Socioeconomic Factors: Socioeconomic Statuses and Background.

The relationship between tobacco use and socioeconomic status were found to link with tobacco use (WHO, 2001). However, such relationships were not consistent. Some studies show that low socioeconomic status positively relates to tobacco use or smoking, where as some show teenagers from higher socioeconomic status in some areas, such as Bombay, India, are more likely to smoke than are those from lower socioeconomic (WHO). Other studies show teenagers who have more money to spend, are more capable to buy cigarettes and have higher rates of tobacco use (WHO).

A longitudinal study with a national representative sample of 15,197 US adolescents showed that lower socioeconomic status was not associated with early teens smoking (Yang, Lynch, Schulenberg, Roux \& Raghunatan, 2008), rather they found that 
higher socioeconomic was a strong predictor of early teens. Among adolescents grades 7 through 12 in wave 1,7 through 11 at wave 1 in wave 2 , and aged 18 to 26 in wave 3 , findings showed a greater prevalence of light to moderate smoking among early and middle adolescents with high socioeconomic background than those with low and middle socioeconomic background with odds ratio of 0.80 (Yang et al., 2008). However, among late adolescents with low and middle socioeconomic who had no further education findings showed a greater prevalence of heavily smoking than those with high socioeconomic background with odds ratio of 1.60 (Yang et al.) Such findings suggest inconsistent effects of family socioeconomic background on smoking among early and middle adolescents.

A cross sectional study among low socioeconomic status (SES), middle SES, and high SES Mexican adolescents, aged 11 to 13, showed that adolescents in low socioeconomic status had the highest prevalence of smoking in spite of an overwhelming belief that smoking cigarettes and smoke from other people's cigarettes are harmful to their health (Bird et al., 2006). Along with having low socioeconomic status, the researchers also found that the proportions of adolescents lived in smoking household, had at least one close friend smoking, and being exposed to public smoking were higher than those who were in middle or high socioeconomic families (Bird et al).

Other factors significant to smoking were found in other studies. Yang et al's study showed that having no further education, accessibility to tobacco products, and living within household smoking were significant predictors of heavy smoking in early 
adults (Yang et al., 2008). In previous literature, Graham (1976) suggested that different attitude and belief backgrounds among socioeconomic groups, and some attitudes and beliefs toward tobacco use might enhance tobacco use among lower socioeconomic groups. Barton, Chassin, and Presson (1982), as well as Tunstall, Gingberg, and Hall (1985) pointed out that these factors are primarily influenced by cigarette advertising. No matter what the real factors are, it is obvious that socioeconomic statuses do not directly influence smoking initiation. They seemed to be just a host or passage for some other factors. It is important to find out what they really are, why they relate to the teens, and how it happens such a way for smoking.

Personal Factors: Knowledge Attitudes-and-Beliefs, Self-Esteem, and Self-Image

Personal factors which include knowledge-attitudes-and-beliefs, self-esteem, and self-image were found to be related to smoking initiation (WHO, 2001). The interaction among knowledge, belief and attitude toward smoking results in smoking among some adolescents and non-smoking among the others. Ideally, knowledge regarding harmful effects of tobacco use should be able to inhibit people from smoking.

Many studies have been conducted to examine if knowledge can protect teens from smoking. Disappointedly, none of these studies-significantly indicate that being knowledgeable to the harms of tobacco use can be fully protective from using tobacco (WHO, 2001). Yet, the results showed that among teenagers in developed countries and in developing countries, those who smoke were less knowledgeable regarding harms of 
smoking than those who don't (WHO). It was even worse when lack of knowledge was influenced by false beliefs and attitudes toward smoking.

Cultural beliefs and inadequacy of education are more common among developing countries. Among developed countries, although knowledge regarding harms of smoking are found to be adequate and accurate in general by many studies, those who smoke underestimated harmful effects of smoking and viewed that such harms were less likely to happen to them. Such viewpoint of smoking is more common among young smokers. This may be because teens are limited in using information wisely (WHO, 2001).

Why is only knowledge not enough to shape non-smoking behavior? This may be because human beings behave accordingly to their own knowledge, beliefs, and attitudes. Female adolescents, who smoke, in spite of being knowledgeable of health risks, do not believe that such health risks will happen to them. In some population groups, benefits of smoking also shape behavior of smoking such as found in low-income pregnant teens (WHO, 2001). Some studies also show that among females, positive attitudes toward smoking leads to initiation of smoking (WHO). It is of interest to find out what kinds of attitudes and beliefs young smokers have, how these attitudes and beliefs are formed, and how they can influence smoking onset.

The study of attitudes and beliefs among adolescents aged 13 to19 showed the more teens had a false belief that most of their peers smoke the more likely they will smoke (Castrucci, Gerleach, Kaufman, \& Orleans, 2002). The study showed this 
relationship was strong among susceptible-but-never smokers, and experimenters. Such relationship was even highest among current smokers (Castrucci et al. 2002). The researchers also found that teens who are susceptible-never smokers, experimenters, and current smokers had positive attitudes towards smoking. They thought that smoking helps people to relax, reduces stress, and increases social comfort. They also believed that those who smoke are popular. The teens were less likely to believe that secondhand smoke is harmful (Castrucci et al.). Castrucci and associates finding support those of Unger et al's. Unger and colleagues (2001), conducted a study of attitudes among adolescents aged 13 to 18 and found that both never-smokers and ever-smokers had positive attitudes towards smoking (Unger, Rohrbach, Howard-Pitney, Ritt-Olson, \& Mouttapa, 2001). Significant odds ratios showed that the teen thought that their best friends would act friendly if they smoked, and smoking cigarettes makes young people look cool. The odds were even higher among teenagers who were ever-smokers. The ever-smokers also believed that most people in their age think it's OK to smoke cigarettes once in a while (Unger et al., 2001).

The teens' beliefs and attitudes were also shaped or formed by what they perceived their peers think or view about smoking. A longitudinal study over 6 years among $4^{\text {th }}$ graders in Oregon State showed that as the samples were growing up, their peers' beliefs and attitudes towards images of smokers gradually gained stronger and stronger influence over their beliefs and attitudes (Andrews, Hampson, \& Barckley, 2008). Such influence reached its peak when the teens were in $8^{\text {th }}$ grade. The study also 
showed that the teens' and what they thought their peer's beliefs and attitudes were, both influenced the teens' intention to smoke; the more the teens believed that their peers viewed people who smoked were cool, exciting, or popular, the more they would believed similarly and the more they intended to smoke. This highlights a significant risk as the previous studies showed that intention to smoke strongly predicted smoking initiation (Andrews et al., 2008).

According to the studies discussed above, positive beliefs and attitudes towards smoking definitely influence smoking initiation. In addition to the belief that most of their peer smoke, the teen's beliefs and attitudes are primarily grounded within boundary of images. Such beliefs and attitudes influence the smoking initiation and place some teenagers who prefer such images into early smokers and the others prone to initiation. Why images are so important to teens that even knowledge of harmful effects of smoking is not enough to prohibit the onset of smoking among them?

Self-esteem, self-image, and body-image are closely studied. Although, related, they differ slightly in describing any individual. Self-esteem is a sense of self, which an individual evaluates his/her self based on the interaction he or she has with others, especially significant others such as parents, friends, and school (WHO, 2001). Selfimage is an individual's perception of his/her ideal self, which develops through social interaction and cognitive self-appraisals (Petersen, Schulenberg, Abramowitz, Offer, \& Jarcho, 1984). Finally, body-image is an individual's mental representation of one's body (Pipher, 1994). From the general concept of self-esteem, self-image, and body-image, one 
may hardly tell exactly what they really are. The way each of these variables is defined provides more understanding and helps in practically identifying them.

Self-esteem is defined as an individual's satisfaction or contentedness of his/her perceived self. This satisfaction or contentedness of one's self is fragile and changeable in early adolescents (Rosenberg, \& Simmons, 1971) influenced by the composition of one's beliefs, opinions, attitudes, values, and feelings about oneself (Rosenberg \& Simmons). Self-image is a result of the composition of an individual's values, experiences, interaction with family-peer-and school or neighborhood context (Petersen et al., 1984). It is defined as physical appearance and external characteristics an individual perceives as positive image acceptable in the community, such as appearing mature, or being cool, tough, sociable, and sexually attractive (WHO, 2001). Body-image is defined as body-look or overall appearance of an individual's body (Pipher, 1994) and is considered as a part of self-image (Petersen et al.).

To simplify, body-image is how an individual feels about his/her body-look. Selfimage is what an individual thinks, feels, or believes him/her is or would be as a whole person. Self-esteem is how contented an individual feels toward his/her self-image.

Self-esteem, self-image, and body-image are found to be interrelated. Although the sense of self image is strongest when an individual reaches his/her adolescent (WHO, 2001), the inter-effect among these variables plays its role through an individual's lifespan. For examples, Kappel and Crowe studied the changes of body image to the change of self-esteem among Australian young adults following stoke (Kappel \& Crowe, 2000). 
The study showed that reduced body-image significantly resulted in reduced physical and global self-esteem among the samples (Keppel \& Crowe). Since self-esteem is found most fragile and changeable during early adolescent, scientists believes that the adolescents are most vulnerable to the onset of health-risk behaviors, such as smoking initiation.

As suspected, self-esteem, self-image, and body-image are also found to be related to the onset of smoking among early adolescents (WHO, 2001). The adolescents reported ever try their first puff as early as by the age of 11 years (Temeo, Field, Berkey, Colditz, \& Frazier, 1999; Kemppaine, Tossavainen, Vartiainen, Pantelejev, \& Puska, 2002; Simons-Morton, \&Haynie, 2003; Mowery, Farrelly, Haviland, Gable, \& Wells, 2004; Bird, Moraros, Olsen, Coronado, \& Thompson, 2006; Seo, Bodde, \& Torrabi, 2009). Having low self-esteem and low expectations for future achievement is found to be significant with adolescents smoking, whereas those who do not smoke have higher self-esteem than those who do (WHO).

The relationship between smoking and self-esteem are not consistent. Some studies found a significant relationship between the variables, some did not. For examples, a study of smoking, stress, and self-esteem among Australian adolescents aged 14 to 18 , showed boys who had low self-esteem were more likely to smoke than were boys who had high self-esteem (Byrne \& Masanov, 2001). In addition, with stress, the more the teens with low self-esteem were stressed, the more likely they smoked (Byrne \& Masanov). In contrast, a study of self-esteem among Turkish adolescents with an 
average age of 15 using Rosenberg's scale failed to show a significant relationship between smoking and self-esteem (Yorulmaz, Aktiirk, Dadeviren, \& Dalkilic, 2002). Similar findings were reported by Wild et al. who failed to find a significant relationship between global self-esteem using Rosenberg's scale and smoking among African American boys in $8^{\text {th }}$ and $11^{\text {th }}$ grade (Wild, Flisher, Bhana, \& Lombard, 2004). A study of the relationship among Turkish late adolescent aged 17 to 24 , also failed to show significant relationships between smoking and either low self-esteem or high self-esteem (Kavas, 2009). However, it is noteworthy that all of these inconsistent findings were studying in general self-esteem or global self-esteem. Surprisingly, when studied in deeper detail of self-esteem, the picture of self-esteem and smoking was clearer and also more consistent.

A study of relationship between smoking and 6 domains of self-esteem among $8^{\text {th }}$ graders and $11^{\text {th }}$ graders in Cape Town, South Africa showed that $8^{\text {th }}$ graders had higher self-esteem in almost all domains of self-esteem except global domain than had $11^{\text {th }}$ graders. In addition, early adolescents in $8^{\text {th }}$ grade reported less smoking prevalence and other health risk behavior than those in $11^{\text {th }}$ grade (Wild et al, 2004). The study also showed that those who were dissatisfied with their academic performance and relationships with their family were more likely to smoke. Surprisingly, those who felt that they were less popular among their peers than they wanted to be were less likely to report tobacco use (Wild et al).

Some domains of self-esteem are reflected differently by gender, especially for 
those who have low self-esteem. Girls who were unhappy with their bodies had a significant relationship with tobacco use, whereas boys who were not contented with their physical strength were less likely to smoke (Wild et al., 2004). This finding was supported by Pipher's (1994) girls become so flooded with how they look that sometimes they over emphasized with something unnecessarily, such as fashion, makeup, and their weight. Wild et al.'s findings also supported by Kawabata et al's (1999) who studied in similar domains of self-esteem -and smoking status among Japanese adolescents.

Kawabata et al studied relationships between self-esteem and smoking among Japanese early adolescents, from $4^{\text {th }}$ to $9^{\text {th }}$ grade. The researchers found while the adolescents were growing up, their satisfaction of their overall self (global self-esteem), relationship with family, and performance at school were gradually decreasing in both sexes (Kawabata, Cross, Nishioka, \& Shimai, 1999). The study also showed that in addition to gradual decrease in these domains of self-esteem, Japanese adolescent girls also became less and less contented with their body-image and physical strength (Kawabata et al, 1999). The researchers also found among Japanese early adolescents smoking significantly related to having low self-esteem in cognitive and family domains. In-contrast, adolescents who had high self-esteem in physical and social domain were more likely to smoke (Kawabata et al.). Such relationships may be due to early development of physical appearance and peer-socialization which placed the adolescents at highest risk of smoking initiation when low cognitive and family self-esteem were taken into account (Kawabata et al.). 
According to the studies discussed above, it is noteworthy that some domains of self-esteem are important to early adolescents regardless of gender, such as schoolperformance domain and family-relationship domain, whereas some domains affects each gender differently, such as images domain. While physical strength was very important to boys, body-look or body-shape was significant to girls. It is also note worthy that when image domain is accounted in the measurement of general self-esteem; the result always shows significant relationships between low self-esteem and smoking.

Wilkinson and Abraham, in their study of the antecedents of adolescent smoking, integrated satisfaction of the way an individual looks and the pride of his/her body in the variable of general self-esteem scale (Wilkinson \& Abraham, 2004). They found that as well as other significant variables, low self-esteem was a strongest predictor of future smoking among United Kingdom adolescents; aged 13 to 14, in both sexes (Wilkinson \& Abraham). This model highlights the importance between self-esteem, self-image, and body-image and whether-an early adolescent will initiate smoking. A longitudinal study of smoking predictors among early female adolescents aged 11 to 15 of which majority participants were Caucasian showed that dissatisfaction with body appearance had influences on a transition from nonsmoker to smoking experimenters and from smoking experimenters to regular smokers (Stice \& Shaw, 2003). Body dissatisfaction also had a high correlation with eating disorder symptoms and stress (Stice \& Shaw). 


\section{Theoretical Definitions}

The smoking behavior absorption.

Before any individual tries his/her first cigarette, the very first step of the initiation is that he/she must know or learn about it. He/she may learn or know about tobacco-use via the learning sensory including seeing, watching, smelling, or even touching tobacco product items. He/she may by-chance see, watch, smell tobacco smoke, and touch tobacco products from many sources including parents smoking, family members smoking, neighbors smoking, friends smoking, and tobacco advertising. Secondly, as the scene of tobacco-use becomes more and more cumulated in the individual cognition process, he/she emerges feelings, emotions, moods, or impression toward smoking, mostly positive, intention to smoke emerges. Thirdly, as the individual has more and more positive feelings responding to tobacco-use behavior, his/her intention to smoke becomes more and more intense. However, it wasn't until the individual gains adequate resources for smoking such as an opportunity to smoke, tobacco-products, and encouragement when getting together with friends that he/she initiates smoking as the beginning of the fourth step. In this step, the adolescent has a chance whether intentionally or intentionally to compare real smoking to the smoking he/she imagines of. He/she may repeat his/her puffs when adequate resources meet until the adolescents is convinced whether it belongs to him/her or not. The time period of this step varies depending on each individual. Some adolescents who think smoking does not belong to them may stop their experiment with smoking before nicotine dependence becomes 
influential, but others may decide to quit too late, who think it belongs to them.

Overwhelming number of empirical studies have found that parents smoking and friends smoking are the most significant sources correlated to smoking initiation among early adolescents. These sources of learning can shape an individual's beliefs and attitudes toward smoking in young age as early as school-age childhood as shown in Porcellato et al.'s (1999).

By witnessing a smoking scene, especially at home, children can absorb emotions, feelings, as well as smoking practice, and then imitate the behavior at the time when resources of smoking are available. Porcellato, Dugdill, Springgett, and Sanderson (1999) examined perceptions of smoking among primary school children aged 4 to 8 , from kindergarten to grade 3 residing in Liverpool, the United Kingdom. The researchers found that without counteraction of health consequences of smoking, the participants viewed smoking scene as a positive grown-up activities. The greatest prevalence of those who depicted joyfulness being in the room full of smokers was kindergarteners. This age group accounted in majority, $60 \%$ of the participants who believed smoking was good to people and a significant number believed it was adult activity (Porcellato et al., 1999). Porcellato et al.'s findings indicated that young children knew about smoking from parents smoking--primary source-and as their age was advancing, they tended to hang with their friends, and learned about smoking from each other. Parent's smoking was a primary source incubating positive attitude and belief for kindergarteners. For older children, as parent's smoking was still holding its influences on incubation of positive 
attitudes, friends' smoking was gradually gaining it significance (Porcellato et al.).

The study suggested that parents were primary educators, from whom young children learned about smoking and health consequences of smoking. Of 1,583 samples, about $40 \%$, regardless of ages, cited their parents as a learning source of smoking. To children, their parents are hero, thus parents smoking shaped the children attitudes and beliefs toward smoking, as shown in the study that $70 \%$ of those who had positive attitudes toward smoking lived with parents who smoked (Porcellato et al., 1999). Furthermore, repeatedly embracing in scenes of parents smoking strengthened their attitudes and beliefs toward smoking more and more, and eventually shaped their intention to smoke. This process and information sharing among children made it easier for smoking materials to get the children attention. Porcellato et al's study showed that even the youngest of the samples, 4 years old and the oldest 8 years old, knew where to buy cigarettes. In draw-and-write investigation with the samples of 976 , about $30 \%$ drew positive characteristics of smoking. In the questionnaire investigation with the samples of 1,583 , about $13 \%$ of the samples showed their intention to smoke, and $6 \%$ had already tried smoking at least one puff in their lifetime. Such findings highlight parents smoking or home smoking as a source from where learning of smoking was rooted. Learning source of smoking also expanded wider as young children aged.

About only $1 \%$ of kindergarteners mentioned friends as a learning source of smoking, whereas friends was mentioned more frequently among $1^{\text {st }}$ and $2^{\text {nd }}$ graders, and most frequently-among $3^{\text {rd }}$ graders. While learning source of smoking and sharing 
information of smoking were expanding to friends more and more, the influence of parent smoking was still powerful. Findings showed that half of the samples lived with parents who smoked and that even though out of $1,583,91 \%$ believed that smoking was bad for people, a significant proportion of them thought that smoking was an adult activity, and it was okay to smoke when they were at adult age because adults are bigger than children (Porcellato et al.)

Positive attitudes and beliefs toward smoking can be cumulative. The more cumulative the positive attitudes and beliefs, the stronger they link to smoking initiation. Castrucci, Gerlach, Kaufman, and Orleans (2002) examined the relationships between positive attitudes toward smoking and an early onset of smoking--intention to-but-never smoking, trying a few puffs in lifetime, and smoking at least one day in the past 30 days. The participants were adolescents in grade 9 to grade 12 , randomly selected from 200 countries. Investigators found adolescents who had positive attitudes toward smoking were at a high risk of smoking initiation. The odds ratios between positive attitudes and smoking status--intentional-to-but-never smokers, experimenters, and current smokers were $1.50,1.27$, and 2.96 respectively. It was noteworthy that the odds ratio was highest among current smokers (Castrucci et al., 2002). Moreover, rather than depicting smoking as being good or bad as did among young children, early adolescents depicted their beliefs and attitudes in clearer and more specific benefits and images of smoking.

Benefits and images of smoking that were most commonly denoted among the participants included: it helps people to relax, reduce stress, increase social comfort, keep 
weight down, and smokers are not less popular (Castrucci et al., 2002). From Castrucci et al.'s findings, it was obvious that early adolescents' interest regarding smoking was central in popularity and self-relaxation, as shown in the findings that attitudes denoted highest among three status of smoking were that those who smoke are not less popular, and that smoking helps people to relax (Castrucci et al.).

Castrucci et al. also found that the stronger the positive attitude, the more advanced the stage of smoking. The more advanced the stage of smoking, the higher the prevalence of positive attitudes (Castrucci et al., 2002). For examples, at each stage of initiation including: intentional-to-but never smoking, experimenting, and currently smoking, the prevalence of the attitude that those who smoke are not less popular was: $74.7,74.0$, and 87.4 percent respectively. The prevalence of relaxing benefit was 45.4 , 43.9, and 78.8 at each stage respectively (Castrucci et al., 2002). Such findings were associated with the following studies.

Seo, Bodde, and Torab (2009) examined the relationships between perception of smoking benefits and smoking in the late onset--using tobacco in the past 30 days. The perceptions examined in the study include: teens who smoke have more friends than those who don't; those who smoke look cool; smoking helps you relax; smoking helps you feel more comfortable in social situation; and smoking helps you keep your weight down. Findings showed that the higher scoring adolescents perceived the benefits of smoking as well as perceived peer acceptance, it's okay to smoke, the more likely they were current smokers--smoked at least one day in the past 30 days- and established 
smokers smoked 20 or more days in the past 30 days (Seo et al., 2009).

The benefit that current smokers and established smokers definitely agreed in highest weighted percentages of 53.8 and 63 respectively was that smoking helps you relax. The benefit which current smokers and established smokers agreed that smoking probably served, the greatest proportion fell in the perceived benefit that smoking helps you feel more comfortable in social situation, at weighted percentages of 40.3 and 36.5 respectively (Seo et al., 2009). The benefit that current smokers and established smokers definitely disagreed at highest proportion--weighted percentage of 76.9- was that smokers do not look cool. They also disagreed to the surveyed attitude that smokers do not probably have more friends than non-smokers; the prevalence was at a weighted percentage of 48 (Seo et al.). Majority of current and established smokers moderately and highly perceived benefits of smoking. The prevalence of participants who moderately and highly perceived benefits of smoking was 50.6 and 31.3 percent respectively. The majority of participants also believed that their peers accepted smoking. The prevalence of those who perceived that their friends definitely accepted smoking was 34.9 percent, and probably accepted it was 43.2 percent (Soe et al.). The higher the participants perceived benefits of smoking, the stronger such beliefs and attitudes influenced their smoking behavior. Similarly, the higher the participants perceived peer acceptance to smoking, the more likely they became current and established smokers. After adjusted for gender, grade, and ethnicity, odds ratios of moderate and high perceived benefits of smoking to current smoking were 5.21 and 15.9 respectively. Odds ratios of probably and 
definitely yes to peer acceptance to smoking to current smoking were 3.64 and 7.22 respectively. After adjusted for gender, grade, and ethnicity, odds ratios of moderate and high perceived benefits of smoking to established smoking were 5.18 and 19.9 respectively. Finally, odds rations of probably and definitely yes to peer acceptance to established smoking were 5.03 and 9.65 respectively (Soe et al.).

Even though children reached their early adolescents, decision to initiate any behavior still elinked to what they perceived from parents' reaction. At the same time, learning by interacting with friends was growing wider and wider. Friends smoking encouraged smoking initiation in a variety ways. In addition to incubating positive beliefs and attitudes towards smoking, parents smoking, and friends smoking also counteracted knowledge of health consequences of smoking, and encouraged the initiation by increasing the sense of being approved or accepted. Thus, intention to smoke was increasing even more, and embracing with friends smoking made the initiation even more feasible.

Flay, Hu, Siddiqui, Day, Hedeker, Petraitis, Richardson, and Sussman (1994) adopted the theory of reasoned action and theory of planned behavior in their longitudinal study to examine the influence of parental smoking and friends' smoking on adolescent initiation and escalation of smoking. The study was conducted among Southern California adolescents, 15 months apart from Time1 to Time2. Samples were seventhgraders at Time1, and eighth-graders at Time2. The study showed that peer smoking had direct and indirect effects on smoking initiation whereas parent smoking had only indirect 
effect (Flay et al., 1994). Exposure to friends smoking directly encouraged the adolescents to initiate smoking. Such exposure also indirectly triggered smoking initiation through a channel of an increase of intention to smoke and a decrease of expectation of negative outcomes of smoking (Flay et al.).

Parents smoking indirectly resulted in smoking initiation through the channel of an increase of intention to smoke, a decrease of expectation of negative outcomes, and an increase of perceived parent approval (Flay et al., 1994). The study also showed that peer smoking and parent smoking significantly triggered smoking onset regardless of ethnicity and gender. However, such influence affected in different ways. The influence of friends smoking was most significant in decreasing negative outcome expectation among Hispanics, and it was significant in decreasing refusal self-efficacy among Whites. Friends smoking more directly triggered smoking initiation among males than females and more effective in increasing intention to smoke and decreasing expectation of negative outcomes of smoking among females than males. Finally, parents smoking had greater indirect effects on females than males (Flay et al.). Parents and friends smoking also had influence on escalation of smoking. However, their influences on smoking initiation were stronger than smoking escalation (Flay et al.).

Even though the findings in Flay et al's study did not confirm that the early adolescents knew about smoking from parent and peer smoking, their findings underscore parent and peer smoking shaped and increased the adolescents' intention to smoke, and significantly predicted the onset of smoking. Parent smoking also shaped the adolescents' 
intention to smoke. By witnessing parents smoking, the adolescents perceived that their parent were more apt to approve their smoking and thought that smoking was not as dangerous as they were told. Peer smoking shaped their intention to initiate smoking by promptly encouraging smoking, and indirectly convinced them that smoking was not as dangerous as they were told.

Absorbing joyfulness while embracing in smoking scenes continually exerts its influence on early adolescent, while learning source of smoking expands-to tobacco advertising, and the children feel encouraged enough to smoke when joining friends who smoke or thinking that most children of their age smoke. In the meantime beliefs and attitudes toward smoking also grow stronger and much more objective. As the children grow older, they interact with persons, things, and situations surrounding them more broadly. At this point, tobacco advertising becomes more and more influential.

Castrucci et al. findings underscored the long effect of parents smoking on smoking initiation. Castrucci et al. (2002) found that among adolescents aged 15 to 19 across 200 countries, those whose parents smoked were more likely than those whose parent did not smoke to be experimenters and current smokers despite their parents' strong opinion against smoking. Moreover, the belief that smoking was a social norm entails even deeper in the smoking onset among this age group. As shown in Castrucci et al.'s study, the majority of those who reported their intention to smoke, experimenters, and current smokers believed that about half or over of adolescents at their age were smoking (Castrucci et al., 2002). In addition, hanging with friends who smoked resulted 
in smoking initiation among adolescents who valued their friends' opinion of smoking (Castrucci et al.). Moreover, such persuasion was even stronger when the adolescents perceived images of smoking as popularity, looking cool, ease in social situation, and weight control. These images combined with a sense of being accepted when smoking encouraged the adolescents to become current smokers and established smokers (Soe et al., 2009).

Seo et al. (2009) studied risk factors predicting current smokers and established smokers among Indiana middle-school and high-school adolescents from grade 6 to 12 in 2000 and 2004. According to Seo et al., respondents who smoked a cigarette at least 1 day during the past 30 days were categorized in current smokers, and respondents who smoked 20 or more of the past 30 day and 100 or more cigarettes during their lifetime were categorized in established smokers. The researchers found that exposure to environment of tobacco smoking (ETS), exposure to tobacco adverting, perceived benefits of smoking, and perceived peer acceptance were significant predictors of both current smoking and established smoking (Seo et al., 2009).

The number of exposure days to smoking environment was significant in predicting smoking stages. The more days in the past 7 days the adolescents exposed to ETS at home or in the car, the more likely they were current smokers or established smokers (Seo et al., 2009). The frequency of exposure to tobacco adverting also predicted smoking onset. The highest exposure to tobacco adverting was at convenience stores. Over a half of respondents reported a lot exposure to tobacco advertising at convenience 
store in 2000 , and a slightly higher proportion in 2004 . The second big proportion of exposure to the advertising was television or movies where the respondents saw actors using tobacco most of the time: 33.9 and 33.0 percent in 2000 and 2004 respectively. Exposure to tobacco advertising on the internet was only 7.2 percent in 2000 , and 10.4 percent in 2004 (Seo et al.).

Seo et al's findings revealed that tobacco advertising was way more aggressive than anti-smoking messages. Exposure to tobacco advertising greatly outweighed exposure to anti-smoking messages. About 6.9 percent of respondents reported exposure to anti-smoking messages in 2000 , and only 14.8 percent in 2004 . On the other hand, about 65.2 percent of respondents in 2000 and 58.9 percent in 2004 reported exposure to tobacco advertising (Seo et al., 2009). The findings also suggested that the influence of tobacco advertising did not work out alone in introducing and persuading smoking habits to the adolescents. It was accompanied with other sources salient to its prospective customers and well adapted to their lifestyles. Parents, family members, and friends are the people adolescents daily participate to. Convenience stores are community local places where most people visit or pass by most often. Finally, television is a media that most people watch every day. All of these were best resources for adolescents to gradually absorb smoking habits.

A study of the relationship between the frequency of exposure to tobacco advertising and smoking initiation among California adolescents in grade $6^{\text {th }}, 7^{\text {th }}$, and $8^{\text {th }}$, showed that more frequently the adolescents were exposed to stores containing cigarette- 
marketing materials, the higher the prevalence of ever smoking was reported (Feighery, Henriksen, Wang, Schleicher, \& Fortmann, 2006). The majority of the samples in Feighery et al.'s study were Hispanics and Whites. Out of 2,063 samples, 61 percent were never-smokers; 19 and 20 percent were susceptible-never smokers--never smoked but showed intention to smoke if offered or in the future--, and ever smokers respectively (Feighery et al., 2006). About 44 percent reported parents smoking and 28 percent had at least one friend who smoked. The highest frequently visited stores were small markets, liquor stores, and convenience stores at a percentage of $87.5,82.9$, and 72.3 respectively. More than half of the participants reported visiting any of these stores often--at least once a week, and reported seeing cigarette-marketing materials when visiting the store. About 50 percent reported perceived often exposure to the materials (Feighery et al., 2006). The findings showed that exposure to cigarette-marketing materials in any retail stores, specific-named stores, actual-seeing the materials, or perceived-seeing the materials was independently associated with a significant increase in the odds of ever-smoking and intention to smoke (Feighery et al.). The findings also showed that the higher the exposure to cigarette-marketing materials, the higher the prevalence of ever smoking (Feighery et al).

It is interesting that in the study by Feighery et al., the participants reported perceived exposure to cigarette-marketing materials slightly less than actual exposure to stores containing cigarette-marketing materials. Would it be possible that some adolescents who lived with non-smoking parents and who did not have friends who 
smoked would less recognize cigarette-marketing materials, and process the messages of the materials in their brain than those whose parents and friends smoked. Unfortunately, this observation was not examined by Feighery et al.'s study.

Learning smoking from tobacco advertising is so actively attractive to its early adolescent customers that some of them even have their favorite advertising. Being favorable to the adolescents, the advertising links the teens to smoking initiation. Castrucci et al. (2002) found that the adolescents who had their favorite advertisement of tobacco products had intention to smoke, or were smoking experimenters, and current smokers. Moreover, tobacco companies also offer cigarette promotional items as a strategy of tobacco advertising. Castrucci et al.'s findings showed that owning or being willing to own a cigarette promotional item was highest in increasing the adolescents' intention to smoke. It also significantly predicted the onset of smoking: experiment with smoking and current smoking (Castrucci et al., 2002). An additional source that increases accessibility to tobacco products may be parents who smoke. Some 7 and 8 year-old participants hypothesized that smoking experimenters must have got cigarettes from their mothers because they cannot buy cigarettes from the store themselves (Porcellato et al., 1999). No matter what source it is to get access to tobacco products, they all make smoking initiation more feasible for those who intend to smoke.

Before an adolescent initiates smoking, he/she must initially have known about smoking and any materials regarding smoking. As the adolescent was gaining information, he/she might feel negative, neutral, or positive toward smoking. For those 
who felt positive to smoking, repeatedly exposing to smoking scenes the individual's positive feelings became positive beliefs and attitudes toward smoking, and then intention to smoke emerged. With the intention to smoke plus opportunity and materials required for smoking available, the adolescent got his/her first puff. Without any intervention to counteract this process, the adolescent might repeat his/her experiment with smoking until nicotine dependence results.

Parent smoking was the primary source that introduced smoking to the children. Parent smoking also weakens the knowledge of health consequences of smoking, increases attitudes toward smoking and intention to smoke, and increases perception of parent approval. This source of learning pertain its influence in a long period of time, even when the individual reached his/her late teen. As the children advanced in age, learning source of smoking expands out to friends. As the children advance in age, friends' smoking gains stronger and stronger influences on the initiation of smoking, and even stronger than parents smoking. Sharing information among friends, friends smoking directly and indirectly encourages the initiation. Tobacco advertising is a source that introduces smoking to the children and encourages smoking initiation. The more frequencies the children exposure is to either one of these introducing sources of smoking, the more likely that the children will initiate smoking in their early adolescence. The higher intense the positive beliefs and attitudes are, the higher the intention to smoke becomes. The higher the intention to smoke is, the more likely the children will initiate smoking. Unfortunately, the relationships between the frequency of exposure to each of 
these introducing sources of smoking, and attitudes and beliefs toward smoking have not been clearly examined. Why adolescents adopted smoking habit, why they initiate smoking, and why they continue-smoking were not clearly answered. Was only susceptibility about what smoking would be enough to encourage them to repeat following puffs or following cigarettes? The investigator hypothesizes that there must be something other than that. The investigator believes their developmental milestones and their achievement in fulfilling their developmental milestones would relate to the decision on whether or not they will initiate smoking. This hypothesis is discussed in clearer detail in the smoking behavior adoption

The smoking behavior adoption.

Why does an adolescent adopt smoking initiation? The present study purposes to explore an explanation to this question. An overwhelming number of empirical studies showed strong relationships between exposure to environment of tobacco smoking parents-friends smoking- tobacco advertising, and positive beliefs and attitudes toward smoking; strong relationships between positive-beliefs-attitudes toward smoking and intention to smoke; strong relationships between intention to smoke and smoking onset--experiment with smoking, current smoking, and established smoking. However, very few have explained why the adolescents viewed smoking so positively that they initiate the habit. What do they see in smoking that matches their desire and what in smoking does the adolescents think it can fulfill such desire and what is that 
desire.

According to personal factors found associated to adolescents smoking, in addition to positive attitudes and beliefs, smoking initiation was mostly found among early adolescents who were low in self-esteem in one or more domains: family selfesteem, school self-esteem, peer self-esteem, self-image, or body image. An interesting issue is that Why was it so? And how does smoking become the choice? The investigator believes that there must be something about smoking that the adolescents finds beneficial to them. The question is what are they and in what way?

Studies of psychosocial development during adolescence show the most important theme during this development is independence and autonomy which eventually fosters sense of self-efficacy and self-esteem, and vice-versa (Coleman \& Hendry, 1990; Tilton-Weaver et al., 2001). The desire of such sense and its significance to adolescents are a gradually cumulative tendency from early adolescence toward early adulthood (Tilton-Weaver et al.). According to descriptive analysis, studies have shown that the tendency of adolescents smoking is positively associated to ages from early adolescent toward adulthood. In other words, the older the adolescents have increased the prevalence of smoking. An overwhelming numbers of studies also showed that the majority of adolescents who initiate smoking and continue until they become regular smoking are adolescents with poor sense of self (Fisher et al., 2004). Such findings lead to the assumption that smoking initiation among early adolescents may be pursued (either intentionally or unintentionally) in order to compensate the ways of growing up in an 
attempt to reach a state of maturity through the transition from childhood to adulthood.

Craving the state of independence and autonomy during adolescence is believed to link to the instinct "sense to survival". The directness of all human behaviors is primarily to survive which mainly focuses on protection of one's life (Wolman, 1998). To be independent is very meaningful to the adolescents because it connects to autonomy, ability to control situations one is facing, and a greater ability to rely on one's own, which finally lead to a greater chance to survive (Wolman). And the children learn from their past experience that physical development and psychosocial development lead to such ability. Thus, it is not uncommon for early adolescents whose intellectual ability has expanded to concern about their security in the future and realize that as far as they still depend on others they will not meet that state although this concern is not yet completely formalized (Wolman).

Childhood is a period of dependence. Children are born helpless due to limited ability to act out. Their chance to live or to die depends upon caregivers who provide the essential for livings to them (Wolman, 1998). The ability to behave during childhood in the first 2 years is limited in the sensorimotor stage which is grounded in simple motor responses caused by sensory stimuli, such as looking, sucking, grasping, and listening (Piaget, 1965). As the years go on, the intellectual ability is expanding. During the ages of 2 to 7 , the children's intellectual ability moves up to the stage of preparatory or preconception thought, which begins when the children start to use symbols and language, such as a toy doll stands for a real baby (Piaget). Between the ages of 7 to 11 
years, the children's cognition develops to the stage of concrete operations. The children are able to use logical rules and learn things in concrete, such as counting numbers (Piaget). During adolescence, physical and psychosocial development is extensive. From early adolescence, about the ages of 11 to 15 , toward late adolescence about the ages of 18-21, the adolescents' intellectual ability is dramatically expanding from formal operation such as using logical symbols, abstract thinking, understanding hypothesis in early adolescence to the ability to aware of nature of the world and social order in late adolescence (Piaget; Wolman). At early adolescence, the children's physical development is also extensive. Their physical growth as well as motor skills spurt as early as 7.5 years or as late as 12 years of age for girls, and by age of 13 for boys ( Mandleco, 2004). Girls average their physical growth spurt at age of 12 . They achieve a peak height velocity of $9 \mathrm{~cm} /$ year and gain a total height of $25 \mathrm{~cm}$ during pubertal growth. Their peak weight velocity lags behind the peak height velocity about 6 months and reaches $8.3 \mathrm{~kg} /$ year at about age of 12.5 years (Susman \& Rogol, 2004). Boys' physical spurt lags behind 2 years later than girls'. They attain a mean peak height velocity of $10.3 \mathrm{~cm} /$ year and gain total height of $28 \mathrm{~cm}$ during pubertal growth. Boys also attain the peak weight velocity at about the same time an average of $9 \mathrm{~kg} / \mathrm{year}$ (Susman \& Rogol). The expansion of cognition and physique arouses the adolescents to prepare for adult life. In fact, lives in adulthood are interdependent between oneself and the environment; their self-supporting activities necessitate interaction with other adults. However, for the children, in order to go through adolescence and reach adulthood, it is 
natural for them to crave independence and tend to be rebellious to parent dependence (Wolman).

To be independent from parent authority for the adolescents means to gradually gain more and more sense of freedom to make decisions on life activities, such as freedom to make new relationships or to take responsibilities on education with partial support (as needed) from family or community rather than to separate from their families (Coleman \& Hendry, 1990). They instinctively desire to be maturely developed with pride, autonomy, and capability to do things on their own. They also wish to be fully accepted and integrated in their society. These qualities secure the feeling that they will soon be independent from their parents and finally gain a full state of adulthood (Coleman \& Hendry). Such desire is significantly strong as soon as the children become adolescence. However, in the path of development during this period it is very important for the adolescents to be able to balance between psychological forces within individuals and psychological forces within the society perceived by the individuals (Coleman \& Hendry). The adolescents learn the direction of growing by interacting with their environment. The adolescents would feel comfortable with growing up, if they sense that they gain adequate ability to balance between external forces and internal forces--the pressures caused by the interaction between their actual developments compared to their inner desire versus the development expected by their community based upon their perception (Coleman \& Hendry). They crave the sense their actual development either physical or psychosocial, or may be both overcomes or equals the normative expected by 
external resources such as their family members or school standards. They also need the sense they are able to play appropriate roles in a variety social settings, while at the same time be able to maintain their sense of self (Coleman \& Hendry). This interaction serves as a driver in pushing the early adolescents through the transition from childhood to adulthood (Coleman \& Hendry).

Naturally, for any normal healthy developed child, development has begun since he/she was born. Activities the child engages in serves as the way to grow up or so called developmental tasks. From a very early age, the child actively engages in development process. Such activities are purposely involved in an attempt to diminish distance between his/her actual development status and socio-cultural expectations (Dreher \& Oerter, 1986). This involvement is even more extensive when the child becomes an adolescent. Children as well as adolescents preview developmental tasks as the way to adulthood. They also preview the tasks as the status of adulthood and the process to become an adult (Dreher \& Oerter). Dreher and Oerter (1986) projected the model of developmental tasks in three steps which go in circle. The first step includes recognizing and assessing both one's own present developmental status and the developmental demands of the surrounding culture. The next step is to estimate the distance between one's own ability and the socio-cultural norms of development to allow oneself set a developmental goal. The third step involves in activities aimed to attain the developmental goal chosen by the child. Through this model, the interaction between the child and his/her environment may create mutual influences which may lead to the 
change of the developmental goal that has been already set and followed. The newly set goal then would be followed by adaptive actions. The child would go through step one toward step three again and again until he/she reach the adulthood (Dreher \& Oerter).

According to the matter that the children preview developmental tasks as the way to become mature and reach adulthood. Children when reach early adolescence become more oriented to developmental tasks. At the same time, such awareness also arouses the adolescents to cope with the problems according to the tasks (Dreher \& Oerter, 1986). Accomplishment with developmental tasks and ability to cope with problems due to such tasks fulfill the adolescents with the most vital themes during adolescence that is the sense of pride and dependency (Coleman \& Hendry, 1990). Changes from a parentdependent state to a self-dependent state are the primary focus and lead to sense of adulthood during adolescence development. Yet, either delayed or sudden changes in self concept and environment can lead to stress and frustration (Labouvie, 1986).

Adolescent development has viewed as a period of transition from childhood to adulthood (Labouvie, 1986). To be successful in this transition, exploration and development of personal identity are, therefore, the main concern. It is inevitable to face many changes during this transition, which involves biological, cognitive, and social changes (Labouvie). Such changes both actual and anticipated, on the bright side, cause feelings of curiosity, excitement, and achievement and on the other side; they also cause feelings of insecurity and anxiety (Labouvie). Even so, the adolescents wish for them. A delay in expected changes can lead to the feeling of inferiority (Breger, 1974). For 
examples, adolescents who are delayed in physical development feel inferior to those who they view as well physically developed (Tilton-Weaver et al., 2001). Psycho-social maturity is another aspect the adolescents expect to gain when they reach the adolescence. They expect to gain more respect, and to be accepted by and able to control their environment (Breger). Among adolescents who felt that they were poorly psychosocially developed viewed themselves inferior to their peer who they perceived as psycho-social mature (Tilton-Weaver et al.). As such, transition from childhood to adulthood as in adolescence time faces stresses induced by either changes or delay in changes or both.

As described above, early adolescents know that in order to be mature into adult lives they are going to change. So, they are expecting changes. However, about in what direction are the adolescents going to change?; how do they absorb the image of changes?; from what and where do they learn and absorb the image of change?; and what would they do if their expected changed had delayed need to be discussed in the present proposal to provide perfect picture to its hypothesis.

Research studies have showed a connection between adolescent behaviors, developmental tasks, and the environment salient to the adolescents. As showed in a study conducted by Dreher and Oerter (1986), conceptualization of development toward adulthood is formed by the influence of the interaction between the adolescent and his/her environment. This interaction is changeably and continuously operated. This interaction serves as a resource that acknowledges the adolescents the idea or direction of 
growing up. The information emerging from the interaction between the adolescents and the contexts surrounding the adolescent serves as a source of social normative expectation perceived by the adolescent (Silbereisen, Noack, \& Eyferth, 1986). Research studies illustrated that chatting and observing others' behaviors are the primary strategies to learn about normative expectation and then to from the conceptualization of growing up (Silbereisen et al., 1986).

According to early adolescence nature, peer's reaction to adolescent's behavior becomes as significant to the adolescent as does the parents' (Silbereisen et al., 1986). Thus, the direction of behavior is formed mainly by observing and chatting with peers as well as with parents, significant others such as siblings or teachers (Silbereisen et al.). In addition, the adolescents also form their own conceptualization by drawing upon information from variety of media accessible to them and from observing others at particular places, especially the places where the adolescents love to hang out such as disco or shopping malls (Silbereisen et al.). Involvement in leisure activities is considered a general way to cope with development task and taking a particular lifestyle can be considered a developmental task (Silbereisen et al.). In addition, such participation sometimes can also serve as a strategy to deal with complex problems due to the developmental tasks (Silbereisen et al.).

Finally, the adolescents form their opinions by evaluating the information via the interaction with others in their surrounding context (Silbereisen et al., 1986). Before the ideas or conceptualization of growing up have permanently formed and the lifestyles 
have been permanently adopted, the adolescents evaluate the behavior formation by chatting and observing others' responses or reactions, especially their peer's (Silbereisen et al.). This interaction creates a crucial drive for healthy development from childhood to adulthood (Moffitt, 1993). Such interaction creates the nature of adolescence that is anyone who becomes adolescence wishes to be fully accepted and integrated in his surrounding context. The adolescent, thus, craves the ability to play appropriate roles in a variety social settings meanwhile to be able to maintain his/her sense of self (Coleman \& Hendry, 1990). This quality reflects the balance between the sense of autonomy, physical maturity, and intellectual maturity, as well as the balance between psychological forces within the adolescent and the ones within the context surrounding the adolescent (Coleman \& Hendry).

Anyway, there must be a point where the adolescent satisfies with a sense of the balance between his/her actual development and the development demanded or expected by the environment or social norms previewed by the adolescent (Dreher \& Oerter, 1986). Such balance tends to be unstable due to the changeable factors, which result in unstable situations surrounding the adolescent. Thus, there will never be a final solution for any conflicting situation during the ongoing development of any adolescent (Dreher $\&$ Oerter). What would it be for the direction of growing up if the adolescent could not meet his/her satisfaction point or the balance of his/her actual development versus expected development? Further descriptive analysis in Tilton-Weaver et al's study showed that about half of the adolescents dissatisfied with their actual development-- 
either physical or psycho-social or both and failed to reach their own expectation on development toward adulthood although they had provided great efforts to do so (TiltonWeaver et al., 2001). Research studies show that content and discontent with physical development and psycho-social development affect the sense of self. In a study of adolescent risk behavior and self-esteem between grade 8 adolescents with mean age of 14.1 and grade 11 adolescents with mean age of 17.4 by Wild, Fisher, Bhana, and Lombard (2004), the findings showed that at the age of 14 where boys were better physically developed and were more capability to sports or athletics than girls ( Lerner \& Steinberg, 2004), grade 8 boys were more likely to feel satisfied with their body image and sports or athletics while grade 8 girls were less likely to feel so and the boys' overall self-esteems were also higher than girls' (Wild, Fisher, Bhana, \& Lombard, 2004). An average age of 14 , newly after physical developmental spurt (Lerner \& Steinberg, 2004), grade 8 girls were more satisfied with the body image and sports or athletics than grade 11 girls, an average age of 17.4 and whose development is leveling off and subcutaneous tissue is cumulative (Mandleco, 2004). The satisfaction with physical development seems to affect the global self-esteem as seen that he younger girls' overall self-esteems were also higher (Wild et al., 2004). Furthermore, among adolescents who were contented with their psycho-social quality such as school performance were more satisfied with their overall sense of self than those who were not, regardless gender (Wild et al.). Such sense of self can also affect the feeling of confidence and success to transition to adulthood. A study of self-esteem by Rosenberg (1965) showed that some adolescents 
who were low self-esteemed felt uncertain about their ability to succeed their goals by the end of their school years. Despites the wish to grow up and become fully independent, the adolescents with low self-esteem viewed that it seemed impossible for them to attain their dreams due to their limited capability (Rosenberg). The findings discussed above illustrate that developmental path for some adolescents is fragile and may progress to a critical state if the adolescents fail to balance between their actual development and their expected development.

The healthy development theory has discussed that the adolescents behave or react to the situation in a way to maintain the point of satisfaction with his/her sense of maturity as well as to keep the stress caused by developmental tasks at the levels they can handle (Coleman, \& Hendry, 1990; Moffitt, 1993). In a longitudinal study among German adolescents between two age groups: an average age group of 11.6 and 14.6, findings showed that the adolescents organize their own developmental strategies by arranging their personal determinant and surrounding contexts according to their own ideas (Silbereisen et al., 1986). As the adolescents are attempting to handle their developmental tasks which include learning to accept their bodies; preparing for working life; forming sex-role identities; achieving emotional autonomy in comparison with parents, they are also developing their own value systems (Silbereisen et al.). They are likely to develop strategies to deal with situations that threaten their sense of becoming fully mature (Coleman \& Handry). Any behaviors adolescents created in order to maintain their sense of growing maturely are healthy developmental strategies and these 
adaptive strategies may even also lead to some behaviors so called antisocial behaviors (Moffitt). This finding is associated with Silbereisen's (1986) finding the majority of anti-social behaviors are in fact created in order to purposively regulate their sense of self, which aim to cope with developmental tasks toward adulthood. A descriptive analysis showed that early adolescents initiated temporary and minor antisocial behaviors at the age of as early as 11 , which presented about five percents. The prevalence of the behaviors was increasing to 32 percent at the age of 15 and by the age of 18 the behaviors were prevalent up to 93 percent of the samples who accepted being involved in any antisocial behaviors (Moffitt). Such findings supported that it is not uncommon for an early adolescent to act out in order to get attention from his/her society but in a different ways from young children.

During adolescence development, the involvement in antisocial behaviors is a way of self-regulation in order to maintain the balance between actual development and expected development. This regulation is an importance aspect of any individual attempting to cope with and adapt to his/her surrounding environment (Breger, 1974). At the mean time, it also brings about the sense of hope and a sense of personal control which are important in monitoring and regulating his/her cognitive appraisal in the situation that the adolescents have to face with unwanted, unintended, or unexpected events and circumstances (Labouvie, 1986). In return, success in maintaining such balance will foster more cumulative feelings of hope, personal control, and personal efficacy (Labouvie). As a result, the sense of autonomy and the sense of independency 
are cumulatively built up; as a result the major theme during adolescence development is fulfilled (Dreher \& Oerter, 1986). However, some healthy developmental reactions can be health threat, such as substance use which includes alcohol, drug, and last but not least smoking. A study of antisocial behavior and smoking showed that adolescents with a high level of rebellion or contradict behavior due to human needs of autonomy, selfdetermination, and reflectance, were at a greater risk of smoking (Miller, Burgoon, Grandpre, \& Alvaro, 2006). The researchers examined factors that place adolescents at high risks of being susceptible to smoking that leads the adolescents to smoking initiation. The samples were Arizona adolescents aged 10 to 20 . The findings also showed other factors along with antisocial behaviors which included prior experimentation to smoking, having more friends who smoked, and dissatisfaction with school performance were significant to susceptibility to smoking and adolescent with high level of susceptibility to smoking were at a high risk of smoking (Miller et al., 2006). Labouvie (1986) argued that substance use become a viable means for adolescents to explore their emotional experiences. Its reliable expectation and immediate effects are attractive to the adolescents. More than that, they believe that they can control their emotion. Simultaneously, they gain false feeling of accomplishment since in fact success in performance of substance use requires neither cognitive effort nor skill effort (Labouvie). Thus, it could be argued that substance use has some adaptation utility for those who have a big gap between actual development and expected development. However, it can easily involve into problem use and substance dependence if the 
adolescents repeatedly use such strategy as their coping actions and if they tolerate to its expected effects (Labouvie).

Tilton-Miller et al (2006) examined factors that place adolescents at high risks of smoking susceptibility which leads to smoking initiation among Arizona adolescents aged 10 to 20 . Similar to previous studies, the researchers found that prior experimentation to smoking, having more friends who smoked, and dissatisfaction with school performance were significant in placing adolescents to susceptibility to smoking and at high risk of smoking (Miller et al., 2006). In addition, the researcher also found that adolescents who were at greater level of psychological reactance--rebellion or contradict behavior due to human needs of autonomy, self-determination, and reflectance--were at a greater risk of smoking (Miller et al.). 


\section{CHAPTER III}

\section{METHODS}

The purpose of this descriptive study is to gain an understanding of factors that influence Thai-American youth's smoking initiation and tobacco use. This focus is based on empirical studies that report the majority of regular adult smokers initiate smoking during this age group. This chapter includes a description of the research aims, design, sample and sampling, data collection procedures, and analytic procedures. The protection of human subjects is also presented.

Specific Aims

Aim 1: Characterize smoking absorption and smoking adoption among ThaiAmerican youth.

Aim 2: Examine the relationships between the domains of smoking specific environment, smoking introductions, smoking believes, intentions to smoke, and smoking adoption among a group of Thai American adolescents. 
Aim 3: Examine which domains (smoking specific environment, smoking introductions, smoking believes, and intentions to smoke) increase the risk for smoking adoption among a group of Thai American adolescents living in Southern California.

Research Design

A cross-sectional descriptive correlational design was used for this study. A descriptive correlational design is a study conducted in a natural setting without any attempt to modify or control the environment (Kerlinger, 1986). Descriptive designs are employed when the researcher wishes to obtain information in areas in which little previous investigation has occurred. Limited studies exist that examine the role of smoking specific environment, smoking introductions, smoking believes, intentions to smoke, and smoking adoption.

\section{Sample and Sampling}

A purposive sample of Thai-American adolescents who live in Southern California was recruited for the proposed study. Inclusion criteria early and middle adolescents age 11 to 15 years old who live in Southern California at the period of time that the study is conducted, be able to read and write in English, computer and internet literate, and have computer and internet access.

Thai-American adolescents were recruited from Thai temples and Thai Information 
and Health Service Center using convenience and snowball methods. These sampling methods are useful for descriptive and correlational studies (Burns \& Grove, 2005). Initial recruitment was performed by convenience sampling; anyone who presented at the time recruitment was conducted was asked to participate. Those who do not meet the criteria and were willing to cooperate with the study were asked to suggest adolescents who also meet the criteria to contact the investigator.

Recruiting the sample from Thai temples may have some inherent bias. In general, Thai temples are non-smoking areas and one of the five precepts suggests nonconsume any kind of substances that compromise mental status and cigarettes in some community groups consider a mild deviation; the majority of subjects may be from nonsmoking family. To reduce such bias and increase the representativeness of the sample, Burns and Grove (2005) suggest a large sample size and recruiting subjects from various centers.

According to the design and statistic analysis for this study, a minimum sample size of $100-200$ subjects or $100-200$ subjects per group in multiple group analysis is recommended (Norris, 2001). Subjects were recruited from seven community centers in Southern California: one Buddhist temple in San Diego, one in Escondido, Valley Center, Riverside, San Bernardino, and two in Los Angeles area.

Parents or guardians and participants who were willing to participate in the study were informed of the purpose of the study, procedures of the study, and advantages and disadvantages of the study to the participants and the whole population. They were also 
informed any information they provide will be kept confidential. Finally, the parent and participant were asked to sign the consent form.

Power, Effect, and Sample Size

There is no consensus on the approach to compute power and sample size with logistic regression; although as pointed out by Katz (1999), 10 outcomes for each independent variable is appropriate. In logistic regression an estimate of the probability of a certain event occurring is made, rather than detecting the difference or relationship that may be present, such as in linear regression. No assumptions are made about the dependent variable (DV) and independent variable (IV), the relationship is non-linear, and is not normally distributed (Munro, 2005). Some authors use the likelihood ratio test; some use the test on proportions; some suggest various approximations to handle the multivariate case. Some advocate the use of the Wald test since the Z-score is routinely used for statistical significance testing of regression coefficients (Demidenko, 2007). Since this a descriptive study and not focused on hypothesis testing, the Final Logistic Regression Model, which includes statistical significance defined by $\mathrm{p}<0.05$, where $\mathrm{p}$ is from the Wald test for Confidence Interval for the Odds ration and overall statistical significance is tested by the likelihood ration test, $\mathrm{p}<0.1$, was used to demonstrate logistic regression model fit. 


\section{Data Collection Procedures}

The data was collected via the internet by computer-base data collection. Participants were asked to participate in the multi-data-collection based on the participants' convenience. Data were collected over a particular time-frame about 3-6 months based on the adequacy to the statistically analysis (sample size). Data-collection protocols suggested by CDC (2004) were adopted and modified to be appropriate to the sample for this study. Procedures for obtaining the participants' sign consent forms and parental permission were followed before administering the questionnaires. The participants who returned their signed consent forms and parental informed consent forms were scheduled for an orientation to participate in the computer-base-data collection. The participants' privacy was protected to reassure that the participation is anonymous and voluntary. During the data collection period, the investigator was in charge of collecting the data. The investigator provided contact information which allowed the participants to reach the investigator for questions and clarification. The participants were able to participate in the study whenever and wherever they desired per the design of the data collecting program.

\section{Measures}

Constructs of the smoking initiation model were examined in the proposed study: "smoking absorption", "smoking adoption", and smoking initiation within adolescence context. 


\section{Smoking absorption.}

Smoking absorption domain is defined as a process that any individual receives messages of smoking or tobacco-use via sensory channels. The absorption occurs in a smoking specific environment where messages about smoking or tobacco-use available to adolescents. Through the smoking introduced channels and as positive pictures, scenes, and images of smoking become more cumulatively cognitive to the adolescents, positive feelings, beliefs, and attitudes toward smoking gradually emerge. Finally, smoking or tobacco use intention becomes more recognized. The smoking absorption is comprised of: 1) the smoking specific environment: parent smoking, peer smoking, and smoking advertisements; 2) the smoking introduced channels: seeing, watching, listening, chatting, smelling, and touching; 3) mental responses specific to smoking: positive feelings, positive beliefs, and positive attitudes toward smoking; and 4) smoking intention.

\section{Smoking adoption.}

The smoking adoption domain is defined as smoking accepted process which occurs through an interaction between inner-person environment opening to smoking initiation and outer-person environment introducing smoking to a child. The innerperson environment is shaped by adolescence context where a child develops through adolescence in order to become mature, namely adult. Such environment will open to smoking initiation when a child evaluates his/her actual development below his/her perceived expected development. Via the interaction with outer-person environment that 
introduces smoking initiation to a child, the adolescent values smoking as an adult activity and adopts it as an additional developmental task or complementary to his/her actual development.

The smoking adoption includes high sensation seeking, low self-image or body-image, low family self-esteem, low school self-esteem, low peer self-esteem and low athletics/sport self-esteem.

\section{Intention to smoke.}

Intention to smoke is defined as an expression of probability of future smoking or tobacco use. Intention to smoke also includes an expression of probability of repeated smoking or tobacco using soon in the future.

The survey for the proposed study is a 97 item questionnaire (see appendix B) comprised of four sections including: 1) demographic data and baseline information of tobacco use, 2) measures of tobacco-use absorption, 3) knowledge counteracting tobaccouse absorption, and 4) measures of smoking adoption. Items of the questionnaire were adopted from seven instruments including: 1) the Middle School Youth Risk Behavior (MSYRBS), 2) the National Youth Tobacco Use Survey (NYTS), 3) the Indiana Youth

Tobacco Survey (IYTS), 4) the Assessment of Prototypes and Subjective Normative Social Images, 5) the Assessment of Intention to Smoke, 6) the Self-Esteem Questionnaire (SEQ), and 7) the 8-item Sensation Seeking Scale. 
Demographic Data and Tobacco Use

The demographic and tobacco use information section contains two parts: four items of demographic data, and seven items asking about tobacco use. Items in section one: demographic data and baseline information were adopted from the Middle School Youth Risk Behavior Survey (MSYRBS) (see appendix C) and the one created by the investigator (see appendix D).

\section{Tobacco-Use Absorption}

The measures of tobacco-use absorption contain five parts: 1) five items of parent smoking or family smoking, 2) two items of peer smoking, 3) six items of tobacco-use promotional products and advertisings, 4) nine items of feelings, beliefs, and attitudes toward smoking, and 5) five items of intention to smoke or tobacco-use.

Items for 1) family smoking, 2) peer smoking, and 3) tobacco advertising were adopted from the National Youth Tobacco-Use Survey (NYTS) (see appendix E). To measure feelings, beliefs, and attitudes toward tobacco-use, items were adopted from NYTS (two items), the Indiana Youth Tobacco-Use Survey (IYTS) (one item) (see appendix F), and the Assessment of Prototypes and Subjective Normative Social Images (six items) (Andrews, \& Peterson, 2006) (see appendix G). Measuring intention to smoke is comprised of 5 items: two items adopted from the Assessment of Prototypes and Subjective Normative Social Images (see appendix G), and three items from the NYTS (see appendix E). 
The Middle School Youth Risk Behavior Questionnaire

The Middle School Youth Risk Behavior Survey (MSYRBS) is a selfadministered questionnaire and consists of 49 multiple-choice items. The questionnaire was derived from the Youth Risk Behavior Surveillance System (YRBSS). The items of MSYRBS are actually a middle school version of YRBSS. Terms and wordings of the items had been changed to be appropriate to reading levels for middle-school students (Zullig, Pun, Patton, \& Ubbes, 2006).

Health risk behaviors contained in the MSYRBS include: a) 10-items of behavior related to unintentional injuries and violence, b) 7 items of tobacco use behavior, c) 8 items of alcohol and other drug use behaviors, d) 7 items of dietary behavior, e) 3 items of physical activity, and f) 2 items of other health-related topics (Zullig et al., 2006). Questions about tobacco use behavior were created based on prioritized objectives which call for reducing the initiation of cigarette smoking, increasing the average age of initiation, and reducing smokeless tobacco use (Marcus, Giovino, Pierce, \& Harel, 1993). Questions, thus, focus on experimentation with cigarette smoking, age of smoking initiation, current pattern of cigarette smoking, regular cigarette smoking, smoking cessation, and use of smokeless tobacco (Marcus et al., 1993). Questions regarding this focus had been adapted from questions used in the Teenage Attitudes and Practices Survey (TAPS) and National Cancer Institute (Marcus et al.).

For the present study, two categories of the Middle School Youth Risk Behavior Survey (MSYRBS) were used to collect demographic data and investigate tobacco use 
behavior among adolescents. The two categories include: a) four questions about demographic data and b) seven questions about tobacco use behavior (see Appendix C).

\section{The National Youth Tobacco Use Survey}

The National Youth Tobacco Use Survey (NYTS) questionnaire is comprised of close-ended questions with multiple-choice response options. The questionnaire contains 81 items. However, only 27 items which correspond to tobacco-use absorption based on social learning theory were adopted which includes family smoking, friend smoking, tobacco-use induced message (tobacco advertising) and promotional products, and knowledge of harmful effects of tobacco-use or anti-smoking messages (see appendix E). The five sections of NYTS were adopted which include: the questions asking about other people smoking and using tobacco around the adolescents, the adolescent's thoughts about tobacco.

The National Youth Tobacco Use Survey is complementary to the national Youth Risk Behavior Survey (YRBS). The YRBS measures youth risk behaviors based on the public health priorities. The NYTS provides comprehensive data regarding tobacco use, exposure to secondhand smoke, smoking cessation, school curriculum, minors' ability to purchase or obtain tobacco products, knowledge and attitudes about tobacco, and familiarity with pro-tobacco and anti-tobacco messages (CDC, 2003). The NYTS is representative to adolescents in grades 6-12 (CDC, 2001). 
The Indiana Youth Tobacco Survey

The Indiana Youth Tobacco Survey (IYTS) questionnaire was developed by the Center for Disease Control and Prevention (CDC) (Seo, Torabi, \& Weaver, 2008). The questionnaire contains questions from two resources: a set of standard questions from the CDC and a set of optional questions added by the Indiana Tobacco Prevention and cessation Program (ITPC) (ITPC, 2007; Seo et al., 2008). Such questions asking about tobacco use, familiarity with pro-and ant tobacco media messages, exposure to ETS, minors' ability to purchase or obtain tobacco products, and general knowledge, attitudes, and beliefs about tobacco which are similar to those in the National Youth Tobacco Use Survey (Seo et al.). The survey also has protocol similar to the National Youth Tobacco Survey (Seo et al.). For the present study, one item of perceived peer acceptance to smoking was adopted (see appendix F). Response options were "definitely yes", "probably yes", "probably not", and "definitely not". Scores ranged from 4, 3, 2, and 1 respectively. Scores were combined with other scores in belief and attitude measures.

The Assessment of Prototypes and Subjective Normative Social Images Questionnaire

The assessment of prototypes and subjective social images focuses on perception of smokers among children and early adolescents. Andrews and Peterson created the assessment by selecting items related to images of smokers from the lists of the students' perceptions of smokers and nonsmokers developed by Dinh, Sarason, and Peterson (1995) The checklists derived from content analyses of tobacco advertisements were 
developed based on the Theory of planned behavior and the prototype/willingness behavior (Dinh, Sarason, \& Peterson, 1995). The prototypes and subjective normative social images of smokers have been linked to intention to smoke in the future (Dinh et al., 1995). Thus, the Assessment of Prototypes and Subjective Normative Social Images consists of two sections: 1) the assessment of prototypes and subjective normative social images of smokers; and 2) the assessment of intention to smoke (Andrews \& Peterson, 2006).

The Assessment of Prototypes and Subjective Normative Social Images of smokers consists of a question to assess prototypes: what do you think about kids who smoke? and a question to assess subjective normative social images: what your friends think about kids who smoke: kids who smoke are cool, neat/exciting, and popular/liked by other kids (Andrews, Hampson, \& Barckley, 2007). Response options were "definitely yes", "probably yes", "probably not", and "definitely not". Scores ranged from 4, 3, 2, and 1 respectively. The responses to the three descriptions of prototypes were summed to measure prototypes and the responses to the three descriptions of images of smokers were summed to measure subjective normative social images of smokers (Andrews et al., 2007) (see appendix G).

\section{The Assessment of Intention to Smoke}

Questions assessing intention to use cigarettes in the future include: Do you think you would smoke when you are grown up? Do you think you would smoke when you 
are: a teenager (for $4^{\text {th }}-6^{\text {th }}$ graders), in high school (for $7^{\text {th }}-8^{\text {th }}$ graders), and out of high school (for $9^{\text {th }}$ and $10^{\text {th }}$ graders). A 4-point response format was used for each question: definitely yes, probably yes, probably not, and definitely not, coded “4”, “3”, “2” and "1" respectively. Scores of the two items were summed and combined with scores of three items from NYTS to measure intention to smoke.

\section{Knowledge about Smoking or Tobacco Use}

The knowledge counteracting tobacco-use absorption section contains five items of received anti-smoking messages from outside classroom and four items of received anti-smoking messages from classroom. Items were adopted from the National Youth Tobacco Use Survey (NYTS) (see appendix E). Exposure to anti-smoking messages from outside classroom at least one time in the past 30 days or response "yes" to at least three items of ones from classroom were categorized into an exposure category, coded "1".

\section{Smoking Adoption}

Smoking adoption contains seven parts: 1) eight items of family self-esteem, 2) eight items of school self-esteem, 3) eight items of peer self-esteem, 4) four items of bodyimage, 5) six items of sport/athletics self-esteem, 6) eight items of global self-esteem, and 7) eight items of sensation seeking. Items of self-esteem from part 1 to 6 were adopted from the Self-Esteem Questionnaire (SEQ) developed by David L. Dubois (Dubois, 
Felner, Brand, Phillips, \& Lease, 1996) (see appendix H). Items of sensation seeking were adopted from the Sensation Seeking Scale developed by Marvin Zuckerman (Zuckerman, 2007) (see appendix I).

\section{The Self-Esteem Questionnaire}

A measure of self-esteem and self-image for the present study is the Self-Esteem Questionnaire (SEQ) developed by David L. Dubois. SEQ consists of measures of six domains of self-esteem that match to the purpose of the present study including: family self-esteem, school performance self-esteem, peer group self-esteem, sport self-esteem, self-image, and global self-esteem. SEQ is considered best fit for the present study over other most frequent used measures of self-esteem for children and adolescents including: the Rosenberg's self-esteem scale, Coopersmith's self-esteem inventory, Harter's selfperception profile for adolescents, and Butler's self-image profile.

Self-Esteem Questionnaire consists of 42 items (see appendix H). Options of responses are rated on a 4-point scale ranging from strongly disagree, disagree, agree, and strongly agree, respectively. Each item is score 1 to 4 in the direction of positive selfesteem. Positively-worded items will be scored: strongly agree $=4$, agree $=3$, disagree $=$ 2 , and strongly disagree $=1$. On the other hand, negatively-worded items will be reverse scored: strongly agree $=1$, agree $=2$, disagree $=3$, and strongly disagree $=4$. SEQ consists of six subscales and each subscale contain a number of items as follows: 1) 8 items of peer-relations; 2) 8 items of family self-esteem; 3) 8 items of school self-esteem; 
4) 6 items of sports/athletics; 5) 4 items of body-image; and 6) 8 items of global selfesteem (Dubois et al., 1996).

The sensation seeking scale

To examine the level of sensation seeking, the 8-items sensation seeking scale was adopted into the present study (see appendix I). The sensation seeking scale is originally developed by Marvin Zuckerman which contains 40 items and measures in a forcedchoice format: true or false (Zuckerman, 2007). The 8-item sensation seeking scale was developed by Hoyle, Stephenson, Palmgreen, Lorch, and Donohew, which was derived from the original one and includes four dimensions of sensation seeking similarly to those contained in the original one (Zuckerman, 2007). These dimensions of sensation seeking include: a) experience seeking, b) thrill and adventure seeking, c) disinhition, and d) boredom susceptibility (Hoyle, Stepheson, Palmgreen, Lorch, \& Donohew, 2002). The 8-item sensation seeking scale (BSSS) is measured in a Likert-scale format, which makes it more advantageous over the original one by greater improving the reliability and validity of the instrument (Ray, 1973; Hoyle et al., 2002). In 5-point scales, the responses to the scale range from strongly disagree, disagree, neither disagree nor agree, agree, and strongly agree (Hoyle et al., 2002). The mean score of the weighed responses for eight items was used to cutoff between high and low sensation seeking.

The study of reliability and validity has shown that when the Likert-scale format was employed into the BSSS, the reliability and validity of the instrument were greater 
improved over the original one (Ray, 1973; Hoyle et al., 2002). The SSS-8 also gains more advantageous over a shorter version of the instrument, the 4-item sensation seeking scale (SSS-4) by containing a higher reliability and validity with a smaller effect size than the SSS-4 (Hoyle et al.; Stephenson, Hoyle, Palmgreen, \& Slater, 2003). Moreover, the content of the SSS-8 is more appropriate for young and older adolescents and avoids unfamiliar activities and terms to most adolescents (Zuckerman, 2007). With all these quality, the investigator considers the SSS- 8 is the best fit to measure the level of sensation seeking for the present study.

\section{Validity and Reliability of the Instrument}

\section{MSYRBS, NYTS, and IYTS.}

The Middle School Youth Risk Behavior Survey (MSYRBS), the National Youth Tobacco Use Survey (NYTS), and the Indiana Youth Tobacco Survey (IYTS) were developed by the United States Centers for Disease Control and Prevention (CDC, 2001; CDC, 2003; CDC, 2004; Seo, Torabi, \& Weaver, 2008). The reliability and validity of the questionnaires were examined based on the fact that the questionnaires are selfreported and closed-ended questionnaires.

\subsection{Reliability questionnaires.}

The United States Centers for Disease Control and Prevention has conducted testretest to examine reliability of the questionnaire. They administered the questionnaire on 
two occasions, two weeks apart. The Kappa statistic has been computed to assess the accuracy of the instrument (CDC, 2004a). Currently, the reliability of the 2005 Middle School Youth Risk Behavior Survey (MSYRBS) was examined by Zullig, Pun, Patton, and Ubbes (2006). The sample size was 232 middle school students in grades seven and eight from two public school districts in a Midwestern state.

The data were collected from two occasions, two weeks apart. The responses were collapsed into dichotomous categories: no risk and at risk. Kappa statistic and prevalence rates were analyzed to assess the reliability of the questionnaire. The investigators employed the criteria of Kappa statistic suggested by Landis and Koch (1977) to describe the strength of reliability. The standard CDC practice for assessing statistical significance of subgroup differences in standard Youth Risk Behavior Surveillance System was used as a criterion determining whether the questionnaire is consistent in measuring health risk behavior among middle school students. Such criterion was that if the $95 \%$ confidence interval of prevalence rates of the first and the second survey (test-retest) did not overlap, they were considered significant different or not consistent in measuring the data (Zullig et al, 2006).

The kappa statistic is an index of agreement for use with nominal scales. It is used as an alternate reliability coefficient for magnitude-scaled data (Cohen, 1968; Landis \& Koch, 1977). The kappa coefficient was analyzed based on percentage or proportion of agreement between observed and expected ones. Kappa statistics is used to test the hypothesis whether there are any differences between two population means when 
measured by a particular nominal scale (Landis \& Koch). The index dictates comparison of the observed agreement versus the expected agreement, which can be accounted for by chance (Cohen; Landis \& Koch). The high reliability dictates the observed values of agreement be higher than the expected values of agreement (Cohen; Landis \& Koch). According to Cohen (1968) and Landis and Koch (1977), kappa coefficient (א) may dictate either positive values or negative values ranging from +1 to -1 depending on the observed values and estimated values. Kappa of +1 describes perfect agreement while kappa of 0 describes no disagreement and kappa of -1 describes complete disagreement.

For large samples, sampling distribution of $\mathrm{\kappa}$ is approximately normal. The $95 \%$ confidence of interval where $z= \pm 1.96$ can be calculated (Cohen, 1968). Cohen also suggests the $95 \%$ confidence of interval, then, be a meaningful criterion for the adequacy of nominal scale reliability. In order to maintain consistent terminology when describing the relative strength of agreement associated with kappa statistics, Landis \& Koch (1977) suggest corresponding ranges of kappa as followings. Kappa of 0.00 or lower represents poor strength of agreement. Kappa of 0.00 to 0.20 represents slight strength. Kappa of 0.21 to 0.40 represents fair strength. Kappa of 0.41 to 0.60 represents moderate strength. Kappa of 0.61 to 0.80 represents substantial strength. Lastly, kappa of 0.81 to 1.00 represents almost perfect strength of agreement.

The results of the examination of reliability of the 2005 Middle School Youth Risk Behavior Survey conducted by Zullig et al. (2006) showed that the mean kappa for the overall instrument was $62.6 \%$ or 0.626 in proportion. According to the ranges of kappa 
suggested by Landis and Koch, the investigators described that the questionnaire obtained substantial strength of agreement or, in other words, it obtained substantial reliability. The examination also showed that for all grouping characteristics there were no significant differences for any group. Tobacco use category obtained substantial strength of agreement with mean kappa of $66.9 \%$ (95\% CI of 54.1, 79.8). For individual tobacco use behavior items, of seven items, one has a almost perfect agreement and one item has a moderate agreement, and the rest have a substantial agreement as followings: a kappa proportion of 0.75 for an ever-used-cigarettes item; of 0.70 for the item of "age of first cigarette $<14$ years old"; of 0.81 for a smoked $>1$ day in past 30 days item; of 0.66 for

the item of "moke $>20$ cigarettes per day on the days smoke during the past 30 days"; of 0.79 for the item of "received cigarettes in past 30 days"; of 0.50 for the item of "smoked at least one cigarette every day for 30 days/regularly"; and of 0.45 for the item of "has used smokeless tobacco" (Zullig et al.).

\subsection{Validity of the questionnaires.}

Williams and colleagues examined the validity of self-report of smoking assessment among adolescents aged 14-17 by investigating the convergence of the instrument (Williams, Eng, Botvin, Hill, \& Wynder, 1979). The researchers employed a health Habits Survey consisting of 12 questions related to cigarette smoking and alcohol use. The responses of cigarette use were compared with plasma cotinine levels which can detect a cigarette using in a past 48 hours since its half-life is 30 hours (Williams et al, 
1979). A sensitivity analysis showed a sensitivity of .95 which means that 95 percent of adolescents who report daily cigarette use had a corresponding detectable cotinine levels. The analysis also showed a specificity of .98 which represents that 98 percent of adolescents who reported never using cigarettes had non-detectable cotinine levels. Such findings support the validity of self-report among adolescents (Williams et al.).

Stacy and colleagues examined self-report smoking among adolescents by investigating the convergence of the instrument among four versions of self-report of smoking including the Oregon Index, National Cancer Institute suggested items, Waterloo stages of smoking, and Waterloo frequency-quantity scales as well as the convergence with plasma carbon monoxide (CO) levels (Stacy, Flay, Sussman, Brown, Santi, \& Best, 1990). Each self-report smoking measure converged moderately well with most of the conceptually related variables assessed including $\mathrm{CO}$ level and psychosocial measures. $\mathrm{CO}$ measures converged the best with self-report smoking assessing very recent smoking. Findings also supported that only little difference existed between openended and closed-ended scales in general levels of convergence. The researchers suggested that either type may be used effectively, depending on the measurement and analytical goals of the investigator (Stacy et al., 1990).

A study conducted by Dolcini and colleagues maybe best correct the limitation of measures of plasma cotinine and carbon monoxide levels which have short half-life and can detect only recent cigarette smoking (William et al., 1979). Dolcini and colleagues investigated the validity of adolescent self-report on smoking among adolescents aged 
12-14 by examining the agreement between the self-report and three biological indicators: carbon monoxide from breath samples, salivary cotinine, and salivary thiocyanate (Dolcini, Adler, Lee, \& Bauman, 2003).

Measurement of thiocyanate is more advantageous over measurements of carbon monoxide and salivary cotinine that it has half-life of 14 days which will allow a detect of current occasional smoking possible (Williams et al., 1979). In the study, respondents were considered smokers if at least one of any of the three indicators were positive which included a level of at least 9 parts per million ( $\mathrm{ppm}$ ) of carbon monoxide, a level of cotinine greater than $10 \mathrm{ng} / \mathrm{ml}$, and a level of at least $1,800 \mu \mathrm{mol} / \mathrm{l}$ (Dolcini et al.,2003). Self-reported behavior questions included: a) ever taken one or more puffs of cigarette in a life time, b) experience with cigarette, c) time since last puff of a cigarette, d) time since last cigarette, e) inhalation patterns, f) ever used smokeless tobacco, and g) last used smokeless tobacco (Dolcini et al.).

According to half-life of each indicator, the self-report items that corresponded most closely to the half-life of carbon monoxide were smoking in the past 9 hours or smoking today. Items reflecting smoking one or more cigarettes in the past 24 hours corresponded well with the half-life of cotinine. Self-reported smoking items for longerterm periods corresponded well to thiocyanate (Dolcini et al., 2003). Findings showed that among the three indicators, the cotinine level was found highest valid whereas the carbon dioxide level was found weakest valid. These results could have been affected by miss-matched questions, too light levels of indicators (a few puffs of smoking), some 
indicators need a particular level to be detected (measures of thiocyanate needs an intense level), and some biological indicators were confounded by other resources (carbon monoxide by household resources, and thiocyanate by food resources). Suggestions were that researchers make precise questions to what they are investigating (Dolcini et al.).

2. The Assessment of Prototypes and Subjective Normative Social Images of Smokers.

\subsection{Reliability.}

The reliability of the Assessment of Prototypes and Subjective Normative Social Images of Smokers:

The Guttman properties of the scales for cigarette users yielded the coefficient of reproducibility (CR) ranging from .96 to 1.00 across grades from $1^{\text {st }}$ to $8^{\text {th }}$ graders for boys and girls. The minimum marginal reproducibility (MMR) among items was lower than CR in each grade from $1^{\text {st }}$ to $8^{\text {th }}$ graders, ranging from .88 to .95 for boys and girls (Andrews et al., 2006). Coefficients of scalability (CS) across grades except $1^{\text {st }}$ graders were higher than .60 , ranging from .79 to .92 for boys, and .72 to .88 for girls. Findings of the Guttman properties and the moderate stability of the scales indicated that the reliability of the assessments was satisfactory and highlighted that the two assessments were a unidimensional scale (Andrews, \& Peterson, 2006). A repeat examine of reliability of the instrument using Cronbach's alpha coefficient analysis yielded an alpha coefficient of .60 for the measure of prototypes and .77 for the measure of subjective normative social images of smokers (Andrew et al., 2007). 
Reliability of the assessment of intention to smoke was examined by running the Cronbach's alpha coefficient. The analysis yielded the alpha coefficient of .75 with the correlation between the two items of the instrument of .61 (Andrews et al., 2007). The coefficient value is acceptable since it met a minimum acceptable value which was suggested that a coefficient of .70 or greater be used to estimate reliability (Dilorio, 2005).

\subsection{Validity.}

Prototypes have been proposed by the theory of planned behavior and the prototype/willingness model to link to intention to smoke in the future (Andrews \& Peterson, 2006). Thus, to examine validity of the instrument, the researchers studied the relationships between the prototypes and intention to smoke. The researchers had cut off the responses of first graders due to unsatisfied Guttman properties in this age group. Hence, only responses of second graders toward eight graders were analyzed (Andrews \& Peterson). Findings showed strong relationships between prototypes and intention to smoke in the future indicating that prototypes significantly predicted intentions for all grades from $2^{\text {nd }}$ to $8^{\text {th }}$, and the prototypes of cigarette smokers become increasingly positive after the fifth grade and stronger among girls than boys (Andrews \& Peterson). The researchers concluded that the evidence of validity was supported (Andrews \& Peterson). 


\section{The Self-Esteem Questionnaire.}

To investigate reliability and validity of the Self-Esteem Questionnaire (SEQ), the developers had conducted to separate studies. The exploratory and confirmatory factor analyses were employed to examine the hypothesized subscale structure in the study one. For the study two, analysis to investigate the convergent and discriminant validity of scores on SEQ was employed using three versions: parallel self-report, interview, and parent-report (Dubois, Felner, Brand, Phillips, \& Lease, 1996).

\subsection{Reliability of the Self-Esteem Questionnaire.}

Reliability of the instrument in study one was examined by splitting the samples into two equal halves and then analyzing internal consistency. Scores of each scale were summed and then analyzed to examine internal reliability of the measures (Dubois et al., 1996). Coefficient alphas of each scale between subsample A and B were as follows: peer relations of .85 and .86 ; School of .88 and .87 ; family of .91 and .90 ; body image .82 and .81 ; sports/athletics of .81 and .82 ; and lastly, global self-esteem of .86 and .86 (Dubois et al.).

In study two, a test-retest of two separate section of the Self-Esteem Questionnaire (SEQ) was conducted. Test-retest correlations for the 2-week interval between questionnaire sessions were as follows: .77 for peer-relation scale, .84 for school selfesteem scale, .82 for family scale, .75 for body-image scale, .74 for sports/athletics scale, and .81 for global self-esteem scale (Dubois et al., 1996). Alpha coefficients for each version of the SEQ were ranged from .81 to .92 for the self-report version, .81 to .91 for 
the interview version, and .84 to .93 for parent-report version (Dubois et al.).

Standards of reliability proposed by Nunnally (1978) suggests that an alpha coefficient of .70 or greater be used to estimate reliability. An instrument with a coefficient of .70 or greater is considered to have adequate reliability indicating interrelatedness among the items and internal consistency of the measurement. Nunnally (1978) also suggested to consider the number of items when comparing two similar scales. A reliability coefficient of .80 reflects a higher reliability than a coefficient of .60 only when the numbers of items on the scales are equivalent (Dilorio, 2005). According to such standards, the self-esteem questionnaire (SEQ) is considered to have a substantially high reliability or in other words, a high consistency in measuring of selfesteem and the test-retest reliability suggested a stability of the instrument over a period of two weeks.

\subsection{Validity of Self-Esteem Questionnaire.}

In study one, the developers used the self-report version of the Self-Esteem Questionnaire (SEQ) as a basis for further analysis (Dubois et al, 1996). Exploratory factor analysis (EFA) was employed to assess the validity of the new scale. EFA is generally used to find out how many factors exist in the data, what items are within each factor, which items are off limited and may be deleted, and whether the number and types of factors are consistent with the underlying theoretical framework used in scale development (Dilorio, 2005). 
According to Dilorio (1996), factors in SEQ must be the six subscales of SEQ: peer relations, school, family, sports/athletics, body image, and global self-esteem, and the numbers of indicators for each factors must be as follows: 8 items of peer relations, 8 items of family self-esteem, 8 items of school self-esteem, 6 items of sports/athletics, 4 items of body-image, and 8 items of global self-esteem (see appendix $\mathrm{H}$ ).

The developers conceptualized that global feeling of self-worth (global selfesteem) was a higher construct influenced by each construct of self-esteem targeted in SEQ-- peer relations, family, school, sports, and body-image-- thus, exploratory factor analysis was conducted (Dubois et al., 1996). Only first-order factors appropriate to this statistics were analyzed using exploratory factor analysis, for SEQ were peer relations, family, school, sports/athletics, and body image (Dubois et al., 1996).

The goal of factor analysis is to retain only factors that explain appreciable amount of variance in the data (Dilorio, 2005). Only factors with Eigen values greater than 1.0 will be extracted and the scree test enhances a more precise decision of which factors will be retained for extraction that is only those factors on the slope and above the point at which the line changes will be retained for further analysis (Dilorio). As expected, the global self-esteem was deducted out from exploratory factor analysis (Dubois et al., 1996). The scree test and Eigen value showed that the 5-factor solution was consistent with the proposed subscale structure of the SEQ (Dubois et al.).

The developers then utilized an oblique rotation method (Dubois et al, 1996). An oblique rotation is used to identify the items that define a factor. An item will have a high 
loading for the factor it identifies and a low loading for the other factors (Dilorio, 2005). In other words, indicators have high loadings for a construct they define and have low loading for other constructs they do not define. Findings showed that items were highly consistent with the proposed subscale structures. Only one item --I am as good as I want to be at reading and writing-that had almost equal loadings on the school and peer factors (Dubois et al.).

Final analysis the developers employed to investigate validity of the SEQ was confirmatory factor analysis (Dubois et al., 1996). Confirmatory factor analysis is often used to investigate the goodness-of fit of the model to the data. It focuses on the measurement model to examine an instrument's construct validity (Norris, 2001). It tests two models simultaneously: a measurement model and a theoretical model. A measurement model is a model of how theoretical constructs are measured (Norris). The theoretical model is a model of hypothesized relationship between the theoretical constructs (Norris).

Of samples of 1800 participants, the developers divided them into two 900 subject subsamples (Dubois et al, 1996). The analysis yielded comparative fit index (CFI) of .91 for subsample $\mathrm{A}$ and .92 for subsample B, indicating a good-fit of the model to the data. When the global self-esteem factor was included into the model, the analysis yielded comparative fit indexes of .88 for subsample A and .90 for subsample B showing a weaker fit than those without the global self-esteem but substantially acceptable (Dubois et al.). Lastly, statistics to examine variation across different groups--boys and 
girls, Whites and African American, and younger (grades 5 and 6) and older (grade 7 and 8)- were employed. Findings indicated similarity the model acted across gender, race and age groupings (Dubois et al.).

For the study two, the validity was examined running convergent and discriminant validity across three different versions of Self-Esteem Questionnaires: selfreport, interview, and parent-report form (Dubois et al., 1996). Self-report form and interview form are identical. The parent-report form had some changes in wording appropriate for parental rating but still was identical to the content of the self-report form (Dubois et al.).

Convergent and discriminant validity are multitrait-multimethod process used to assess construct validity. This method is based on the concept that the traits or constructs and the manner in which the traits or constructs are measured may cause them to share their variance (Dilorio, 2005). Convergent validity is analysis of similarity by comparing the same trait using two independent methods so called monotrait-heteromethod correlations or validity coefficients. If they yield similar results, then evidence of convergent validity exists (Dilorio). For the SEQ, the developers measured levels of selfesteem using three versions of SEQ: self-report, interview, and parent-report version (Dubois et al., 1996). If the SEQ is convergent, the three versions of SEQ must have similar results and thus correlations between them must be high.

Discriminant validity is used to examine correlations between dissimilar constructs. Discriminant validity is sometimes called heterotrait-heteromethod 
correlations since it involves the comparison of two or more traits, each measured by at least two methods (Dilorio, 2005). The constructs or traits should yield low correlation between them, if they differ from each other (Dilorio). To the author's perspective, each construct of SEQ should be different and each pair of them--peer relations, family, school, sports/athletics, body image, and global self-esteem--should yield low correlations between them.

Rules of multitrait-multimethod matrix proposed by Campbell and Fiske suggested that a) reliability coefficients representing measuring the same trait by the same method have the highest values; b) monotrait-heteromethod correlations (measuring the same trait by different methods) should be sufficiently high to provide support for convergent validity; c) heterotrait-monomethod correlations (measuring different traits using the same method) should be lower than the monotrait-heteromethod correlations; and d) heterotrait-heteromethod correlations (measuring different traits by different methods) should have the lowest correlations (Dilorio, 2005).

Findings supported that the self-esteem questionnaire met the rules of multitraitmultimethod matrix suggested by Campbell and Fiske. The reliability coefficients of SEQ representing measuring of monotrait-monomethod are considered highest among the values in the matrix as discussed above in the reliability of SEQ section. Monotraitheteromethod correlations are also considered substantially high. Findings showed that correlations between corresponding scores of self-report version and interview version ranging from .71 to .85 with mean of .78 (Dubois et al., 1996). Except the correlations 
between parent-report version and the other two which have lower correlations than those between self-report and interview version. This may be due to different perspective between parent and the adolescents. Correlations between corresponding scores of selfreport and parent-report version were ranging from .34 to .57 with the mean of .44 , and correlations between corresponding scores of interview and parent-report version were ranging from .32 to .57 with the mean of .45 (Dubois et al.). However, based on Campbell and Fiske's suggestion, the evidence is considered be adequate to support convergent validity of the instrument.

Findings also supported for the evidence of discriminant validity. Correlations between scales measuring different constructs of SEQ using the same method (heterotrait-monomethod) were lower than those of same construct by different methods (monotrait-heteromethod). Heterotrait-monomethod correlations (different constructs measured by one method) of SEQ had a correlation mean of .55 which was significantly lower than monotrait-heteromethod correlation mean (same trait by different methods). Lastly, the heterograft-heteromothod correlations of SEQ (measuring different constructs by different methods) had a lowest correlation with a correlation mean of .29 (Dubois et al., 1996). Therefore, the evidence of discriminant validity was supported which means the SEQ contains scales measuring different constructs of self-esteem. Thus, this instrument when used to measure self-esteem will have a high potential to yield a meaning of multidimensional self-esteem among adolescents in an age range of grade 5 to 9 . 


\section{The Sensation Seeking Scale.}

\subsection{Reliability of the 8-item Sensation Seeking Scale.}

The reliability of a measure refers to the consistency of responses the instrument obtains when repeated in the same population with same condition but in the different time (Burns \& Groves, 2001). In the other word, the measure is reliable if the data collected using such measure in the second time from the same population in the same event to the first time are comparable to the data collect in the first time (Burns \& Groves).

The reliability of the 8 -item sensation seeking scale was examined by Hoyle, Stepheson, Palmgreen, Lorch, and Donohew (2002). To examine the reliability and validity of the SSS-8, the researchers conducted a two separate study, study one and study two. The study one had a sample size of 1263 middle school and high school students from $8^{\text {th }}$ grader to 11 the graders. The majority of the participants were White. The analysis in the study one yielded consistency of standard deviations across the items. Internal consistency of the 8-item set had a coefficient alpha of 0.76 (Hoyle et al., 2002). Internal consistencies for Whites, and other (Asian-American, Hispanic, and Native American) yielded coefficient alpha between 0.74 and 0.79 whereas coefficient alpha for African-American was .68 (Hoyle et al., 2002). The effect size for the ethnicity effect was small with $\eta^{2}=0.05$ (Hoyle et al.). There were also no differences between grade levels. Across the four grade levels from $8^{\text {th }}, 9^{\text {th }}, 10^{\text {th }}$, and $11^{\text {th }}$, the coefficient alpha values were $0.78,0.75,0.75$, and 0.78 respectively (Hoyle et al.). In study two, the 
reliability of SSS-8 was reexamined by the advantage of confirmatory factor analysis used in the study. Actually, the researchers employed confirmatory factor analysis (CFA) to examine the validity of the instrument. However, CFA can also evaluate the reliability--test-retest by examine the consistency in measurement error over time as well as the factor structure (Arion \& Norris, 2001). In Study Two, SSS-8 yielded coefficient alpha of .74, which was statistically significant indifferent from coefficient alpha in Study One (Hoyle et al.).

The standards for reliability recommends a coefficient alpha range from .70 to .80 is considered be deemed acceptable for research purposes (Barnett, Macmann, \& Lentz, 2003). According to this suggestion, the investigator considers the instrument is reliable. However, to be accepted for the study, the instrument needs to be valid as well.

\subsection{Validity of the8-item Sensation Seeking Scale.}

Validation is defined as the accuracy, adequacy, and appropriateness of any measurement and the data collection procedure of the measurement to the purpose of a research study in dictating the abstract construct being examined in the study (Goodwin \& Goodwin, 1991; Burn \& Grove, 2001; Barnett et al., 2003). Validity of the 8-item sensation seeking scale, thus, must reflect that the scale and its procedure to collecting the data are appropriate to the proposed concepts. It must also reflect that it provides adequate and accurate means of data collection with an appropriate sample size for the researchers to test hypothesis and develop meanings out of such concepts (Barnett et al.).

To examine the validity of the 8-item sensation seeking (BSSS), Hoyle and his 
team had conducted the Study Two separately from the Study One and employed confirmatory factor analysis (CFA) and root mean square error of approximation (RMSEA) to confirm the fitness of the model. The Study Two had a sample size of 6368 adolescents in grades $7^{\text {th }}$ through $12^{\text {th }}$ in the southern United States within a 32-month period. The sample was $54 \%$ female and the majority of the participants were White (86\%). The potential responses were the 5-point scales and "don't know" and "refuse to answer". The researchers also noted the reliability of the instrument in the study two, the total coefficient alpha of 0.74 , of which was not significantly different from coefficient alpha for the study one (Hoyle et al, 2002).

According to the matter that the 8-item sensation seeking scale was derived from the original sensation seeking scale of which the items were reduced 40 items to 8 items and obtained four subscales of sensation seeking, the developers had employed two statistics of confirmatory factor analysis: a confirmative fit index and root mean square error of approximation to evaluate the structural validity of the scale. As the concepts of SSS-8 resemble those of the original scale, the developers considered the intended meanings of sensation seeking that high sensation seeking links to likelihood of taking risks, especially for substances use among adolescents (Zuckerman, 2007). The developers thus examined the fit of the model to the collected data, association of sensation seeking with drug-related attitudes, intentions, and behavior, and group differences whether the model works equally well in different sample subgroups (Hoyle et al., 2002). 
Confirmatory factor analysis is a structural equation modeling, which involves diagrams showing causal flows among variables (Mertler \& Vannatta, 2005). Basically, the statistic is used to test a hypothesis about the existing factor structure (Burns \& Grove, 2001). It is also used to test theory about hidden processes that might occur among variables, which cannot be measured directly but can only be approximated with actual measures (Mertler \& Vannatta). The underlying purpose of factor analysis is to determine if measures for different variables are in fact measuring something in common and enhance in allocating a smaller number of underlying hypothetical variables (Mertler \& Vannatta).

Confirmatory factor analysis focuses on the measurement model to examine an instrument's construct validity. It tests two models simultaneously: a measurement model and a theoretical model. A measurement model is a model of how theoretical constructs are measured (Norris, 2001). In the study of BSSS, the author believes that the measurement model is sensation seeking and four subscales of sensation seeking: experience seeking, thrill and adventure seeking, disinhition, and boredom susceptibility are indicators constructing for sensation seeking. BSSS contains two items for each indicator. The theoretical model is a model of hypothesized relationship between the theoretical constructs (Norris). According to Norris's, the author believes that the theoretical model of BSSS is the model of relationship between subscales and between sensation seeking and drug-related attitudes, intentions, and behavior.

Confirmative fit index ranges from 0 to 1 . Values that are greater than .09 are 
considered to indicate that the model has a good fit to the collected data (Aroian \& Norris, 2001). Root mean square error of approximation is also used to examine the fit of the model but in a different way from the confirmative fit index.

Root mean square error of approximation (RMSEA) is used to test the fit of the model by assessing the degree of lack of fit of the model (Browne \& Cuddeck, 1993). It measures the mean square of error and tells how much an estimator is different from the true value of the quantity being measured because such statistic is calculated from error or in other word, the standard deviation. RMSEA ranges from 0 to 1 and the smaller the RMSEA, the closer the model would fit (Aroian \& Norris, 2001). Values of more than .1 justify rejecting the hypothesis indicating poor fit (Aroian \& Norris) meaning that the difference is so big that the model may not equally work for different sample groups which refers to invalidity of the instrument. Values of .05 or less are considered a good fit which means that the degree of lack of fit is so small that the model works equally well to explain the data in different groups of subjects (Browne \& Cudeck; Arorian \& Norris; Norris, 2001). Therefore, Browne and Cudeck suggested values of .05 or less be considered a good fit, values of .08 or less be considered a reasonable fit, and values of .1 or greater be a poor fit (Browne \& Cudeck).

The 8-item sensation seeking scale, for the estimation of the single-factor model, has comparative fit index of 0.93 and root mean square error of approximation of 0.069 with $90 \%$ confidence interval of $(0.065,0.074)$ (Hoyle et al., 2002). Correlations of sensation seeking as measured by the 8-item sensation seeking with measures of tobacco- 
use-related attitudes, intentions, and behavior illustrated that higher sensation seeking is associated with less negative attitudes toward smoking and higher intention to smoke and currently smoke (Hoyle et al.).

According to the suggestion of cutoff values for confirmatory factor analysis, CFI of 0.93 indicates that the model has a good fit to the collected data (Browne \& Cudeck, 1993; Aroian \& Norris, 2001). RMSEA of 0.069 with $90 \%$ of confidence interval of $(0.065,0.074)$ indicates that the degree of lack of fit of the model is marginally small and the model, then, is considered a reasonable fit (Browne \& Cudeck). Values of CFI and RMSEA demonstrate the validity of SSS-8. According to Hoyle et al.'s study (Hoyle et al, 2002), BSSS also makes significant meaning to the risk of smoking among adolescents. For the present study, the investigator considers BSSS is valid and a best appropriate instrument to use to measure the variable of sensation seeking.

\section{Analytic Procedures}

Dependent variables.

Smoking initiation was categorized into dichotomous responses: a) $0=$ noinitiate-smoking (never smoke) and b) $1=$ yes-initiate-smoking (ever smoke and currently smoke). The mental responses specific to smoking and intention to smoke were categorized into dichotomous responses: a) $0=$ negative and b) $1=$ positive; and a) $0=$ no-intention to smoke and b) 1= yes-intention to smoke. 
Independent variables.

Independent variables are items of indicators for each construct. Variables of the smoking absorption construct are parent smoking, peer smoking, exposure to tobacco advertisings, feelings, beliefs, attitudes toward smoking, and intention to smoke. Variables of the smoking adoption construct are family self-esteem, school self-esteem, peer self-esteem, body-image, sport/athletic self-esteem, global self-esteem, sensation seeking, and perceived smoking as acceptable task.

The smoking specific environment was assigned based on the participants' response yes-or-no to one or more components of the environment including parent smoking, peer smoking, and exposure to smoking adverting. The frequency of the exposure to each component was collected as well. Feelings, beliefs, and attitudes toward smoking were measured and categorized into dichotomous category: positive and negative.

The background ready to accept smoking was measured by family self-esteem, school self-esteem, peer self-esteem, body-image, sport/athletic self-esteem, global selfesteem and sensation seeking. Each component was grouped into two categories: a) high and b) low based on the classification of each measurement. For the perception of smoking as acceptable developmental task, the participants were asked to respond in a four-point scale questionnaire from definitely yes to definitely not. 


\section{Data Analysis Procedures}

The investigator expected that if there are no smoking-specific environments and no-channels of smoking introduction, there will be no positive feelings toward smoking, and no positive beliefs and attitudes toward smoking. If there is no any of mentalresponse specific to smoking, there will be no intention to smoke. If the adolescents have the background ready to smoking and the smoking absorption, the adolescents will initiate smoking despite the recall of health risk warning if they value smoking as acceptable developmental task and if the gap of development has not been corrected. With the background and encouragement to smoking and the availability of supplies and opportunity, the smoking will be initiated.

Questionnaires with invalid responses were excluded from data analysis. The variables were coded before the investigator conducted the analysis. For smoking status, the never-smoking group was coded as 0 ; and the ever-smoking group coded as 1 . The smoking specific environment was coded as 0 for the no-exposure to any component and coded as 1 for yes-exposure to one or more components. The code of 1 was assigned to active activity participation category. Finally, for self-esteem levels, the code of 0 was assigned to the low self-esteem category. The code of 1 was assigned to the high selfesteem category.

Three statistical approaches were used: Descriptive statistics to examine the characteristics of smoking absorption, smoking adoption, and smoking initiation among Thai-American youths; Correlations to examine relationships; and Logistic Regression to 
examine which factors increase the odds of smoking among Thai American youths.

\section{Descriptive Statistics}

\subsection{Frequency distribution, mean and standard deviation.}

Frequency distribution statistics were computed to examine the prevalence of each indicator of smoking absorption which includes smoking specific environment (parent smoking, peer smoking, and exposure to tobacco advertisings), and positive feelings, beliefs, and attitudes toward smoking. Frequency distribution statistics were computed to examine the prevalence of smoking initiation, received anti-smoking education messages, and each indicator of smoking adoption and conditional background "ready to accept smoking" which includes low family self-esteem, school self-esteem, peer self-esteem, body-image, sport/athletic self-esteem, global self-esteem, and high sensation seeking. Descriptive statistics were also be computed to examine means and standard deviations of each indicator of conditional background "ready to accept smoking" to make a cutoff score between low and high level of each indicator (Those with scores below the mean scores will be categorized as low, and those with scores above the mean scores will be categorized as high).

\subsection{Chi-Square.}

A review of literature indicated slightly different pattern of smoking between boys and girls globally. However, it is possible that smoking pattern between boys and 
girls in some regions may massively vary. The investigator believes it is worth examining if difference of smoking pattern exists among very-few-have-known-of population such as Thai-American adolescents who live in Southern California. Chisquare statistics were computed to examine if characteristics of smoking absorption and smoking adoption are different between groups: boys and girls, age groups, low-high self-esteem groups, and low-high sensation seeking groups. For a two-group case such as between boy-and-girl and high-and-low group case with continuous variables, $t$-test was computed. For k-group case such as age groups between 10-16 years old and grade levels between 5 to higher than 9 with continuous variables, one-way ANOVA was computed. For categorical variables, Chi-square was computed.

\section{Correlations}

\subsection{Correlation coefficients ( $r$ ) and Spearman correlation coefficient (Rho).}

Correlations were computed to examine relationships between indicators of smoking absorption domain, smoking adoption domain, and smoking initiation and to examine if there are relationships between variables in this domain. Spearman correlation coefficient was used to examine relationships between categorical variables and continuous variables in smoking absorption, smoking adoption and smoking initiation

Correlations will also reveal whether such relationship (if ever exists) is negatively or positively relational. Multiple correlation $(R)$ will be computed to examine the relationship between smoking initiation (one dependent variable) and groups of 
indicators of smoking absorption and adoption (a combination of independent variables). It is possible that in behavioral research there may be overlapping relationships between indicators of smoking absorption and smoking adoption on smoking initiation if the relationships ever exist.

The investigator must be concerned when using Pearson correlations statistics. Variables proposed must each have a normal distribution and the level of the data should be at least ordinal scale. The relationships between variables if ever exist must be linear. Lastly, every value of $\mathrm{X}$, the distribution of $\mathrm{Y}$ scores must have approximately equal variability (Munro, 2001)

\subsection{Logistic Regression.}

Logistic regression analyses were used to examine which predictors increased the odds of smoking initiation. It is used to examine the relationships between a dichotomous dependent variable and a set of independents variables with multiple levels of data (Mertler, \& Vannatta, 2005; Munro, 2005). The purposes of using logistic regression and multiple regressions are quite similar. The difference between these statistic methods is that logistic can works on the dependent variables with dichotomous categories while multiple regressions works on a continuous dependent variable (Munro). Logistic regression provides the odds ratio which is useful in indicating predictors on the outcome and describing the probability the outcome will occur given the predictive conditions (Pagano \& Gauvreau, 2000; Munro). 


\section{CHAPTER 4}

\section{RESEARCH FINDINGS}

The purpose of this study was to develop knowledge about Thai American adolescents who lived in Southern California regarding smoking initiation, tobacco-use related environment, and intra-personal characters related to smoking initiation. This chapter will present the sample, the response rate, and the statistic findings of this study.

\section{Description of Sample}

A purposive sample of 217 youths were recruited from seven Thai-community centers located in four counties of Southern California: three centers in San Diego County, one in San Bernardino County, one in Riverside County, and two in Los Angeles County. Responses rates included San Diego County with 75 responses $339.7 \%$ of sample); Riverside County with 8 responses (4.2\%); San Bernardino County with 13 responses (6.9\%); and Los Angeles County with 93 responses (49.2\%). Approximately $88 \%(n=189)$ completed the questionnaire.

Table 4.1 summarizes the demographic characteristics of this sample. 
Table 4.1

Demographic Characteristics of Study Sample $(N=189)$

\begin{tabular}{|c|c|c|}
\hline Characteristic & $\mathrm{n}$ & $\%$ \\
\hline \multicolumn{3}{|l|}{ Age } \\
\hline 10 & 17 & 9.0 \\
\hline 11 & 51 & 27.0 \\
\hline 12 & 24 & 12.7 \\
\hline 13 & 32 & 16.9 \\
\hline 14 & 24 & 12.7 \\
\hline 15 & 25 & 13.2 \\
\hline 16 & 16 & 8.5 \\
\hline \multicolumn{3}{|l|}{ Gender } \\
\hline Female & 103 & 54.5 \\
\hline Male & 84 & 44.4 \\
\hline No response & 2 & 1.1 \\
\hline \multicolumn{3}{|l|}{ Grade Level } \\
\hline Lower than $5^{\text {th }}$ grade & 1 & .5 \\
\hline $5^{\text {th }}$ grade & 25 & 13.2 \\
\hline $6^{\text {th }}$ grade & 41 & 21.7 \\
\hline $7^{\text {th }}$ grade & 28 & 14.8 \\
\hline $8^{\text {th }}$ grade & 27 & 14.3 \\
\hline $9^{\text {th }}$ grade & 26 & 13.8 \\
\hline Higher than $9^{\text {th }}$ grade & 39 & 20.6 \\
\hline No response & 2 & 1.1 \\
\hline
\end{tabular}




\begin{tabular}{lcc}
\hline Characteristic & $\mathrm{n}$ & $\%$ \\
\hline Place of Birth & & \\
Thai-related-born in the United States & 134 & 70.9 \\
Thai-related-born in Thailand & 29 & 15.3 \\
Not related themselves as Thai & 23 & 12.2 \\
No response & 3 & 1.6 \\
\hline
\end{tabular}

The sample was fairly evenly distributed by gender with female (54.5\%), and almost three quarters $(70.9 \%)$ were born in the United States. Age ranged from 10 to 16 years with the mean age 12.71 years old $(S D=1.835) ; 27 \%$ reported age of 11 .

\section{Response Rate for Computer-Base Form and Paper Base Form}

The present study used two data correction forms: a computer-based questionnaire (CBQ) or Survey-Monkey and a paper-based questionnaire (PBQ). The data collection was conducted over a 7-month period, during July 1, 2011 to January 31, 2012. Fiftyfive participants preferred the CBQ, of those 32 completed ( $16.9 \%$ of the sample), and 11 were willing to change from the CBQ to the PBQ due to poor internet access. The response rate for the $\mathrm{CBQ}$ was $58.2 \%$ with response return ranged from the $1^{\text {st }}$ day to by the $4^{\text {th }}$ week after the signed agreement had been obtained. Of 181 participants who preferred PBQ, 157 completed and returned the survey (83.1\% of the sample). The response rate for the PBQ was $86.7 \%$ with response return ranged from the $1^{\text {st }}$ day to by the $6^{\text {th }}$ week after signed agreement had been made. For participants who could not complete the questionnaire right away, phone call reminders and thank-you messages 
were made within the first week to correct some difficulties the participants might have and within the $3^{\text {rd }}$ week after the actual contact to remind the participant to complete the questionnaire. Most responses were received on the $1^{\text {st }}$ day the instrument was administered at the community centers (130 responses from both the CBQ and PBQ).

\section{Statistical Analysis}

The statistical analysis included (a) examining the frequencies and percentages for all data, and means and standard deviations for intra-personal characters related to smoking initiation; (b) examining the differences between groups; and (c) examining the relationships between variables. The following sections will outline the statistical procedures and rationale used.

\section{Descriptive Statistics}

The frequencies and percentage were examined for 7 items of smoking initiation measurement, 13 items of tobacco-use promoting environment, 9 items of belief and attitude toward smoking, 5 items of intention to smoke, and 9 items of received antismoking messages. The means and standard deviations for 6 items of participants' belief and attitude toward smoking, 3 items of friends' belief and attitude toward smoking, 8 items of family self-esteem, 8 items of friend self-esteem, 8 items of school self-esteem, 4 items of body-image self-esteem, 6 items of athletics/sports self-esteem, 8 items of global self-esteem, and 8 items of sensation seeking were examined. Table 4.2 and Table 4.3 summarize the frequency and percentage for the 43 items of the tobacco- 
use-related environment and Table 4.4 summarizes the means and standard deviations for the intra-personal characters related to smoking initiation including the belief and attitude toward smoking, self-esteem, and sensation seeking.

Independent Sample T-test was examined for differences between genders and One Way ANOVA was examined for differences in continuous variables of self-esteem subscales and sensation seeking by age groups, grade levels, and place of birth. Table 4.5 summarizes significant differences between genders, age groups, grade levels, and nationalities in 7 factors: (a) smoking initiation, (b) exposure to tobacco-use related environment, (c) belief and attitude toward smoking, (d) intention to smoke, (e) exposure to antismoking messages, (f) self-esteem, and (g) sensation seeking.

\section{Smoking Initiation.}

The majority of Thai-American adolescents age 10 to 16 had never tried smoking a cigarette nor smoked daily. Only 12 participants (6.3\%) reported ever trying a cigarette, $3(1.6 \%)$ reported smoking during the past 30 days, and $2(1.1 \%)$ reported smoking daily. The youngest age ever smoked a whole cigarette was 8 years old. Among those who reported currently smoking, days of smoking during the past 30 days ranged from 6 to 9 days to all 30 days and a number of cigarettes being smoked ranged from 6 to more than 20 cigarettes per day. 
Table 4.2

Descriptive Statistics for Smoking Initiation and Tobacco-Use Related Environment

\begin{tabular}{llll} 
Characteristic & $\mathrm{n}$ & $\%$ \\
\hline
\end{tabular}

Smoking Initiation

Have tried cigarette smoking, at least one puff Yes

12

6.3

No

170

89.9

No response

7

Age of smoking a whole cigarette for the fist time

8 years old or younger

1

.5

11 years old

2

1.1

13 years old

2

1.1

14 years old or older

3

1.6

Days of smoking during the past 30 days

6 to 9 days

1

.5

All 30 days

2

1.1

Cigarettes being smoked per day during the past 30 days

6 to 10 cigarettes

More than 20 cigarettes

How did you get your own cigarettes during the past 30 days?

Convenient store

2

1.1

Some other way

1

.5

Have you smoked daily for 30 days?

Yes

No

186

98.4 


\section{Characteristic}

3 to 5 days

All 30 days

Category of smoking initiation

Non-initiation

Smoking initiation

Missing responses n

1

2

.5

1.1

165

17

87.3

7

9.0

3.7

Tobacco-Use Related Environment: Family Smoking

In the same room with someone who was smoking during the past 7 days

0 days

1 or 2 days

3 to 4 days

5 to 6 days

7 days

No response
160

13

6

1

7

2

85.7

6.9

3.2

.5

3.7

1.1

In the same car with someone who was smoking during the past 7 days

0 days

1 or 2 days

5 or 6 days

7 days

No response
172

10

1

4

2

132

57
91.0

5.3

.5

2.1

1.1

Have seen someone in your household smoking

No

Yes
69.8

30.2 
Characteristic

No

179

94.7

Yes

8

No response

2

1.1

Rules about smoking inside your home

Not allowed anywhere inside my home

153

81.0

Allowed in some places or at some times

8

No rules about smoking inside my home

19

10.1

Allowed anywhere inside my home

9

4.8

Exposure to family smoking category

Not-exposed

95

50.3

Exposed

91

48.1

Missing response

Tobacco-Use Related Environment: Friend Smoking

Number of closest friends who smoke cigarettes

None

155

One friend

Two friends

Four friends

3

1.6

Five or more

Not sure

Number of friends who use chewing tobacco, snuff, or dip

None

One friend

Two friends

Four friends

Five or more 


\begin{tabular}{ccc}
\hline Characteristic & $\mathrm{n}$ & $\%$ \\
\hline Not sure & 7 & 3.7 \\
No response & 3 & 1.6 \\
Category of exposure to friend smoking & & \\
Not-exposed & 152 & 80.4 \\
Exposed & 34 & 18.0
\end{tabular}

Tobacco-Use Related Environment: Tobacco-Use Promotional Products and Advertisings Use or wear something that has tobacco company name or picture on it

Definitely not

Probably not

Probably yes

Definitely yes

No response

Buy of receive something that has tobacco company name or picture on it

No

Yes

No response

Category of exposure to promotional products

No

Yes

No response

See actors using tobacco from TV or movies

Do not watch TV or movies

Never

Hardly ever

Some of the time

Most of the time
180 


\begin{tabular}{|c|c|c|}
\hline Characteristic & $n$ & $\%$ \\
\hline \multicolumn{3}{|c|}{ See ads for tobacco product from the internet } \\
\hline Do not use the internet & 3 & 1.6 \\
\hline Never & 49 & 25.9 \\
\hline Hardly ever & 69 & 36.5 \\
\hline Some of the time & 50 & 26.5 \\
\hline Most of the time & 16 & 8.5 \\
\hline \multicolumn{3}{|c|}{ See ads for tobacco products from newspaper or magazines } \\
\hline Do not read newspaper & 51 & 27.0 \\
\hline Never & 43 & 22.8 \\
\hline Hardly ever & 41 & 21.7 \\
\hline Some of the time & 39 & 20.6 \\
\hline Most of the time & 8 & 4.2 \\
\hline All of the time & 5 & 2.6 \\
\hline No response & 2 & 1.1 \\
\hline \multicolumn{3}{|c|}{ See ads for tobacco products from a convenient store, super market, or gas station } \\
\hline Never go to the places & 5 & 2.6 \\
\hline Never & 17 & 9.0 \\
\hline Hardly ever & 29 & 15.3 \\
\hline Some of the time & 67 & 35.4 \\
\hline Most of the time & 40 & 21.2 \\
\hline All of the time & 28 & 14.8 \\
\hline No response & 3 & 1.6 \\
\hline \multicolumn{3}{|c|}{ Category of exposure to promotional advertisings: } \\
\hline No exposure & 20 & 10.6 \\
\hline Exposure & 167 & 88.4 \\
\hline No response & 2 & 1.1 \\
\hline
\end{tabular}


The ways that the adolescents could get their own cigarettes were from convenient stores, super markets, discount stores, gas stations or other. Of 189 participants, 3 reported using chewing tobacco, snuff or dip ranged from 3 to 5 days to all 30 days. Smoking initiation had dichotomized into: non-smoking initiation and smoking initiation based on the criteria that response "yes" or "indicating ways to get cigarettes" to at least one item in this factor was categorized into a smoking initiation. Results showed the majority of the sample had not initiated smoking. Only $17(9.0 \%)$ had and $7(3.7 \%)$ were unable to put into any category due to missing data. Of 17 initiators, 9 were current smokers and the youngest age was $10(\mathrm{n}=2)$.

\section{Tobacco-Use Related Environment}

Almost half of the sample had been exposed to family smoking ( $n=91,48.9 \%)$. This categorization was based on the criteria that response "yes" or "witness" a scene of family smoking to at least $1 \mathrm{item}$ of this factor were categorized into an exposure to family smoking category - coded 1 . Among those who were exposed to family smoking, more adolescents reported "saw their family members smoking" $(n=57,30.2 \%)$ than other exposure categories. Of 189 participants, 27 reported (14.28\%) being in the same room with someone who was smoking and $15(7.93 \%)$ riding in the same car with someone who was smoking. Days of being exposed ranged from 1 days to 7 days. The majority of the sample had rules against smoking inside their home $(n=153,81.0 \%)$. 
Exposure to friend smoking was less prevalent than exposure to family smoking among Thai-American adolescents. Among those who were exposed, 34 (18\%) reported having at least one closest friend who smoked and $18(9.5 \%)$ having at least one friend who used chewing tobacco, snuff, of dip. Response "having at least one friend or not sure about number of friends" to at least one item of this factor was categorized into an exposure category-coded 1 . The results revealed $37(19.6 \%)$ had been exposed to friends tobacco use (either smoke or smokeless or both).

Exposure to tobacco-use promotional products or advertisings was found most frequently among exposures. Response "definitely yes" or "probably yes" to at least one item of promotional products was categorized into an exposure to the product-coded 1; and response to be exposed at least "some of the time" to at least one item of promotional advertising was categorized into an exposure category-coded 1 . The results showed the majority of the sample ( $n=167$, or $88.4 \%$ ) was exposed to smoking advertisings at least some of the time from at least one source. While exposure to smoking advertisings was prevalent, there was only $17(9.0 \%)$ reported being exposed to promotional products. The exposure to promotional advertising was predominantly from TV or movies with $65.60 \%$ ( $n=124)$ ranging from some of the time to most of the time, and from a convenient store or gas station with $71.4 \%(n=135)$ ranging from some of the time to all of the time. 


\section{Belief and Attitude toward Smoking}

Table 4.3 presents the frequency and percentage for belief and attitude toward smoking and intention to smoke. The majority of the sample strongly believed smoke from other people's cigarette is harmful to them $(n=119,63.0 \%)$; not safe to smoke for a year or two then quit after that $(n=122,64.6 \%)$; kids who smoke are not cool $(n=168$, $88.9 \%$ ), not neat or exciting ( $n=158,83.6 \%$ ), and not popular or liked by other kids ( $n$ $=113,59.8 \%)$. Interestingly, only $46.6 \%(n=88)$ had strong belief and attitude against "people your age think it is okay to smoke". Only strong belief and attitude against all the statements of these items were classified as "negative belief and attitude toward smoking"--coded 0 the rest were coded 1 . The analysis showed only $32(16.9 \%)$ had strong negative belief and attitude toward smoking or tobacco use. The majority of the sample also believed that their peer had negative belief and attitude against the statement that kids who smoke are cool $(n=125,66.1 \%)$, neat or exciting $(n=130,68.8 \%)$, and popular or liked by other kids $(n=112,59.3 \%)$. Only strong belief and attitude against the statements of these items were categorized into "peer's negative belief and attitude toward smoking"- coded 0 . The analysis showed $98(51.9 \%)$ believed that their peers had negative belief and attitude toward smoking.

\section{Intention to Smoke}

Majority of the sample responded strongly negatively to the intention to smoke items; $85.7 \%$ responded "definitely not smoke" when they are teenager or older; $80.4 \%$ when 
Table 4.3

Descriptive Statistics for Belief and Attitude and Intention to Smoke

\begin{tabular}{|c|c|c|c|c|c|c|c|c|c|c|}
\hline \multirow[b]{3}{*}{ Characteristic } & \multicolumn{10}{|c|}{ Responses } \\
\hline & \multicolumn{2}{|c|}{$\begin{array}{c}\text { Definitely } \\
\text { not }\end{array}$} & \multicolumn{2}{|c|}{$\begin{array}{c}\text { Probably } \\
\text { not }\end{array}$} & \multicolumn{2}{|c|}{$\begin{array}{c}\text { Probably } \\
\text { yes }\end{array}$} & \multicolumn{2}{|c|}{$\begin{array}{c}\text { Definitely } \\
\text { yes }\end{array}$} & \multicolumn{2}{|c|}{$\begin{array}{c}\text { No } \\
\text { response }\end{array}$} \\
\hline & $\mathrm{n}$ & $\%$ & $\mathbf{n}$ & $\%$ & $\mathrm{n}$ & $\%$ & $\mathrm{n}$ & $\%$ & $\mathrm{n}$ & $\%$ \\
\hline
\end{tabular}

Belief and Attitude: Participants'

$\begin{array}{lllllllllll}\text { Cigarette smoke is harmful } & 10 & 5.3 & 6 & 3.2 & 49 & 25.9 & 119 & 63.0 & 5 & 2.6\end{array}$

$\begin{array}{lllllllllll}\text { It is safe to smoke } & 122 & 64.6 & 46 & 24.3 & 10 & 5.3 & 8 & 4.2 & 3 & 1.6\end{array}$

$\begin{array}{lllllllllll}\text { It is okay to smoke } & 88 & 46.6 & 53 & 28.8 & 35 & 18.5 & 8 & 4.2 & 5 & 2.6\end{array}$

$\begin{array}{lllllllllll}\text { Kids who smoke are cool } & 168 & 88.9 & 16 & 8.5 & 2 & 1.1 & 3 & 1.6 & - & -\end{array}$

$\begin{array}{lllllllllll}\text { Are neat/ exciting } & 158 & 83.6 & 21 & 11.1 & 6 & 3.2 & 1 & .5 & 3 & 1.6\end{array}$

$\begin{array}{lllllllllll}\text { Are popular/liked } & 113 & 59.8 & 48 & 25.4 & 25 & 13.2 & 3 & 1.6 & - & -\end{array}$

Belief and Attitude: Peers'

$\begin{array}{llllllllll}\text { Kids who smoke are cool } & 125 & 66.1 & 55 & 29.1 & 7 & 3.7 & 2 & 1.1 & -\end{array}$

$\begin{array}{lllllllllll}\text { Are neat/exciting } & 130 & 68.8 & 50 & 26.5 & 7 & 3.7 & 2 & 1.1 & - & -\end{array}$

Are popular/liked: $\quad \begin{array}{lllllllllll}112 & 59.3 & 48 & 25.4 & 25 & 13.2 & 2 & 1.1 & - & -\end{array}$

Intention to Smoke

Would smoke when you

$\begin{array}{llllllllllllll}\text { are teenager... } & & 162 & 85.7 & 17 & 9.0 & 9 & 4.8 & - & - & 1 & .5\end{array}$

$\begin{array}{lllllllllll}\text { When you are grown up } & 152 & 80.4 & 32 & 16.9 & 3 & 1.6 & 2 & 1.1 & -\end{array}$

If best friends offered you

$\begin{array}{llllllllllll}\text { a cigarette } & 166 & 87.8 & 17 & 9.0 & 1 & .5 & 4 & 2.1 & 1 & .5\end{array}$

$\begin{array}{lllllllllll}\text { Will try a cigarette soon } & 160 & 84.7 & 17 & 9.0 & 2 & 1.1 & 1 & .5 & 2 & 1.1\end{array}$

Will smoke during the

\begin{tabular}{lllllllllll} 
next year & 176 & 93.1 & 8 & 4.2 & 1 & .5 & 3 & 1.6 & 1 & .5 \\
\hline
\end{tabular}


they are grown up; $87.8 \%$ if their best friends offered them a cigarette; $84.7 \%$ will definitely not try a cigarette soon; and $93.1 \%$ not at any time during the next year. Responses other than "definitely not" to at least one item in this factor were categorized into an intention to smoke category-coded 1 . Only strong responses-“definitely not"against all the items in this factor were categorized into a non-intention to smoke - coded 0 . The results revealed $28.0 \%(n=53)$ had intention to smoke.

\section{Recalled Antismoking Messages}

Table 4.4 summarizes the frequency and percentage for the exposure to antismoking messages, self-esteems, and sensation seeking. Recalled antismoking messages from outside classrooms were predominantly on TV $(n=110$ or $58.2 \%$ or the sample), and on billboards or outdoor signs ( $n=187$ or $99.0 \%)$ with at least 1 to 3 times in the past 30 days. The radio, internet, and magazines or newspaper were found not attractive resources to Thai-American adolescents. Only $25.4 \%$ of the sample reported recalling antismoking messages from the radio, $39.7 \%$ from the internet, and $32.4 \%$ from magazines or newspaper. Responses to recall antismoking messages to at least one resource were categorized into an exposure category-coded 1. The statistical analysis showed the entire sample $(n=189)$ was exposed to antismoking messages from outside classroom to at least one source and at least 1 to 3 times in the past 30 days. 
Table 4.4

Descriptive Statistics for Antismoking Messages, Self-Esteem and Sensation Seeking

\begin{tabular}{|c|c|c|}
\hline Characteristic & $\mathrm{n}$ & $\%$ \\
\hline \multicolumn{3}{|l|}{ Intention to Smoke } \\
\hline \multicolumn{3}{|l|}{ Category of intention to smoke } \\
\hline No intention to smoke & 131 & 69.3 \\
\hline Intention to smoke & 53 & 28.0 \\
\hline Missing responses & 5 & 2.6 \\
\hline \multicolumn{3}{|l|}{ Antismoking Messages } \\
\hline \multicolumn{3}{|l|}{ On TV during the past 30 days } \\
\hline Did not watch TV & 15 & 7.9 \\
\hline None & 62 & 32.8 \\
\hline 1 to 3 times in the past 30 days & 63 & 33.3 \\
\hline 1 to 3 times per week & 24 & 12.7 \\
\hline Daily or almost daily & 14 & 7.4 \\
\hline More than once a day & 9 & 4.8 \\
\hline No response & 2 & 1.1 \\
\hline \multicolumn{3}{|l|}{ On the radio during the past 30 days } \\
\hline Did not listen to the radio & 41 & 21.7 \\
\hline None & 100 & 52.9 \\
\hline 1 to 3 times in the past 30 days & 27 & 14.3 \\
\hline 1 to 3 times per week & 10 & 5.3 \\
\hline Daily or almost daily & 7 & 3.7 \\
\hline More than once a day & 4 & 2.1 \\
\hline \multicolumn{3}{|c|}{ On the internet during the past 30 days } \\
\hline Did not use the internet & 9 & 4.8 \\
\hline None & 104 & 55.5 \\
\hline
\end{tabular}




\begin{tabular}{|c|c|c|}
\hline Characteristic & $\mathrm{n}$ & $\%$ \\
\hline 1 to 3 times in the past 30 days & 46 & 24.3 \\
\hline 1 to 3 times per week & 13 & 6.9 \\
\hline Daily or almost daily & 9 & .4 .8 \\
\hline More than once a day & 7 & 3.7 \\
\hline No response & 1 & .5 \\
\hline \multicolumn{3}{|c|}{ On billboards or outdoor signs during the past 30 days } \\
\hline None & 1 & .5 \\
\hline 1 to 3 times in the past 30 days & 99 & 52.4 \\
\hline 1 to 3 times per week & 56 & 29.6 \\
\hline Daily or almost daily & 17 & 9.0 \\
\hline More than once a day & 15 & 7.9 \\
\hline No response & 1 & .5 \\
\hline \multicolumn{3}{|c|}{ In magazines or newspapers during the past 30 days } \\
\hline Did not read magazines or newspaper & 87 & 46.0 \\
\hline None & 68 & 36.0 \\
\hline 1 to 3 times in the past 30 days & 21 & 11.1 \\
\hline 1 to3 times per week & 3 & 1.6 \\
\hline Daily or almost daily & 6 & 3.2 \\
\hline More than once a day & 4 & 2.1 \\
\hline \multicolumn{3}{|c|}{ Category of exposure to antismoking messages from outside classrooms } \\
\hline Exposure & 189 & 100.0 \\
\hline Non-exposure & 0 & 0.0 \\
\hline \multicolumn{3}{|c|}{ Practice ways to say "No" during the past 12 months } \\
\hline Yes & 63 & 33.3 \\
\hline No & 78 & 41.3 \\
\hline Not sure & 48 & 25.4 \\
\hline
\end{tabular}




\begin{tabular}{|c|c|c|}
\hline Characteristic & n & $\%$ \\
\hline \multicolumn{3}{|c|}{ Taught the reasons why people your age smoke } \\
\hline Yes & 68 & 36.0 \\
\hline No & 78 & 41.3 \\
\hline Not sure & 42 & 22.2 \\
\hline No response & 1 & .5 \\
\hline \multicolumn{3}{|c|}{ Taught that most people your age do not smoke } \\
\hline Yes & 63 & 33.3 \\
\hline No & 74 & 39.2 \\
\hline Not sure & 52 & 27.5 \\
\hline \multicolumn{3}{|c|}{ Taught about the dangers of tobacco use } \\
\hline Yes & 117 & 61.9 \\
\hline No & 41 & 21.7 \\
\hline Not sure & 30 & 15.9 \\
\hline No response & 1 & .5 \\
\hline \multicolumn{3}{|c|}{ Category of exposure to antismoking from classrooms } \\
\hline Exposure & 61 & 32.3 \\
\hline Non-exposure & 128 & 67.7 \\
\hline \multicolumn{3}{|l|}{ Self Esteem } \\
\hline \multicolumn{3}{|l|}{ Family self-esteem } \\
\hline High self-esteem & 98 & 51.9 \\
\hline Low self-esteem & 87 & 46.0 \\
\hline Missing response & 4 & 2.1 \\
\hline \multicolumn{3}{|l|}{ School self-esteem } \\
\hline High self-esteem & 80 & 42.3 \\
\hline Low self-esteem & 103 & 54.5 \\
\hline Missing response & 6 & 3.2 \\
\hline
\end{tabular}




\begin{tabular}{|c|c|c|}
\hline Characteristic & $\mathrm{n}$ & $\%$ \\
\hline \multicolumn{3}{|l|}{ Friend self-esteem } \\
\hline High self-esteem & 77 & 40.7 \\
\hline Low self-esteem & 104 & 55.0 \\
\hline Missing response & 8 & 4.2 \\
\hline \multicolumn{3}{|c|}{ Body-image self-esteem } \\
\hline High self-esteem & 85 & 45.0 \\
\hline Low self-esteem & 99 & 52.4 \\
\hline Missing response & 5 & 2.6 \\
\hline \multicolumn{3}{|c|}{ Athletics/sports self-esteem } \\
\hline High self-esteem & 83 & 43.9 \\
\hline Low self-esteem & 105 & 55.6 \\
\hline Missing response & 1 & .5 \\
\hline \multicolumn{3}{|l|}{ Global self-esteem } \\
\hline High self-esteem & 75 & 39.7 \\
\hline Low self-esteem & 98 & 51.9 \\
\hline Missing response & 16 & 8.5 \\
\hline \multicolumn{3}{|l|}{ Sensation Seeking } \\
\hline High level & 84 & 44.4 \\
\hline Low level & 97 & 51.3 \\
\hline Missing response & 8 & 4.2 \\
\hline
\end{tabular}

Recalled antismoking messages from the classroom were predominantly on a topic about the dangers of tobacco use $(n=117$ or $61.9 \%)$ during the past 12 months. Other topics were less frequently recalled by the participants; only $33.3 \%$ of the sample 
recalled on a practicing-ways-to-say "No" topic; $36.0 \%$ on a topic of reasons why people your age smoke; and $33.3 \%$ on a topic of that most people your age do not smoke. Responses "yes" to at least three items in this factor were categorized into an exposure category - coded 1 and the other responses were coded $0-$ a non-exposure category. The results revealed $32.2 \%$ of the sample $(n=61)$ had been exposed to antismoking messages from classrooms and $67.7 \%(n=128)$ had not.

\section{Self-Esteem}

The self-esteem measurements were in ordinal scales with scores for each item ranged from 1 to 4 . Reliability of the instruments between the computer-basedquestionnaire (CBQ) and paper-based-questionnaire (PBQ) were Cronbach's Alpha of $.853(n=31)$ and $.858(n=154)$ for family self-esteem; $.829(n=30)$ and $.890(n=153)$ for school self-esteem; .801 $(\mathrm{n}=31)$ and $.748(\mathrm{n}=150)$ for friend self-esteem; $.709(\mathrm{n}=31)$ and $.745(n=153)$ for body-image self-esteem; $.761(n=31)$ and $.755(n=157)$ for athletics/sports self-esteem; and finally $.811(\mathrm{n}=28)$ and $.748(\mathrm{n}=145)$ for global selfesteem.

Scores of each self-esteem scale were summed and the means was used to cutoff low and high self-esteem categories-coded 0 and 1 respectively. According to this cutoff, slightly more than half reported high self-esteem (51.9\%), in contrast to those reporting low self-esteem for school (54.5\%); friend (55\%); body-image (52.4\%); athletics/sports (55.6\%); and global self-esteem (51.9\%) (Table 4.4). 


\section{Sensation Seeking}

The sensation seeking measurement was in an ordinal scale, scores for each item ranged from 1 to 5 with a possible overall score ranging from 8 to 40 . Scores were summed and the means was used to cutoff between low and high categories. According to this cutoff, the frequency and percentage of the low and high categories were fairly evenly distributed with slightly more than half $(51.3 \%)$ youth reporting low sensation seeking. The reliability of the scale was Cronbach's Alpha of $.817(n=31)$ for CBQ and $.754(n=150)$ for $P B Q$.

Table 4.5 summarizes belief and attitude toward smoking, self-esteems categories and sensation seeking. The measurement of belief and attitude toward smoking was in an ordinal scale. Scores for each item ranged from 1 to 4 with maximum scores of 28 for the participants' belief and attitude and 12 for peers' belief and attitude. Possible maximum scores for each self-esteem scales were 32 for family self-esteem, 32 for school selfesteem, 32 for friend self-esteem, 12 for body-image self-esteem, 24 for athletics/sports self-esteem, and 32 for global self-esteem. When the means of each self-esteem scale were computed to find its position on the percentile rank of its possible maximum score, family self-esteem and school self-esteem were found higher than the other self-esteem scales with a $82^{\text {nd }}$ and $81^{\text {st }}$ percentile rank respectively.

Belief and attitude scores were not normally distributed. The curves skewed to the right. Similarly, the intention to smoke was extremely skewed to the right. Self-esteem scales and sensation seeking scale had acceptable normal distribution. Self-esteem 
subscales were screwed with several extreme values, which were not the results from errors in coding or a failure in the data collection. They were actual values collected from the sample.

Table 4.5

Belief and Attitude, Intention to Smoke, Self-Esteem, and Sensation Seeking

\begin{tabular}{lccccc}
\hline Characteristic & $M d n$ & Mode & $M$ & $S D$ & $\%$ \\
\hline Belief and Attitude toward Smoking & & & & & \\
Participant's belief and attitude & 8.0 & 7 & 8.7 & 2.433 & - \\
$\quad$ Friends' belief and attitude & 3.0 & 3 & 4.32 & 1.721 & - \\
Intention to Smoke & 0.0 & 0 & .98 & 2.449 & - \\
Self-Esteem & & & & & \\
$\quad$ Family self-esteem & 26.0 & 24 & 26.27 & 3.803 & 82 \\
$\quad$ School self-esteem & 26.0 & 24 & 25.94 & 4.291 & 81 \\
$\quad$ Friend self-esteem & 25.0 & 24 & 25.42 & 3.127 & 79 \\
$\quad$ Body-image self-esteem & 12.0 & 12 & 12.38 & 2.093 & 77 \\
$\quad$ Athletics/sports self-esteem & 17.0 & 16 & 17.05 & 3.124 & 71 \\
$\quad$ Global self-esteem & 25.0 & 24 & 25.22 & 3.517 & 79 \\
Sensation Seeking & 25.0 & 22 & 25.54 & 5.725 & 64 \\
& & & & &
\end{tabular}

\section{Inferential Statistics}

\section{Differences between and among groups.}

The descriptive statistic analysis discussed above concluded characteristics of the sample regarding smoking initiation and its related factors. The investigator then wondered if these characteristics described the entire sample equally or there were some 
differences in the sample since it contained some differing groups such as boys and girls, born in Thailand and born in the United States, age groups, and grade levels. Statistical analyses to study differences between and among groups for seven factors including: (a) smoking initiation, (b) exposure to tobacco-use related environment, (c) belief and attitude toward smoking, (d) intention to smoke, (e) exposure to antismoking messages, (f) self-esteem, and (g) sensation seeking were conducted.

From the measures of central tendency, the belief and attitude scales, and intention to smoke scales were significantly positively skewed (Hinkle, Wiersma, \& Jurs, 2003). The self-esteem and sensation seeking were not perfectly distributed and had some outliers and extreme values (Duffy \& Jacobson, 2005), however, they fit the pattern of the normal curve that they were symmetrical, unimodal, and their proportion of scores found in a particular area of the normal curve met the identification of a normal curve (Burns \& Grove, 2001). Therefore, they were considered continuous scores with a normal distribution. The outliers and extreme values were also considered carefully. An acceptable suggestion was that to analyze the data with the values and then compare the results with those when such values were removed (Duffy \& Jacobson). The investigator found the results were similar. It was rationalized to ignore the outliers and extreme values where the results were similar between with and without such values when the data analyzing (Duffy \& Jacobson).

The statistics adopted for the following analyses were as follows, Chi-Square test was computed to examine smoking initiation, exposure to tobacco-use related 
environment, belief and attitude toward smoking, intention to smoke, and exposure to antismoking messages by gender. Independent Sample $t$-test for differences by gender was examined for continuous variables including self-esteem and sensation seeking. To examine if there was any differences among age groups, grade levels, and place of birth, One-Way ANOVA with Scheffe Posthoc test was computed (Hinkle et al. 2003). ANOVA was conducted for continuous variables self-esteem subscales and sensation seeking. Kruskal-Wallis test for categorical variables and skewed scores including smoking initiation, exposure to tobacco-use related environment, belief and attitude toward smoking, intention to smoke, and exposure to antismoking messages were examined (Hinkle et al.). Mann-Whitney test was run to identify where the differences existed if there were any. Table 4.6 summarizes differences found between and among groups (Hinkle et al.).

Boys were statistically significantly different from girls in seven variables: smoking initiation, exposure to tobacco promotional products, positive belief and attitude toward smoking, and intention to smoke were more prevalent among boys. Boys had higher sensation seeking levels but lower family self-esteem, and school self-esteem than girls.

Differences also existed among age groups. The differences were found in the exposure to friends smoking, tobacco promotional products, tobacco use advertisings, participants' belief and attitude, friends' belief and attitude, school self-esteem, and sensation seeking. Older adolescents reported higher means values for all statistically 
Table 4.6

Differences between and among Groups

\begin{tabular}{lccccccc}
\hline Characteristic & $\chi^{2}$ & $F$ & $d f$ & $p$ & $M$ & $S D$ & $n$ \\
\hline Between Genders & & & & & & & \\
Smoking initiation & 9.365 & - & 1 & .002 & - & - & 178 \\
Exposure to promotional products & 14.235 & - & 1 & .000 & - & - & 185 \\
Participants' belief and attitude & - & 6.809 & 175 & .010 & -.637 & .368 & \\
Intention to smoke & 5.453 & - & 1 & .020 & - & - & 182 \\
Family self-esteem & - & 5.847 & 181 & .017 & .772 & .562 & \\
School self-esteem & - & 11.586 & 179 & .001 & 2.178 & .620 & \\
Sensation seeking & - & 4.225 & 177 & .041 & -2.489 & .845 &
\end{tabular}

Among Age Groups

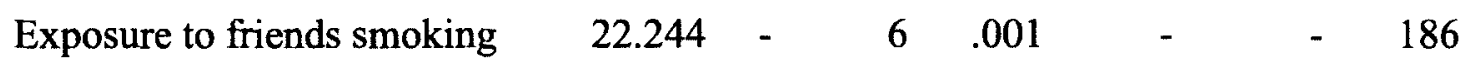

Exposure to tobacco promotional

Products

$\begin{array}{lllllll}20.862 & - & 6 & .002 & - & - & 186\end{array}$

Exposure to tobacco use

$\begin{array}{lccccccc}\text { Advertisings } & 23.847 & - & 12 & .021 & - & - & 185 \\ \text { Participants' belief and attitude } & 26.837 & - & 6 & .000 & - & - & 179 \\ \text { Friends' belief and attitude } & 30.593 & - & 6 & .000 & - & - & 187\end{array}$




\begin{tabular}{lccccccc}
\hline Characteristic & $\chi^{2}$ & $F$ & $d f$ & $p$ & $M$ & $S D$ & $n$ \\
\hline \multicolumn{7}{c}{ Between/Within } \\
School self-esteem & - & 5.011 & $6 / 176$ & .000 & - & - & 182 \\
Age 10 and 16 & & & & & 5.228 & 1.404 & \\
Age 11 and 16 & & & & & 4.188 & 1.164 \\
Sensation seeking & - & 2.484 & $6 / 174$ & .025 & & & 180
\end{tabular}

Among Grade Levels

$\begin{array}{llllllllll} & \text { Exposure to friends smoking } & 19.750 & - & & 6 & .003 & - & - & 184\end{array}$

Wear something with tobacco

$\begin{array}{llllllllll}\text { company name on it } & 19.810 & - & 5 & .001 & - & - & 184\end{array}$

$\begin{array}{lllllllll}\text { Exposure to smoking advertisings } 31.730 & - & & 5 & .000 & - & - & & 182\end{array}$

Participant belief and attitude

$\begin{array}{lllllllllll}\text { toward smoking } & 20.485 & - & & 5 & .001 & - & - & 176\end{array}$

$\begin{array}{lllllllll}\text { Friends' belief and attitude } & 30.327 & - & & 6 & .000 & - & - & 185\end{array}$

Between/Within

School self-esteem

$\begin{array}{llll}- & 6.194 & 5 / 174 \quad .000\end{array}$

179

Grade 5 and grade higher than 9

$4.260 \quad 1.035$

Grade 6 and grade higher than 9

$3.974 \quad .904$

Grade 7 and grade higher than 9

$3.754 \quad .988$

Among Place of Birth

$\begin{array}{llllllllll}\text { Exposure to friends smoking } & 6.823 & - & 2 & .033 & - & - & 183\end{array}$ 
significant variables, except school self-esteem, for this variables younger adolescents reported higher mean values. Differences did not exist in smoking initiation and intention to smoke. Findings of differences among grade levels resembled those of age groups except for sensation seeking; there were no significant differences among grade levels. Scheffe Posthoc test showed differences existed between age 10 and 15, 10 and 16,11 and 15, and between 11 and 16 . Differences among nationalities were found in the exposure to friends smoking. The Mann-Whitney test showed that adolescents who did not relate themselves as Thai were more exposed to friends smoking than adolescents who related themselves as Thai both born in Thailand and in the United States.

\section{Relationships between variables.}

The present study examined the relationship of variables regarding smoking initiation gleaned from the literature. Pearson product-moment correlation $(r)$ for continuous variables were examined including self-esteem and sensation seeking; Spearman rank correlation coefficient $\left(r_{\mathrm{s}}\right.$ or rho) for significantly skewed scores were examined including the exposure to tobacco-use related environment, belief and attitude toward smoking, intention to smoke, and smoking initiation (Hinkle et al.; Monro, 2005). Point-biserial correlation coefficient $\left(r_{\mathrm{pb}}\right)$ for one dichotomous variable with one continuous variable was examined including smoking initiation and family and school self-esteems; and the smoking initiation and intention to smoke (Hinkle et al.; Munro). Table 4.7 summarizes correlations found in the study. 
Table 4.7

Correlations between Variables Related to Smoking Initiation

\begin{tabular}{lrrrrr}
\hline Characteristic & $r$ & $r h o$ & $r_{p b}$ & $p$ & $n$ \\
\hline Intrapersonal Variables & & & & & \\
$\quad$ Family self-esteem and school self-esteem & .397 & - & - & .000 & 180 \\
Family self-esteem and sensation seeking & -.281 & - & - & .000 & 177 \\
School self-esteem and sensation seeking & -.268 & - & - & .000 & 176 \\
Tobacco-Use Related Variables & & & & & \\
Belief/attitude and exposure to family smoking - & .240 & - & .001 & 176 \\
Belief/attitude and exposure to friends smoking - & .337 & - & .000 & 186 \\
Belief/attitude and exposure to advertisings & - & .220 & - & .003 & 176 \\
Belief/attitude and peer's belief and attitude & - & .534 & - & .000 & 178 \\
Belief/attitude and intention to smoke & - & .457 & - & .000 & 184 \\
Intention and smoking initiation & - & - & .541 & .000 & 177
\end{tabular}

Between Intrapersonal and Tobacco-Use Related Variables

\begin{tabular}{llllll} 
Family self-esteem and intention to smoke & - & -.322 & - & .000 & 184 \\
School self-esteem and intention to smoke & - & -.332 & - & .000 & 183 \\
Family self-esteem and initiation to smoke & - & - & -.222 & .003 & 178 \\
School self-esteem and initiation to smoke & - & - & -.330 & .000 & 176 \\
\hline
\end{tabular}
Among intrapersonal variables, the family self-esteem and school self-esteem had a statistically significant positive relationship. Each of the mean scores of these self- 
esteems subscales were inversely related to sensation seeking. Findings indicate those who had high family self-esteem were more likely to have high school self-esteem and were less likely to have high sensation seeking. The intrapersonal variables also were found related to intention to smoke. The family self-esteem and school self-esteem were inversely related to the intention to smoke. This finding suggests among Thai-American adolescents, the higher the self-esteem the less likely they would intend to smoke.

Among the tobacco-use related variables, the participants' belief and attitude was positively related to exposure to family smoking, friends smoking and tobacco advertisings, peer belief and attitude, and intention to smoke. In other words, the more they were exposed to tobacco-use related environment the more likely they would have positive belief and attitude toward tobacco-use. The more the adolescents perceived their friends had positive belief and attitude toward smoking and the more they have positive belief and attitude toward smoking the more likely they would intend to smoke.

Since the prevalence of smoking initiation was extremely low among the sample, and the findings showed a significant relationship between smoking initiation and smoking intention, it was decided to examine the variables related to the intention to smoke. The investigator now wondered if there were any differences between adolescents who had intention to smoke and those who did not. To examine the differences between these two groups, One-Way ANOVA for differences between group means in continuous variables and Chi-Square test $\left(\chi^{2}\right)$ for differences in categorical variables were examined. 
Mann-Whitney test was examined to explain how the mean rank described each group. Table 4.8 summarizes the differences found between an intention-to-smoke group and a non-intention-to-smoke group.

Findings indicate adolescents who had intention to smoke and those who did not were significantly different in almost all of the variables in the tobacco-use-related factors. Differences were not statistically significantly found in the exposure to the smoking advertising variable and the exposure to antismoking messages from classroom and outside classroom. The Mann-Whitney test showed that the intention-to-smoke group had significantly higher Mean-Ranks in all variables than the no-intention-tosmoke group. In other words, adolescents who had intention to smoke had been exposed to family smoking, friends smoking, and tobacco promotional products than those who did not have intention to smoke. They also had higher positive belief and attitude toward smoking and perceived their friends would have positive belief and attitude toward smoking. Moreover, smoking initiation was significantly more prevalent among those who had intention to smoke than those who did not. Differences also existed between the intention to smoke and the no-intention to smoke in the intrapersonal variables. The intention-to-smoke group was found to have statistically significant lower family selfesteem, school self-esteem, and friend self-esteem while having higher sensation seeking level than the no-intention to smoke group. 
Table 4.8

Differences between Intention and Non-Intention to Smoke

\begin{tabular}{lccccc}
\hline Characteristic & $\chi^{2}$ & $F$ & $d f$ & $p$ & $n$ \\
\hline Tobacco-Use-Related Variables & & & & & \\
$\quad$ & & & & & \\
Exposure to family smoking & 9.024 & - & 1 & .003 & 181 \\
Exposure to friends smoking & 16.401 & - & 1 & .000 & 181 \\
Exposure to tobacco promotional products & 5.457 & - & 1 & .019 & 182 \\
Belief/attitude toward smoking & 26.690 & - & 2 & .000 & 180 \\
Peers' belief/attitude toward smoking & 18.929 & - & 2 & .000 & 182 \\
Smoking initiation & 18.968 & - & 1 & .000 & 177 \\
Intrapersonal Variables & & & & & \\
Family self-esteem & & & & & \\
School self-esteem & - & 15.657 & $1 ; 178$ & .000 & 179 \\
Friend self-esteem & - & 22.809 & $1 ; 177$ & .000 & 178 \\
Sensation seeking & - & 9.111 & $1 ; 174$ & .003 & 175 \\
\hline
\end{tabular}

Odds ratio and predictors.

The findings discussed above provided detail about the variables of interest in the present study and characteristics of risk to intention to smoke and smoking initiation. In the final analysis, the investigator wished to find out which factors significantly increased the risk to smoking initiation. From previous analyses, findings show the smoking 
initiation had a very small sample size $(n=17)$ with statistically significant relationship with the intention to smoke which had a much bigger sample size $(n=53)$. A better alternative was to study the intention to smoke group. Simple Logistic Regression was used to examine the probability of the smoking initiation by the intention to smoke. Table 4.9 summarizes the odds ratio of the intention to smoke on the smoking initiation.

\section{Table 4.9}

Summary of Logistic Regression Analysis for Variables Predicting

Smoking Initiation $(n=177)$

\begin{tabular}{|c|c|c|c|c|c|c|c|c|}
\hline \multirow[t]{2}{*}{ Variables } & \multirow[t]{2}{*}{ B } & \multirow[t]{2}{*}{ SE } & \multirow[t]{2}{*}{ Wald } & \multirow[t]{2}{*}{$d f$} & \multirow[t]{2}{*}{$p$} & \multirow[t]{2}{*}{$\operatorname{Exp}(B)$} & \multicolumn{2}{|c|}{$95 \% \mathrm{CI}$ for $\mathrm{EXP}(\mathrm{B})$} \\
\hline & & & & & & & Lower & Upper \\
\hline \multicolumn{9}{|l|}{ Step 1} \\
\hline Intention to smoke & .458 & .114 & 16.186 & 1 & .000 & 1.581 & 1.265 & 1.977 \\
\hline Constant & -3.144 & .383 & 67.392 & 1 & .000 & .043 & & \\
\hline
\end{tabular}

Negelkerke $\mathrm{R}^{2}=.334$ (Hosmer and Lemeshow Test), .191

Model (Likelihood ratio) Chi-square $=29.195$ (1), $p=.000$

Percent correct classified $=92.1 \%$

Logistic Regression for predicting variables with increased odds for the intention to smoke included five variables: exposure to family smoking, exposure to friend smoking, participants' belief and attitude, family self-esteem, and school self-esteem. Outliers outside two standard deviation and the significant change in the -2-loglikelihood (if a variable is dropped) larger than the variable entered were removed (George \& Mallery, 2007). Based on an exploratory nature of the study, a simultaneous 
method was applied. Table 4.10 summarizes the odds ratio of variables predicting the intention to smoke.

Table 4.10

Summary of Logistic Regression Analysis for Variables Predicting

Intention to Smoking

\begin{tabular}{lrrrrrrrrr}
\hline Variables & B & SE & Wald & $d f$ & $p$ & $\operatorname{Exp}(\mathrm{B})$ & \multicolumn{2}{c}{$95 \%$ CI for EXP (B) } \\
\cline { 6 - 9 } & & & & & & & & Lower & Upper \\
\hline Step 1 & & & & & & & & \\
Family smoking & -.069 & .071 & .932 & 1 & .334 & .934 & .813 & 1.073 \\
Friend smoking & .082 & .065 & 1.591 & 1 & .207 & 1.086 & .955 & 1.234 \\
Belief/attitude & .474 & .119 & 15.711 & 1 & .000 & 1.606 & 1.271 & 2.030 \\
Family self-esteem & -.038 & .066 & .328 & 1 & .567 & .963 & .845 & 1.097 \\
School self-esteem & -.142 & .052 & 7.307 & 1 & .007 & .868 & .783 & .962 \\
Constant & -.250 & 2.420 & .011 & 1 & .918 & .779 & & \\
\hline
\end{tabular}

Negelkerke $\mathrm{R}^{2}=.371$ (Hosmer and Lemeshow Test), .199

Model (Likelihood ratio) Chi-square $=49.173(5), p=.000$

Percent correct classified $=\mathbf{7 7 . 9 \%}$

Of the five variables, two were statistically significant in the equation: the participant's belief and attitude toward smoking and the school self-esteem. The odds ratio of the school self-esteem indicated the probability of having intention to smoke was almost one time smaller among adolescents who had high school self-esteem than those 
who had low self-esteem. The odds ratio of the belief and attitude variable also indicated among Thai American adolescents age 10 to 16 , the probability of having intention to smoke was almost two times greater when the adolescents had positive attitude toward smoking. From the odds of the intention to smoke variable predicting the smoking initiation, we also learned the probability to initiating smoking was almost two times greater when the adolescents had intention to smoke. 


\section{CHAPTER 5}

\section{DISCUSSION}

Campaigns against tobacco-use among adolescents have been conducted for decades worldwide (WHO, 2008e). In some countries smoking or tobacco-use has shown signs of gradual decrease. On the other hand some countries see signs of gradual decrease and then increase, some with surging increase are evident (CDC, 2008). This phenomenon alerted health care providers (HCPs) for changes in tobacco use and to look for specific factors related to tobacco use such as changes in marketing campaigns produced by tobacco companies, changes in environment where the adolescents resided, or even changes in growth development affecting both physical and mental aspects of an individual. However, being alert to such changes would be impossible if the providers did not know what to look at. Indeed, being alert to such changes might be ineffective if the providers looked at some factors and ignored other important factors due to an inadequate understanding of them.

The purpose of this study was to define a more complete picture of tobacco use among adolescents age 10 to 16 where very early smoking or tobacco use had been 
initiated. The study was conducted among Thai-American adolescents, a sample of youth to our knowledge have never been studied before.

The aims of the study were to examine: (a) the characteristics of smoking absorption (tobacco-use related environment) and smoking adoption (intrapersonal environment ready for adopting tobacco-use) among Thai-American adolescents; (b) differences of characteristics of smoking absorption and adoption between and among groups of interest; (c) the relationships between variables of smoking absorption and smoking adoption; and (d) which factors increase the risk of smoking initiation among ThaiAmerican adolescents.

\section{Discussion of Results}

Findings indicate smoking initiation was not prevalent among Thai-American adolescents aged 10 to 16 residing in Southern California when compared to the national prevalence. The majority of the sample $(87.3 \%)$ did not smoke or use any form of tobacco, indeed only $9.0 \%(n=17)$ had ever smoked. The distribution of the initiation was 4 in grade 5, 2 in grade 6,1 in grade 7, 1 in grade 8,2 in grade 9, and 7 in grade higher than 9 . Of 17 participants who had already initiated smoking, 9 were currently smoking or about $4.8 \%$ of the entire sample. The distribution of current smokers was: 3 in grade 5, 1 in grade 7, 2 in grade 8, 2 in grade 9, and 1 in grade higher than 9. The prevalence of smokeless tobacco was $1.6 \%$ of the sample $(n=3)$. The distribution was: 2 in grade 5 and 1 in grade 8 . In contrast, nationally, the prevalence of tobacco-use initiation was over $50.0 \%$ in high school students and more than $25 \%$ were current smokers in 2009 (American Cancer Society, 2010). The use of smokeless tobacco was 
found approximately 1 in 7 high school boys and more than $2 \%$ in high school girls (American Cancer Society). The prevalence of tobacco-use initiation among middle school was not as high as found in high school students. Yet, it was considerably higher than found in the present study. Nationally, the prevalence of current tobacco-user was more than $8 \%$ (American Cancer Society). About 3\% reported using smokeless tobacco, with the majority smoking cigarettes (American Cancer Society).

Among Thai-American adolescents, the age of initiation was quite similar to the national average. According to the US for Center for Disease Control and Prevention (CDC), in 2008 survey, more than $25 \%$ of adolescents age 12 or older were current tobacco users (American Cancer Society, 2010). In the present study, among ThaiAmerican adolescents, smoking initiation was found in age 11, 15, and 16 and the youngest age of initiation was 10 years old (6.25\% of subsample of initiation). Among participants who reported age of ever smoking a whole cigarette for the first time, 1 reported the age of 8 years old. The youngest age of current smokers was 11 years old. There are two ways to interpret these findings. First, smoking initiation may be shifting to younger ages. Second, the initiation found in age 8 and 11 in this study was quite extreme and might not be known in other studies or in normal course of analysis (Munro, 2005). However, it did actually happen in other samples. Smoking initiation was found in an even younger age, for example in Indonesia the youngest age of smoking was found in age of 2 years old (Kelly, 2010). Such incidence strongly highlighted the influences of tobacco-use environment on the children. 
Exposure to family smoking was reported by almost half of the sample (48.9\%) while exposure friends smoking was reported by $18.0 \%$ of the sample. Not surprisingly, tobacco-use promotional products and advertisings were found to have the highest rate over the other two resources. Of 189 participants, 167 (88.4\%) were exposed to tobaccouse promotional products and advertisings. Such contrary findings to the initiation suggest instead of studying only prevalence alone, researchers may need to consider the quality of the exposure including exposure to tobacco-use messages in convenient stores, gas stations, or supermarkets. This may explain why the initiation was not higher when compared to the exposure. However, frequency of exposure might lead to familiarity and it would be easier to accept something the individual is familiar with (Liao, Yeh, \& Shimojo, 2011). Notably, frequent exposure and individual preferences may function together. For TV, family smoking, or friends smoking may need less subsequent exposure because they contained much more detail appealing to emotion. If such exposure contained positive emotion, positive belief and attitude could emerge (Liao et al, 2011). On the other hand, for those who witnessed their family members suffering form tobacco-use related illness or even death might feel differently. Another reason may arise from the samples recruited from Thai Buddhist temples where the five precepts were the main stream of practice which included the trait to keep away from things tampering human minds-such as alcohol, drugs, or even cigarettes (in some temples). However, future studies should be conducted for reliable explanations.

Although exposure to tobacco-use environment did not directly link to smoking initiation, it did not mean that there was no cognitive process regarding tobacco use 
among those who were exposed to it. In the correlation analysis, positive belief and attitude toward smoking was found positively associated with exposure to family smoking, friends smoking, and tobacco-use advertisings. Correlation analysis showed positive relationships between belief/attitude and exposure to family smoking $(\mathrm{rho}=.240$, $p=.001)$, to friends smoking $(\mathrm{rho}=.337, p=.000)$ and to tobacco-use advertising (rho= $.220, p=.003$ ). These findings indicate those with exposure to family smoking, friends smoking, and/or tobacco-use advertisings are more likely to have positive belief and attitude toward smoking.

Exposure to antismoking messages was prevalent among the samples, specifically billboards or outdoor signs $(99.0 \%)$ and TV $(58.2 \%)$. Overall the entire sample was exposed to antismoking messages from outside the classroom in the past 30 days. The exposure to antismoking from the classroom was less than from the outside the classroom. Only $32.2 \%$ recalled ever being exposed to them in the classroom over the past 12 months. The findings suggest television and outdoor signs or billboards are good resources to target smoking initiation. If the design and content presented on the signs decreases an adolescents' intention to smoke, such resources may be the most cost effective education program to fight against smoking initiation.

Intrapersonal factors were found almost equally represented between low and high level groups. This equality may be due to the use of the mean score as a cutoff between high and low categories, of which the scores were normally distributed. The mean scores of self-esteem subscales and sensation seeking were high when compared to the possible full scores. The self-esteem scores were at an above of $71^{\text {st }}$ percentile rank of 
the full scores. The sensation seeking score was slightly lower at above the $64^{\text {th }}$ percentile rank of the full scores, slightly more than half were classified in the low level of sensation seeking. Such findings suggest the contentedness of self was important for adolescents in this age group and to meet at least average contented levels the positive thought toward self should be as high as $71^{\text {st }}$ percentile rank or higher among ThaiAmerican adolescents. Self-esteem categories were also important in protecting against smoking initiation, as shown in the correlational findings: high self-esteem levels were inversely related to smoking intention: rho of $-.322(p=.000 ; n=180)$ for family selfesteem and rho of $-.332(p=.000 ; n=179)$ for school self-esteem.

\section{Differential Analysis Results}

Findings from the present study support those from previous studies where boys were more engaged in smoking initiation than girls (American Cancer society, 2010). Indeed, boys had more exposure to promotional products, higher positive belief and attitude towards smoking, more intention to smoke, lower family self-esteem, school selfesteem, and higher sensation seeking than girls. Findings point out variables which may put boys at increased risk compared to girls.

Differences also existed among age groups. There were differences in the exposure to friends smoking, tobacco promotional products, and tobacco advertisings. Differences were also found in the participants' belief and attitude toward smoking, friends' belief and attitude toward smoking, school self-esteem, and sensation seeking. These findings support those from previous studies, it appears the adolescents were 
growing older, they were more exposed to friends smoking, tobacco promotional products, and advertisings. More also perceived their friends would think positively to smoking characters, and had higher sensation seeking levels. In contrast, their school self-esteem was lower. This finding supports previous studies that reported a dramatic decrease of self-esteem occurred during middle school years with the crucial predictor of social incongruity adolescents experienced in the school settings (Rhodes, Roffman, Reddy, \& Fredriksen, 2004). The findings also indicate among Thai-American adolescents the statistically significant changes regarding tobacco-use were at age 15 . The findings from the examination on differences among grade levels support those found in age groups and at grade levels of 9 or higher, the adolescents would think differently from those in lower grade levels in almost all the variables discussed above. The differences found among age groups and among grade levels suggest the cognitive process regarding tobacco-use or smoking among Thai-American adolescents could be recognized at the grade level of 9 or higher. Interestingly, while tobacco-use related variables and self-esteem categories were significantly different among age groups and among grade levels, smoking initiation and intention to smoke were not. This may be caused by the incidence of smoking initiation found in age of 11 , and an increased number reporting intention to smoke found in age 13. This gradual increase was also present in other age groups, reminding health care researchers to be cautious about the shift of smoking initiation.

Difference among place of birth was not evident. This may be the results of shared religious, cultural, and social activities among the samples. In contrast, 
differences were found in the exposure to friends smoking and the attitude that smoking was acceptable for this age. Participants in the group "I am not Thai in anyway" were more exposed to friends smoking and thought that smoking was acceptable for this age than those in the group "Thai born in US" and "Thai born in Thailand".

\section{Correlation Analysis Results}

Findings from the present study support previous research. Boys were more prone to smoking-related factors than girls (American Cancer Society, 2010) and had weaker intra-personal environments, especially with their family and performance at school which may affect their future life due to the sense of insecure supports from both family and the adolescents per se. Boys also had higher sensation seeking, intention to smoke, and smoking initiation. The findings also indicated as the adolescents were "growing up" either by their ages or by school grade, they were more prone to some of the smoking related factors, weaker in family relationships, and school performance, but higher in sensation seeking. Due to the close cultural and social activities, place of birth seemed less predictive of smoking-related factors. In contrast to exposure to friend smoking and attitude "it was okay to smoke".

Positive belief and attitude toward smoking was found positively related to intention to smoke and intention to smoke was found positively related to smoking initiation. These findings suggest the more the adolescents had positive belief and attitude toward smoking the more likely they would "intend to smoke", and the more they intended to smoke the more likely they would initiate smoking. These findings support 
the theoretical framework proposed in the study regarding their influences on each other. Exposure to family and friends smoking environment, smoking or tobacco promotional products, and positive belief and attitude toward smoking appeared to be risk factors for belief and attitude toward smoking. Among Thai-American adolescents, such risk factors were strong when they were in objective forms or in close environment to the adolescents such as products that the adolescents wore, or being in the same room, or riding in the same cars with those who were smoking. The greater exposure to such environment or products the more likely they would think positively toward smoking. This may be because most of the smoking environments they encountered were in positive mood or atmosphere. Unfortunately, the present study did not examine these variables. Further research is needed.

The findings on relationships between the smoking initiation, levels of selfesteem and sensation seeking support some of the previous studies. Levels of self-esteem categories appeared to be protective factors against smoking initiation. The strongest ones were the family self-esteem and the school self-esteem. The findings indicate the adolescents' relationships with family as well as their performance at school were very important to the adolescents in this age group. These factors could help in fighting against the smoking or tobacco use initiation. Contentedness in relationships with friends, though its correlation value was slightly smaller than those of the family and school self-esteem, also appeared to be protective. This finding indicated that socializing with friends was important to Thai-American adolescents aged 10 to 16 . 
Correlation analysis found positive relationships between sensation seeking and intention to smoke. Such findings support those found in previous studies. In contrast, sensation seeking was inversely correlated to the family self-esteem $(r=-.281, p=.000)$; and the school self-esteem $(r=-.268, p=.000)$. These findings indicate those who had low levels of family self-esteem and/or school self-esteem were more likely to have high levels in sensation seeking than those who had high levels in the two self-esteems categories. However, from the investigator's perspective, sensation seeking was a compensation for the sense of unsecured family relationships and performance at school or friend socialization. In order to fill this gap some adolescents may seek alternatives, such as activities that made them feel more acceptable, cool, exciting, and popular or liked by others. The relationship between item: "I wish I had more to be proud of" in the global self-esteem and the scores of sensation seeking supported this observation. The correlation indicated that the more they agreed with this statement the higher the sensation seeking. Since the item was reversed score, the Spearman correlation presented in a negative relationship, rho of $-.226(p=.003, n=170)$. There was one item of sensation seeking not fit in this relationship which is "I would live to have new and exciting experiences, even they are illegal" not correlated with "I wish...to be proud of" but found correlated to smoking initiation. This phenomenon may be one of many reasons why sensation seeking sometimes was found correlated to smoking initiation and at other times not.

Findings from Chi-Square and ANOVA for differences between the intention to smoke and the no-intention to smoke support those from correlation analysis. The 
intention to smoke group were significantly different from the no-intention to smoke group in almost all the tobacco-use-related variables than the no-intention to smoke group. They were statistically significantly higher in exposure to family smoking, friends smoking, and tobacco promotional products, positive belief and attitude toward smoking, peers' belief and attitude toward smoking, and initiation of smoking. They were also significantly higher in sensation seeking level but lower in family self-esteem, school self-esteem, and friend self-esteem than the no-intention to smoke group. These findings suggest self-esteem variables were protective factors against tobacco use and tobaccouse-related variables were the risks.

Findings from correlation analysis showed that none of these relationships between the intention to smoke and other variables of study, and between smoking initiation and intention to smoke had a perfect relationship ( $r= \pm 1)$ (Munro, 2005).

\section{Logistic Regression Analysis Results}

Logistic Regression yielded two strongest predictors on intention to smoke including belief and attitude toward smoking and school self-esteem among ThaiAmerican Adolescents aged 10 to 16 . However, these predictors may not apply to other ethnic groups. For examples, among Arab-American adolescents aged 14 to 18, friends and family members were the strongest predictors on tobacco-use (Rice et al., 2006). In the present study exposure to family smoking, friends smoking, and family self-esteem were also found predictive on intention to smoke, but contained fairly small odds and failed to provide the evidence at a .05 level of significance. This may be because the 
exposure to tobacco-use environment did not directly influence the intention and/or their effects were already in the belief and attitude as shown above i.e. they had positive relationships with the belief and attitude variable.

While the belief and attitude had positive effects on intention to smoke with the odds ratio of 1.635 , the school self-esteem obtained inverse effects on intention to smoke with the odds ratio of .781 . The odds ratio of the two variables suggests the risk was stronger over the intention to smoke than protective factor. While the probability of having intention to smoke was almost two times among those who had positive belief and attitude toward smoking, the probability of being protected from intention to smoking among those who had high school self-esteem was only almost one time greater. For those who had both positive attitudes toward smoking and low school self-esteem, the probability of having intention to smoke may be even greater.

\section{Limitation}

Findings from this study must be interpreted in relation to several limitations. The samples were ethnic specific-Thai-related ethnic group, who could be recruited into the study by a convenient sampling and snowball sampling. These methods limited recruitment to only persons who met the criteria and were present at the time the recruitment was conducted or were suggested into the study. This might result in recruiting some specific individuals who shared similarity. In addition, it also limited the chance for prospective participants who were not present at the time the recruitment was conducted to participate in the study. 
The present study used two forms of data collection: a computer-based questionnaire (Survey Monkey) and a paper-based questionnaire (PBQ). The two forms faced limitations in different ways. Ideally, a computer-based questionnaire (CBQ) provided a convenient time and place for the participants and decreased pressure and coercion in answering the questions regarding vulnerable topics such as tobacco use and self-esteems. However, in actual research setting, the investigator found a major limitation was internet access. Some participants did not have computers or internet network at home, other had poor internet speed which was not appropriate for interactive program such as $\mathrm{CBQ}$, and some had parents who worked during the library hours, as a result could not use the internet at the library. The CBQ itself also caused a limitation. The program needed hi-speed internet such as $4 \mathrm{G}$ internet speed, needed time to download some applications, and needed time in confirming the answer. The server of the website was down several times causing difficulties in logging into the program and some participants needed to switch to the PBQ. While the CBQ took 30 minutes to complete the PBQ typically used only 15 minutes. Although the participants would participate in the questionnaire based on their convenience, whether the participant would visit the questionnaire or the questionnaire would be completed could not be guaranteed, as shown in the loss rate of CBQ was $27.27 \%$, while the PBQ had only $3.08 \%$ of loss.

The PBQ, on the other hand, had other limitations. During administration it was difficult to control for privacy and surroundings where the participants were completing the questionnaire. Many times the investigator observed participants loved to do the questionnaire and share the answers with their friends or siblings, which may affect the 
accuracy of the responses due to the influences from others' thinking. In addition, the PBQ was also easy for parents to do a double check on the responses although they stated that they understood the purpose of the study. Some parents loved to review their children's answers. They wanted to know what their children thought. This may be because they were worried about their children to allow any secret between them and their children. Some parents rushed the children to complete the questionnaire despite a prepaid envelop would be provided if they preferred it. In this case, the participants were answering the questions under pressure and sometimes missing responses.

Both forms of questionnaires were self-report of which there may be over report or under report to each question based on the participants' feeling and attitude at the time. This may result in a deviation of validity of the measurement. Moreover, the questionnaire contained an extensive number of questions - 97 questions which might intimidate some prospective participant away.

A personal character of each child itself also could cause limitation in participation. Some children the investigator met were so shy, quiet, and social separated that they did not wish to participate in spite of an incentive of a 10-dollar gift card and encouragement from the parents.

Some of the questions in the questionnaire were socially sensitive and vulnerable especially those about smoking initiation, family smoking, and friends smoking. As found in the process of screening data, massive missing data were in these sections. The investigator personally witnessed the scene where a participant was teased by one of her friends when she told them that she had ever tried smoking. This might result in missing 
responses. Participants' responses with more than $15 \%$ data missing were excluded, as a result the sample size decreased to 189 participants.

\section{Implication for Nursing Practice}

The smoking-initiation pattern emerging from the present study suggests risks of smoking increase as the children age. This however is not true for all youth, some adolescents are fortunate enough to be protected from smoking initiation despite growing older while some early adolescents were unfortunate to be surrounded by the risks and prematurely initiate smoking. In the later case, findings suggest health care providers (HCP) understand adolescents do not intend to be bad. On the other hand, they are trying to be good and fill the gap they perceive that they are far from their expectation. Rather we need HCP to understand if an adolescent initiates smoking, our society is part of the cause. The only thing, initiators need to know is that smoking is not a solution and what are the better options for them.

Findings further suggest the need to approach adolescents appropriately to their mental development. Although, adolescents have the tendency of growing away from childhood toward adulthood, they are neither children nor adults. They are adolescents and have their own personalities. HCPs should communicate with them in "teen language", not in child or adult languages. For instance, a participant came to share his idea with the investigator why some of his friends did not smoke because cigarettes were "too much like adult behavior", but they smoked weed because it was more like teens. This disclosure reminds us to consider if "for health care prevention to promote desirable health behaviors, need to target teen behaviors and interpretations". 
Finally, it would be helpful if nurses could assess risks and protective factors for smoking initiation using a brief questionnaire; for example, by using only questions about belief/attitude toward smoking and school self-esteem, nurses would be able to decide if a Thai-American adolescent was at risk or protective. By using this approach, we will need only 7 items in belief and attitude and 8 items in school self-esteem taking only a minute to complete.

For some particular ethnic/racial groups, such as Thai-American adolescents age 10-16, assessing tobacco-use risks should include the belief/attitude toward smoking and the school self-esteem. Similarly, in addition to focusing on education about its harm to human physical, to provide impacts to tobacco-use we also need to educate parents and families about social influences on unhealthy behaviors such as smoking. Suggestion for help in planning for healthy alternatives that look cool, exciting, popular, and not too hard or too easy to achieve are needed.

\section{Implication for Future Research}

For some ethnic groups such as Thai-American age 10 to 16 living in Southern California, belief/attitude toward smoking and school self-esteem may provide adequate information on risks and protective factors against tobacco-use. However, the question is what ethnic groups are they, if their characteristics are similar, and if this suggestion can apply to dominant population?

Smoking initiation prevalence found in this study is low. It would be interesting to further explore why in this ethnic group or in some other ethnic groups the prevalence is very low. The finding from this exploration would be beneficial in creating impacts on 
tobacco - use and healthy alternatives that match adolescence characters. As we have learned adolescents are not children or adults, they have their own characteristics, preferences, and language; and these tend to change based on the ongoing changing situations.

The present study contains an extensive number of items in order to obtain data of all possible factors related to smoking initiation which causes some limitations to the study. As presented above, only a few of them were key variables. The rest are related to them and have their effects hidden in them. Further research is needed to develop and test a shorter assessment forms with similar populations, as well as other ethnic/racial groups. 


\section{References}

American Cancer Society (2008). The tobacco atlas: Cigarette consumption $\left(2^{\text {nd }}\right.$ Ed.).

Retrieved November 2, 2008, from

http://www.cancer.org/docroot/AA/content/AA_2_5_9x_Tobacco_Atlas.asp

American Cancer Society (2010). Child and teen tobacco use. Retrieved on April 10, 2012 from http://www.cancer.org/acs/groups/cid/documents/webcontent/002963pdf.pdf

Andrews, J.A., Hampson, S., \& Barckley, M. (2007). The effect of subjective normative social images of smokers on children's intentions to smoke. Nicotine \& Tobacco Research, 10(4), 589-597.

Andrews, J.A., Hampson, S., \& Barckley, M. (2008). The effect of subjective normative social images of smokers on children's intentions to smoke. Nicotine \& Tobacco Research, 10(4), 589-597.

Andrews, J.A., \& Peterson, M. (2006). The development of social images of substance users in children: A Guttman unidimensional scaling approach. Journal of Substance Use, 11(5), 305-321.

Aroian, K.J., \& Norris, A.E. (2001). Confirmatory factor analysis. In B. H. Munro, Statistical methods for health care research $\left(4^{\text {th }}\right.$ ed.). New York: Lippincott.

Ayatollahi, S.A., Mohammadpoorasl, A., \& Rajaeifard, A. (2005). Predicting the stages of smoking acquisition in the male students of Shiraz's high schools, 2003. Nicotine \& Tobacco Research, 7(6), 845-851.

Barnett, D.W., Macmann, G.M., Lentz, Jr. F.E. (2003). Personality assessment research: 
Applying criteria of confidence and helpfulness. In C. R. Reynolds \& R. W. Kamphaus (Eds.), Handbook of psychological \& educational assessment of children :Personality, behavior, and context ( $2^{\text {nd }}$ ed., pp. 3-29). New York, NY: The Guilford Press.

Barton J, Chassin L, Presson CC, Sherman SJ (1982). Social image factors as motivation for smoking initiation in early and middle adolescence. Child Development, $53(6), 1499-1511$.

Bird, Y., Moraros, J, Olsen, L. K., Coronado, G.D., \&Thompson, B. (2006). Adolescents' smoking behaviors, beliefs on the risks of smoking, and exposure to ETS in Juarez, Mexico. American Journal of Health Behavior, 30(4), 435-446.

Borio, G. (2003). Tobacco timeline: The twentieth century 1950-199-the battle is joined. Retrieved October 25, 2008, from www.tobacco.org/resources/history/Tobacco_History20-2.html

Borio, G. (2007). The tobacco timeline. Retrieved June 13, 2008, from http://www.tobacco.org/History/Tobacco_History.html

Brook, J.S., Pahl, K., \& Ning, Y. (2006). Peer and parental influences on longitudinal trajectories of smoking among African Americans and Puerto Ricans. Nicotine \& Tobacco Research, 8(5), 639-651.

Browne, M.W. \& Cudeck, R. (1993). Alternative ways of assessing model fit. In K. A. Bollen \& J. S. Long (Eds.), Testing structural equation models (pp.136-162). London: Sage Publications, Inc.

Burns, N., \& Grove, S. K. (2001). The practice of nursing research: Conduct, critique, \& 
utilization $\left(4^{\text {th }}\right.$ ed.). Philadelphia: W.B. Saunders Company.

Burns, N., \& Grove, S.K. (2005). The practice of nursing research: Conduct, critique, and utilization $\left(5^{\text {th }}\right.$ ed.). St. Louis, Missouri: Elsevier Saunders.

Butler, R.J., \& Gasson, S.L., (2005). Self esteem/self concept scales for children and adolescents: A review. Child and Adolescent Mental Health, 10( 4), 190-201.

Byrne, D.G., \& Mazanov, J. (2001). Self-esteem, stress and cigarettes smoking in adolescents. Stress and Health, 17(22), 105-110.

Canada Tobacco (2008). History of tobacco. Retrieved June 17, 2008, from http://www.imperialtobaccocanada.com/onewebca/sites

Castrucci, B.C., Gerlach, K.K., Kaufman, N.J., \& Orleans, C.T. (2002). The association among adolescents' tobacco use, their beliefs and attitudes, and friends' and parents' opinions of smoking. Maternal and Child Health Journal, 6(3), 159-167.

Center for Disease Control and Prevention (2001). Youth tobacco surveillance-United States, 2000. Morbidity and Mortality Weekly Report, 50 (SS-4), Inclusive page number.

Center for Disease Control and Prevention (2003). Tobacco use among middle and high school students-United States, 2002. Morbidity and Mortality Weekly Report, $59(33), 1063-1068$.

Centers for Disease Control and Prevention (2004a). Methodology of the Youth Risk Behavior Surveillance System. Morbidity and Mortality Weekly Report, 53(RR12). Retrieved November 1,2010 , from http://www.cdc.gov/mmwr/PDF/rr/rr5312.pdf 
Center for Disease Control and Prevention (2004b). 2004 Surgeon General's report: The health consequences of smoking. Retrieved October 24, 2008, from http://www.cdc.gov/tobacco/data_statistics/sgr/sgr_2004/chapters.htm

Centers of Disease Control and Prevention (2006). The health consequences of involuntary exposure to tobacco smoke: A report of the Surgeon General. Retrieved October 16 2008, from http://www.surgeongeneral.gov/library/secondhandsmoke/report/fullreport.pdf

Centers for Disease Control and Prevention (2007). History of the Surgeon General's Report on Smoking and Health. Retrieved April 23, 08, from http://www.cdc.gov/tobacco/data_statistics/sgr/history.htm

Center for Disease Prevention and Control (2008). Global youth tobacco survey surveillance 2000-2007. MMWR, 57 (ss01), 1-21. Retrieved on April 10, 2012 from http://www.cdc.gov/mmwr/preview/mmwrhtml/ss5701al.htm

Chickenhead Productions, Inc. (2009). Truth in advertising. Retrieved January 12, 2009, from http://www.chickenhead.com/truth/kooll.html

Coleman, J.C., \& Hendry, L. (1990). The nature of adolescence ( $2^{\text {nd }}$ ed.). London: Routledge.

Crain Communication Inc.(2005). The advertising century: The Marlboro Man. Retrieved January 12, 2009, from http://adage.com/century/icon01.html.

Demidenko, E. (2007). Sample size determination for logistic regression revisited. Statistics in Medicine, 26(18), 3385-3397.

Dolcini, M.M., Adler, N.E., Lee, P., \& Bauman, K.E. (2003). An assessment of the 
validity of adolescent self-reported smoking using three biological indicators. Nicotine \& Tobacco Research, 5(4), 473-483.

Dilorio, C.K. (2005). Measurement in health behavior: Methods for research and evaluation. San Francisco, CA: Jossey-Bass A Wiley Imprint.

Dinh, K.T., Sarason, I.G., \& Peterson, A.V. (1995). Children's perceptions of smokers and nonsmokers: A longitudinal study. Health Psychology, 14(1), 32-40.

Dreher, E., \& Oerter, R. (1986). Children's and adolescents' conceptions of adulthood: The changing view of a crucial developmental task. In R.K. Silbereisen, K. Eyferth, \& G. Rudinger (Eds.), Development as action in context: Problem behavior and normal youth development (pp.87-107). New York: SpringerVerlag.

Dubois, D.L., Felner, R.D., Brand, S., Phillips, R.S.C., \& Lease, A. M. (1996). Early adolescent self-esteem: A developmental-ecological framework and assessment strategy. Journal of Research on Adolescence, 6(4), 543-579.

Duffy, M.E.,\& Jscoben, B.S. (2005). Univariate descriptive statistics. In B. H. Munro (Ed.), Statistical methods for health care research (5 ${ }^{\text {th }}$ ed.) (pp. 33-72), Philadelphia: Lippincott Williams \& Wilkins.

Feighery, E.C., Henriksen, L., Wang, Y., Schleicher, N. C., \& Fortman, S.P. (2006). An evaluation of four measures of adolescents' exposure to cigarette marketing in stores. Nicotine \& Tobacco Research, 8(6), 751-759.

Flay, B.R., Hu, F.B., Siddiqui, O., Day, L.E., Hedeker, D., Petraitis, J., et al., (1994). Differential influence of parental smoking and friends' smoking on adolescent 
initiation and escalation of smoking. Journal of Health and Social Behavior, $35(3), 248-265$.

Geckova, A.M., Stewart, R., Dijk, J.P.V., Orosova, O., Groothoff, J.W., \& Post, D.( 2005). Influence of socio-economic status, parents and peers on smoking behavior of adolescents. European Addition Research, 11(4), 204-209.

George, D., \& Mallery, P. (2007). SPSS for windows step by step: A simple guide and reference 14.0 update. Boston: Pearson Education, Inc.

Goodwin, L. D., \& Goodwin, W.L. (1991). Focus on psychometrics estimating construct validity. Research in Nursing \& Health, 14(3), 235-243.

Graham H (1976). Smoking in pregnancy. The attitudes of expectant mothers. Social science and Medicine, 10: 399-405.

Hinkle, D.E., Wiersma, W., Jurs, S. G. (2003). Applied statistics for behavioral sciences $\left(5^{\text {th }}\right.$ ed.). Boston: Houghton Mifflin Company.

Hoyle, R.H., Stephenson, M.T., Palmgreen, P., Lorch, E.P., \& Donohew, R. L. (2002). Reliability and validity of a brief measure of sensation seeking. Personality and Individual Differences, 32(3), 401-414.

Indiana Tobacco Prevention and Cessation Program (2007). Results from the 2006 Indiana Youth Tobacco Survey: Final comprehensive report. Retrieved November 21, 2010, from http://www.in.gov/itpc/files/IYTS_Final_Report_2006.pdf

Kappel, C.C., \& Crowe, S.F. (2000). Changes to body image and self-esteem following stoke in young adults. Neuropsychological Rehabilitation, 10(1), 15-31. 
Kavas, A.B. (2009). Self-esteem and health-risk behaviors among Turkish late adolescents. Adolescence, 44(173), 187- 198.

Kawabata, T., Cross, D., Nishioka, N., Shimai, S. (1999). Relationship between selfesteem and smoking behavior among Japanese early adolescents: Initial results from a three year study. Journal of School Health, 69(7), 280- 284.

Kelly, K.C. (2010). Indonesia children smoking as young as two years old. Retrieved on April 11, 2012 from http://www.huliq.com/10017/93716/indonesia-childrensmoking-young-two-years-old

Kemppainen, U., Tossavainen, K., Vartiainen, E., Pantelejev, V., \& Puska, P. (2002). Smoking patterns among ninth-grade adolescents in the Pitkaranta District (Russia) and in Eastern Finland. Public Health Nursing, 19(1), 30-39.

Kobus, K. (2003). Peers and adolescent smoking. Addiction, 98(Suppl 1), 37-55.

Kvalseth, T.O. (1991). A coefficient of agreement for nominal scales: An asymmetric version of Kappa. Educational and Psychological Measurement, 51(1), 95-101.

Landis, J.R., \& Koch, G.G. (1977). Measurement of observer agreement for categorical data. Biometrics, 33(1), 159-174.

Lemieux, P. (2001). The World Bank's tobacco economics. Retrieved October 23, 2008, from http://www.pierrelemieux.org/artwelfarewb.pdf

Lerner, R.M., \& Steinberg, L. (Eds.) (2004). Handbook of adolescent psychology ( $2^{\text {nd }}$ ed.). Hoboken, New Jersey: John Wiley \& Sons. 
Liao, H.I., Yeh, S.L., \& Shimojo (2011). Novelty vs. familiarity principles in preference decisions: task-context of past experience matters. Frontiers in Psychology, 2(43), 1-8. Retrieved on April 11 from http:/www.ncbi.nlm.nih.gov/pmc/articles/PMC31 10941/pdf/fpsyg-02-00043.pdf

Mathers, C.D., Bernard, C., Iburg, K.M., Inoue, M., Fat, D.M., Shibuya, K., et al., (2004). Global burden of disease in 2002: Data sources, methods and results. Retrieved September 29, 2008, from http://www.who.int/healthinfo/paper54.pdf

Mathers, C.D., \& Loncar, D. (2006). Updated projections of global mortality and burden of disease, 2002-2030: Data sources, methods, and results. Retrieved October 15, 2008, from http://www.who.int/healthinfo/statistics/bod_projections2030_paper.pdf

McGhee, S. M., Ho, L. M., Lapsley, H. M., Chau, J., Cheung, W. L., Ho, S. Y., et al., (2006). Cost of tobacco-related diseases, including passive smoking in Hong Kong. Tobacco Control, 15(2), 125-130.

Mertler, C.A., \& Vannatta, R.A. (2005). Advanced and multivariate statistical methods: Practical application and interpretation ( $3^{\text {rd }}$ ed.), Glendale, CA: Pyrczak Publishing.

Miller, C.H., Burgoon, M., Grandpre, J.R., \& Alvaro, E.M. (2006). Identifying principal risk factors for the initiation of adolescent smoking behaviors: The significance of psychological reactance. Health Communication, 19(3), 241-252.

Moffitt, T.E. (1993). Adolescence-limited and life-course-persistent antisocial behavior: A development taxonomy. Psychological Review, 100(4), 674-701. 
Mowery, P.D., Farrelly, M.C., Haviland, M.L., Gable, J.M., \& Wells, H.E. (2004). Progression to established smoking among US youths. American Journal of Public Health, 94(2), 331-337.

Munro, B.H. (2001). Correlation. In B. H. Munro, Statistical methods for health care research $\left(4^{\text {th }}\right.$ ed.) (pp. 223-243). New York: Lippincott.

Munro, B.H. (2005). Correlation. In B. H. Munro (Ed.), Statistical methods for health care research $\left(5^{\text {th }}\right.$ ed.) (pp. 239-258), Philadelphia: Lippincott Williams \& Wilkins.

Munro, B.H. (2005). Logistic regression. In B. H. Munro (Ed.), Statistical methods for health care research ( $5^{\text {th }}$ ed.) (pp. 301-320), Philadelphia: Lippincott Williams \& Wilkins.

Norris, A.E. (2001). Structural equation model. In B. H. Munro (Ed.), Statistical methods for health care research ( $4^{\text {th }}$ ed.) (pp. 379-404). New York: Lippincott.

Nunnally, J.C. (1978). Psychometric theory (2 $2^{\text {nd }}$ ed.). New York: McGraw-Hill Book Company.

Pagano, M., \& Gauvreau, K. (2000). Principles of biostatistics ( ${ }^{\text {nd }}$ ed.). Pacific Grove, CA: Duxbury Thomson Learning.

Petersen, A., Schulenberg, J., Abramowits, R., Offer, D., \& Jarcho, H. (1984). A selfimage questionnaire for young adolescents (SIQYA): Reliability and validity studies. Journal of Youth and Adolescence, 13(2), 93-111.

Pipher, m. (1994). Reviving Ophelia: Saving the selves of adolescent girls. New York: Putnam. 
Porcellato, L., Dugdill, L., Springett, J., \& Sanderson, F.H. (1999). Primary school children's perceptions of smoking: Implications for health education. Health Education Research, 14(1), 71-83.

Rhodes, J., Roffman, J., Reddy, R., \& Fredriksen, K. (2004). Changes in self-esteem during the middle school years: a latent growth curve study of individual and contextual influences. Journal of School Psychology, 42(3), 243-261.

Rice, V.H., Weglicki, L. S., Templin, T., Hammad, A., Jamil, H., \& Kulwicki, A. (2006). Predictors of Arab American adolescent tobacco use. Merrill Palmer Q, 52(2), $327-342$.

Robert, B. (2007). Inventions in the tobacco industry. North Carolina Museum of History. Retrieved June 23, 2008, from http://www.ncmuseumofhistory.org/collateral/articles/f06.inventions.in.tobacco.in dustry.pdf

Robinson, L.A., Murray, D.M., Alfano, C.M., Zbikowski, S.M., Blitsein, J.,L., \& Klesges, R.C. (2006). Ethnic differences in predictors of adolescent smoking onset and escalation: A longitudinal study from $7^{\text {th }}$ to $12^{\text {th }}$ grade. Nicotine \& Tobacco Research, 8(2), 297-307.

Rosenberg, M., \& Simmons, R.G. (1971). Black and White self-esteem: The urban school child. Washington, DC: American Sociological Association.

Rosenberg, M., \& Simmons, R.G. (1971). Black and White self-esteem: The urban school child. Washington, DC: American Sociological Association.

Rosenberg, M. (1965). Society and the adolescent self-image. Princeton, N.J.: Princeton 
University Press.

Seo, D.C, Boode, A.E., \& Torab, M.R. (2009). Salient environmental and perceptual correlates of current and established smoking for 2 representative cohorts of Indiana adolescents. Journal of School Health, 79(3), 98-107.

Seo, D-C., Torabi, M.R., \& Weaver, A.E. (2008). Factors influencing openness to future smoking among nonsmoking adolescents. Journal of School Health, 78(6), 328336.

Silbereisen, R.K., Noack, P., \& Eyferth, K. (1986). Place for development: Adolescents, leisure settings, and developmental tasks. In R.K. Silbereisen, K. Eyferth, \& G. Rudinger (Eds.), Development as action in context: Problem behavior and normal youth development (pp.87-107). New York: Springer-Verlag.

Simons-Morton, B., \& Haynie, D.L.(2003). Psychosocial predictors of increased smoking stage among sixth graders. American Journal of Health Behavior, 27(6), 592-602.

Stice, E., \& Shaw, H. (2003). Prospective relations of body image, eating, and eating, and affective disturbances to smoking onset in adolescent girls: How Virginia slims. Journal of Consulting and Clinical Psychology, 71(1), 129-135.

Stephenson, M.T., Hoyle, R.H., Palmgreen, P., \& Slater, M.D. (2003). Brief measures of sensation seeking for screening and large-scale surveys. Drug and Alcohol Dependence, 72(3), 279-286.

Tomeo, C.A., Field, A.E., Berkey, C.S., Colditz, G.A., \&Frazier, A.L. (1999). Weight concerns, weight control behaviors, and smoking initiation. Pediatrics, 104(4), 918-924. 
Tunstall CD, Gingberg D, Hall SM (1985). Quitting smoking. International Journal of Mental Health and Addiction, 20(6-7), 1089-1112.

TV Acres (2009). Advertising slogan. Retrieved January 10, 2009, from www.tvacres.com/adslogans

Unger, J.B., Rohrbach, L.A., Howard-Pitney, B., Ritt-Olson, A., \& Mouttapa, M. (2001). Peer influences and susceptibility to smoking among California adolescents. Substance Use \& Misuse, 36(5), 551-571.

Wang, D. (1998). Cultural studies final paper: The Marlboro myth. Retrieved January 14,2009 , from www.eng.fju.edu.tw/Literary_Criticism?crit97_work/Marlboro.htm.

Wild, L.G., Flisher, A.J., Bhana, A., \& Lombard, C. (2004). Associations among adolescent risk behaviors and self-esteem in six domains. Journal of Child Psychology and Psychiatry, 45(8), 1454-1467.

Wilkinson, D., \& Abraham, C. (2004). Constructing an integrated model of the antecedents of adolescents smoking. British Journal of Health Psychology, 9(3), 315-333.

Williams, C.L., Eng, A., Botvin, G.J., Hill, P., \& Wynder, E.L. (1979). Validation of students' self-reported cigarette smoking status with plasma cotinine levels. American Journal of Public Health, 69(12), 1272-1274.

Wisconsin Historical Society (2009). Cigarette trade cards. Retrieved January 10, 2009, from http://www.wisconsinhistory.org/whi/feature/cigarette/

World Health Organization (2001). Women and the tobacco epidemic: Challenges for 
the $21^{\text {st }}$ century. Retrieved November 20, 2008, from http://whqlibdoc.who.int/hq/2001/WHO_NMH_TFI_01.1.pdf

World Health Organization (2002a). Tobacco smoke and involuntary smoking: Summary of data reported and evaluation. Retrieved October 10, 2008, from http://monographs.iarc.fr/ENG/Monographs/vol83/volume83.pdf

World Health Organization (2002b). The Tobacco Atlas. Retrieved April 23, 2008, from http://www.who.int/tobacco/en/atlas7.pdf on April 23, 2008

World Health Organization (2004). The tobacco atlas: Health education. Retrieved October 16, 2008, from http://www.who.int/tobacco/en/atlas34.pdf World Health Organization (2004a). The tobacco atlas: Tobacco consumption. Retrieved October 16, 2008, from http://www.who.int/tobacco/en/atlas8.pdf World Health Organization (2004). The tobacco atlas: Tobacco Control Organizations. Retrieved October 16, 2008, from http://www.who.int/tobacco/en/atlas29.pdf World Health Organization (2004b). The tobacco atlas: The history of tobacco. Retrieved October 16, 2008, from http://www.who.int/tobacco/en/atlas2.pdf

World Health Organization (2006). World health statistics 2006. Retrieved October 21, 2008, from http://www.who.int/whosis/whostat2006_erratareduce.pdf

World Health Organization (2007). World health staistics2006: Health status: Mortality.

Retrieved September 10, 2007, from www.who.int/whosis/whostat2006_mortality.pdf

World Health Organization (2008a). Health statistics and health information system: Global burden of disease (GBD) 2000. Retrieved October 15, 2008, from 
http://www.who.int/healthinfo/gbdwhoregionmortality2000v3.xls

World Health Organization (2008b). Health statistics and health information system: Global burden of disease (GBD) 2001. Retrieved October 15, 2008, from http://www.who.int/entity/healthinfo/statistics/gbdwhoregionmortality2001.xls

World Health Organization (2008c). Health statistics and health information system: Global burden of disease (GBD) 2005. Retrieved October 15, 2008, from http://www.who.int/healthinfo/statistics/bod_deathbyregion.xls

World Health Organization (2008d). World health statistics 2008. Retrieved October 21, 2008, from http://www.who.int/whosis/whostat/EN_WHS08_Full.pdf

World Health Organization (2008e). WHO report on the global tobacco epidemic, 2008 MPOWER package. Retrieved October 23, 2008, from http://www.who.int/tobacco/mpower/mpower_report_full_2008.pdf

Yang, S., Lynch, J., Schulenberg, J., Roux, A.V.D., \& Raghunathan, T. (2008). Emergence of socioeconomic inequalities in smoking and overweight and obesity in early adulthood: The national longitudinal study of adolescent health. American Journal of Public Health, 98(3), 468-477.

Yorulmaz, F., Aktiirk, Z., Dagdeviren, N., \& Dalkilic, A. (2002). Smoking among adolescents: Relation to school success, socioeconomic status, nutrition, and selfesteem. Swiss Medical Weekly, 132, 449-454.

Zuckerman, M., (2007). Sensation seeking and risky behavior. Washington, DC: American Psychological Association.

Zullig, K. J., Pun, S., Patton, J.M., \& Ubbes, V. A. (2006). Reliability of the 2005 Middle 
School Youth Behavior Survey. Journal of Adolescent Health, 39(6), 856-860. 
Appendix B

Section One: Baseline Information and Demographic

I) Demographic data (from middle school youth risk behavior survey: MSYRBS).

1. How old are you?
a. 10 years old or younger
b. 11 years old
c. 12 years old
d. 13 years old
e. 14 years old
f. 15 years old
g. 16 years old or older

2. What is your sex?
a. Female
b. Male

3. In what grade are you?
a. 6th grade
b. 7 th grade
c. 8th grade
d. Other

4. In what country were you born?
a. Thailand
b. The United States 
c. Other, please indicate....

This item has been changed into the question asking "Are you Thai in any way?" and the answers have been changed to " a. No, I am not Thai in any way; b. Yes, I am Thai and was born in Thailand; c. Yes, I am Thai and was born in the United States; d. Yes, I am Thai andwas born in another country"

\section{II) Tobacco Use.}

5. Have you ever tried cigarette smoking, even one or two puffs?
a. Yes
b. No

6. How old were you when you smoked a whole cigarette for the first time?
a. I have never smoked a whole cigarette
b. 8 years old or younger
c. 9 years old
d. 10 years old
e. 11 years old
f. 12 years old

g. 13 years old

h. 14 years old or older

7. During the past 30 days, on how many days did you smoke cigarettes?
a. 0 days
b. 1 or 2 days
c. 3 to 5 days 
d. 6 to 9 days

e. 10 to 19 days

f. 20 to 29 days

g. All 30 days

8. During the past 30 days, on the days you smoked, how many cigarettes did you smoke per

day?

a. I did not smoke cigarettes during the past 30 days

b. Less than 1 cigarette per day

c. 1 cigarette per day

d. 2 to 5 cigarettes per day

e. 6 to 10 cigarettes per day

f. 11 to 20 cigarettes per day

g. More than 20 cigarettes per day

9. During the past 30 days, how did you usually get your own cigarettes?

(Select only one response.)

a. I did not smoke cigarettes during the past 30 days

b. I bought them in a store such as a convenience store, supermarket, discount store, or gas

station

c. I bought them from a vending machine

d. I gave someone else money to buy them for me 
e. I borrowed (or bummed) them from someone else

f. A person 18 years old or older gave them to me

g. I took them from a store or family member

h. I got them some other way

10. Have you ever smoked cigarettes daily, that is, at least one cigarette every day for 30 days?
a. Yes
b. No

11. During the past 30 days, on how many days did you use chewing tobacco, snuff, or dip,

such as Redman, Levi Garrett, Beechnut, Skoal, Skoal Bandits, or Copenhagen?
a. 0 days
b. 1 or 2 days
c. 3 to 5 days
d. 6 to 9 days
e. 10 to 19 days
f. 20 to 29 days
g. All 30 days

Section Two: Measures of Tobacco-Use Absorption (Smoking Specific Environment)

\section{I) Parent Smoking (or Family Smoking):}

12. During the past 7 days, on how many days were you in the same room with someone who smoking cigarettes? 

a. 0 days
b. 1 or 2 days
c. 3 or 4 days
d. 5 or 6 days
e. 7 days

13. During the past 7 days, on how many days did you ride in a car with someone who was smoking cigarettes?
a. 0 days
b. 1 or 2 days
c. 3 or 4 days
d. 5 or 6 days
e. 7 days

14. Does anyone who lives with you now smoke cigarettes?
a. Yes
b. No

This item has been modified to "..."

15. Does anyone who lives with you now use chewing tobacco, snuff, or dip?
a. Yes
b. No

16. Which statement best describes the rules about smoking inside your home?
a. Smoking is not allowed anywhere inside my home
b. Smoking is allowed in some places or at some times 
c. Smoking is allowed anywhere in my home

d. There are no rules about smoking in my home

\section{II) Peer Smoking:}

17. How many of your four closet friends smoke cigarettes?
a. None
b. One
c. Two
d. Three
e. Four
f. Not sure

18. How many of your four closest friends use chewing tobacco, snuff, or dip?
a. None
b. One
c. Two
d. Three
e. Four
f. Not sure

\section{III) Tobacco Advertisings:}

(item 66 of NYTS).

19. During the past 12 months, did you buy or receive anything that has a tobacco company name or picture on it?
a. Yes 
b. No

20. Would you ever use or wear something that has a tobacco company name or picture on it such as a lighter, t-shirt, hat or sunglasses?
a. Definitely Yes
b. Probably Yes
c. Probably Not
d. Definitely Not

21. When you watch TV or go to movies, how often do you see actors using tobacco?
a. I don't watch TV or go to movies
b. Most of the time
c. Some of the time
d. Hardly ever
e. Never

22. When you are using the internet, how often do you see ads for tobacco products?
a. I do not use the internet
b. Most of the time
c. Some of the time
d. Hardly ever
e. Never

23. When you read newspapers or magazines, how often do you see ads or promotions for cigarettes and other tobacco products?
a. I do not read newspapers or magazines 

b. All of the time
c. Most of the time
d. Some of the time
e. Hardly ever
f. Never

24. When you go to a convenience store, supermarket, or gas station, how often do you see ads for cigarettes and other tobacco products or items that have tobacco company names or pictures on them?
a. I never go to convenience store, supermarket, or gas station
b. All of the time
c. Most of the time
d. Some of the time
e. Hardly ever
f. Never

IV) Feelings, Beliefs, and Attitudes toward Smoking:

25. Do you think the smoke from other people's cigarettes is harmful to you?
a. Definitely Yes
b. Probably Yes
c. Probably Not
d. Definitely Not

26. Do you think it is safe to smoke for only a year or two, as long as you quit after that?
a. Definitely Yes 
b. Probably Yes

c. Probably Not

d. Definitely Not

27. Do most people of your age think it is okay to smoke?
a. Definitely Yes
b. Probably Yes
c. Probably Not
d. Definitely Not

What do you think about kids who smoke?

28. Kids who smoke are cool
a. Definitely Yes
b. Probably Yes
c. Probably Not
d. Definitely Not

29. Kids who smoke are neat/exciting
a. Yes
b. No
c. Not sure

30. Kids who smoke are popular/liked by other kids
a. Yes
b. No
c. Not sure 
The assessment of normative social images of smokers:

What your friends think about kids who smoke?

31. Kids who smoke are cool
a. Yes
b. No
c. Not sure

32. Kids who smoke are neat/exciting
a. Yes
b. No
c. Not sure

33. Kids who smoke are popular/liked by other kids
a. Yes
b. No
c. Not sure

\section{V) Intention to Smoke:}

34. Do you think you would smoke when you are grown up?
a. Yes
b. No
c. Not sure

35. Do you think you would smoke when you are: a teenager (for $4^{\text {th }}-6^{\text {th }}$ graders), in high school (for $7^{\text {th }}-8^{\text {th }}$ graders), and out of high school (for $9^{\text {th }}$ and $10^{\text {th }}$ graders).
a. Yes 
b. No

c. Not sure

36. If one of your best friends offered you a cigarette would you smoke it?
a. Definitely Yes
b. Probably Yes
c. Probably Not
d. Definitely Not

37. Do you think that you will try a cigarettes soon?
a. I have already tried smoking cigarettes
b. Yes
c. No

38. Do you think you will smoke a cigarette at anytime during the next year?
a. Definitely Yes
b. Probably Yes
c. Probably Not
d. Definitely Not

Section Three: Knowledge Counteracting Tobacco-Use Absorption

\section{I) Knowledge of Harmful Effects of Tobacco Use:}

39. During the past 30 days, how many times did you see anti-smoking messages on TV?
a. I did not watch TV in the past 30 days
b. None
c. 1 to 3 times in the past 30 days 
d. 1 to 3 times per week

e. Daily or almost daily

f. more than once a day

40. During the past 30 days, how many times did you hear anti-smoking messages on the radio?

a. I did not listen to the radio in the past 30 days

b. None

c. 1 to 3 times in the past 30 days

d. 1 to 3 times per week

e. Daily or almost daily

f. more than once a day

41. During the past 30 days, how many times did you see anti-smoking messages on the internet?

a. I did not use the internet in the past 30 days

b. None

c. 1 to 3 times in the past 30 days

d. 1 to 3 times per week

e. Daily or almost daily

f. more than once a day

42. During the past 30 days, how many times have you seen anti-smoking messages on billboards or outdoor signs?

a. None in the past 30 days 
b. 1 to 3 times in the past 30 days

c. 1 to 3 times per week

d. Daily or almost daily

e. more than once a day

43. During the past 30 days, how many times did you see anti-smoking messages in magazines or newspapers?
a. I did not read magazines or newspapers
b. None in the past 30 days
c. 1 to 3 times in the past 30 days
d. 1 to 3 times per week
e. Daily or almost daily
f. more than once a day

44. During this school year, did you practice ways to say "No" to tobacco in and of your classes (for example, by role playing)?
a. Yes
b. No
c. Not sure

45. During this school year, were you taught in any of your classes the reasons why people your age smoke?
a. Yes
b. No
c. Not sure 
46. During this school year, were you taught in any of your classes that most people your age do not smoke cigarettes?
a. Yes
b. No
c. Not sure

47. During this school year, were you taught in any of your classes about the dangers of tobacco use?
a. Yes
b. No
c. Not sure

Section Four: Measures of Smoking Adoption (Condition Background Ready to Accept Smoking)

Self-esteem (Family, School, Peer, and self-image or body image) Scale

\section{I) Family Self-Esteem:}

48. I am happy about how much my family likes me.
a. Strongly agree
b. Agree
c. Disagree
d. Strongly disagree

49. I am too much trouble to my family.
a. Strongly agree
b. Agree 

c. Disagree
d. Strongly disagree

50. I get in trouble too much at home.
a. Strongly agree
b. Agree
c. Disagree
d. Strongly disagree

51. I feel OK about how important I am to my family.
a. Strongly agree
b. Agree
c. Disagree
d. Strongly disagree

52. I get along as well as I would like to with my family.
a. Strongly agree
b. Agree
c. Disagree
d. Strongly disagree

53. My family pay enough attention to me.
a. Strongly agree
b. Agree
c. Disagree
d. Strongly disagree 
54. I am happy with how much my family loves me.

a. Strongly agree

b. Agree

c. Disagree

d. Strongly disagree

55. I feel good about how much my family cares about my ideas.

a. Strongly agree

b. Agree

c. Disagree

d. Strongly disagree

II) School Self-Esteem:

56. I am as good a student as I would like to be.

a. Strongly agree

b. Agree

c. Disagree

d. Strongly disagree

57. I am doing well on school work as I would like to.

a. Strongly agree

b. Agree

c. Disagree

d. Strongly disagree

58. I am good enough at math. 

a. Strongly agree
b. Agree
c. Disagree
d. Strongly disagree

59. I am as good at reading and writing as I want to be.
a. Strongly agree
b. Agree
c. Disagree
d. Strongly disagree

60. I get grades that are good enough for me.
a. Strongly agree
b. Agree
c. Disagree
d. Strongly disagree

61. I feel OK about how good of a student I am.
a. Strongly agree
b. Agree
c. Disagree
d. Strongly disagree

62. I do as well on tests in school as I want to.
a. Strongly agree
b. Agree 

c. Disagree
d. Strongly disagree

63. I get too many bad grades on my report cards.
a. Strongly agree
b. Agree
c. Disagree
d. Strongly disagree

III) Peer Self-Esteem:

64. I am popular with kids my own age as I want to be
a. Strongly agree
b. Agree
c. Disagree
d. Strongly disagree

65. I am as good as I want to be at making new friends.
a. Strongly agree
b. Agree
c. Disagree
d. Strongly disagree

66. I have as many close friends as I would like to have.
a. Strongly agree
b. Agree
c. Disagree 
d. Strongly disagree

67. I an as well liked by other kids a I want to be.
a. Strongly agree
b. Agree
c. Disagree
d. Strongly disagree

68. I feel good about how well I get along with other kids.
a. Strongly agree
b. Agree
c. Disagree
d. Strongly disagree

69. I wish my friends like me more than they do.
a. Strongly agree
b. Agree
c. Disagree
d. Strongly disagree

70. I feel good about how much my friends like my ideas.
a. Strongly agree
b. Agree
c. Disagree
d. Strongly disagree

71. I feel OK about how much other kids like doing things with me. 

a. Strongly agree
b. Agree
c. Disagree
d. Strongly disagree

\section{IV) Body image:}

72. I am happy with the way I look.
a. Strongly agree
b. Agree
c. Disagree
d. Strongly disagree

73. I like my body just the way it is.
a. Strongly agree
b. Agree
c. Disagree
d. Strongly disagree

74. I feel good about my height and weight.
a. Strongly agree
b. Agree
c. Disagree
d. Strongly disagree

75. I wish I looked a lot different.
a. Strongly agree 
b. Agree

c. Disagree

d. Strongly disagree

V) Sport/Athletics Self-Esteem:

76. I am as good at sports/physical activities as I want to be.

a. Strongly agree

b. Agree

c. Disagree

d. Strongly disagree

77. I wish I was better at sports/physical activities.

a. Strongly agree

b. Agree

c. Disagree

d. Strongly disagree

78. I feel OK about how well I do when I participate in sports/physical activities.

a. Strongly agree

b. Agree

c. Disagree

d. Strongly disagree

79. I am happy about how many different kinds of sports/physical activities I am good at.

a. Strongly agree

b. Agree 

c. Disagree
d. Strongly disagree

80. I wish it were easier for me to learn new kinds of sports/physical activities.
a. Strongly agree
b. Agree
c. Disagree
d. Strongly disagree

81. I participate as many different kinds of sports/physical activities as I want to.
a. Strongly agree
b. Agree
c. Disagree
d. Strongly disagree

\section{VI) Global Self-Esteem:}

82. I am happy with the way I can do most things.
a. Strongly agree
b. Agree
c. Disagree
d. Strongly disagree

83. I sometimes think I am a failure (a "loser").
a. Strongly agree
b. Agree
c. Disagree 
d. Strongly disagree

84. I am happy with myself as a person.
a. Strongly agree
b. Agree
c. Disagree
d. Strongly disagree

85. I am the kind of person I want to be.
a. Strongly agree
b. Agree
c. Disagree
d. Strongly disagree

86. I often feel ashamed of myself.
a. Strongly agree
b. Agree
c. Disagree
d. Strongly disagree

87. I like being just the way I am.
a. Strongly agree
b. Agree
c. Disagree
d. Strongly disagree

88. I am as good a person as I want to be. 

a. Strongly agree
b. Agree
c. Disagree
d. Strongly disagree

89. I wish I had more to de proud of.
a. Strongly agree
b. Agree
c. Disagree
d. Strongly disagree

\section{VII) Sensation Seeking Scale:}

(Experience seeking)

90. I would like to explore strange places
a. Strongly agree
b. Agree
c. Neither agree nor disagree
d. Disagree
e. Strongly disagree

91. I would like to take off on a trip with no pre-planed routes or timetables.
a. Strongly agree
b. Agree
c. Neither agree nor disagree
d. Disagree 
e. Strongly disagree

(Boredom susceptibility)

92. I get restless when I spend too much time at home
a. Strongly agree
b. Agree
c. Neither agree nor disagree
d. Disagree
e. Strongly disagree

93. I prefer friends who are excitingly unpredictable.
a. Strongly agree
b. Agree
c. Neither agree nor disagree
d. Disagree
e. Strongly disagree

(Thrill and adventure seeking)

94. I like to do frightening things.
a. Strongly agree
b. Agree
c. Neither agree nor disagree
d. Disagree
e. Strongly disagree

95. I would like to try bungee jumping. 

a. Strongly agree
b. Agree
c. Neither agree nor disagree
d. Disagree
e. Strongly disagree

(Disinhibition)

96. I like wild parties.
a. Strongly agree
b. Agree
c. Neither agree nor disagree
d. Disagree
e. Strongly disagree

97. I would live to have new and exciting experiences, even if they are illegal.
a. Strongly agree
b. Agree
c. Neither agree nor disagree
d. Disagree
e. Strongly disagree 


\section{Appendix C}

The 2005 Middle School Youth Risk Behavior Survey Questionnaire

Three categories will be adopted from the 2005 Middle School Youth Risk Behavior Survey Questionnaire. Category one asking about demographic data consists of three items: item 1,2 and 3. Category two asking about tobacco use consists of seven items: item 18, 19, 20, 21, 22, 23, and 24 .

1. How old are you?
a. 10 years old or younger
b. 11 years old
c. 12 years old
d. 13 years old
e. 14 years old
f. 15 years old
g. 16 years old or older
2. What is your sex?
a. Female
b. Male

3. In what grade are you?
a. 5th grade
b. 6th grade
c. 7 th grade
d. 8th grade 
e. $9^{\text {th }}$ grade

f. Other

The next 7 questions ask about tobacco use.

18. Have you ever tried cigarette smoking, even one or two puffs?

a. Yes

b. No

19. How old were you when you smoked a whole cigarette for the first time?

a. I have never smoked a whole cigarette

b. 8 years old or younger

c. 9 years old

d. 10 years old

e. 11 years old

f. 12 years old

g. 13 years old

h. 14 years old or older

20. During the past 30 days, on how many days did you smoke cigarettes?
a. 0 days
b. 1 or 2 days
c. 3 to 5 days
d. 6 to 9 days
e. 10 to 19 days
f. 20 to 29 days 
g. All 30 days

21. During the past 30 days, on the days you smoked, how many cigarettes did you smoke per

day?

a. I did not smoke cigarettes during the past 30 days

b. Less than 1 cigarette per day

c. 1 cigarette per day

d. 2 to 5 cigarettes per day

e. 6 to 10 cigarettes per day

f. 11 to 20 cigarettes per day

g. More than 20 cigarettes per day

22. During the past 30 days, how did you usually get your own cigarettes?

(Select only one response.)

a. I did not smoke cigarettes during the past 30 days

b. I bought them in a store such as a convenience store, supermarket, discount store, or gas

station

c. I bought them from a vending machine

d. I gave someone else money to buy them for me

e. I borrowed (or bummed) them from someone else

f. A person 18 years old or older gave them to me

g. I took them from a store or family member 
h. I got them some other way

23. Have you ever smoked cigarettes daily, that is, at least one cigarette every day for 30 days?

a. Yes

b. No

24. During the past 30 days, on how many days did you use chewing tobacco, snuff, or dip, such as Redman, Levi Garrett, Beechnut, Skoal, Skoal Bandits, or Copenhagen?
a. 0 days
b. 1 or 2 days
c. 3 to 5 days
d. 6 to 9 days
e. 10 to 19 days
f. 20 to 29 days
g. All 30 days 


\section{Appendix D}

\section{Demographic Data Form:}

4. Are you Thai in any way?

a. No, I am not Thai in any way

b. Yes, I am Thai and was born in Thailand

c. Yes, I am Thai and was in the United States

d. Yes, I am Thai and was in other country 


\section{Appendix E}

Items from the National Youth Tobacco Use Surveys (NYTS):

The questions asking about other people smoking and using tobacco around the adolescents.

Item 50 of NYTS. During the past 7 days, on how many days were you in the same room with someone who smoking cigarettes?
A. 0 days
B. 1 or 2 days
C. 3 or 4 days
D. 5 or 6 days
E. 7 days

Item 51 of NYTS. During the past 7 days, on how many days did you ride in a car with someone who was smoking cigarettes?
A. 0 days
B. 1 or 2 days
C. 3 or 4 days
D. 5 or 6 days
E. 7 days

Item 52 of NYTS. Do you think the smoke from other people's cigarettes is harmful to you?
A. Definitely yes
B. Probably yes 

C. Probably not
D. Definitely not

Item 53 of NYTS. Does anyone who lives with you now smoke cigarettes?
A. Yes
B. No

Changed to 4 . Have you seen any of your family members smoking?
a. No, none of my family members smokes
b. I rarely see any of my family members smokes
c. My family member/members has/have stopped smoking
d. Yes, since I was in preschool
e. Yes, since I was in my early elementary years
f. Yes, since I was in my late elementary years
g. Yes, since I was in my early middle school
h. Yes, recently

Item 54 of NYTS. Does anyone who lives with you now use chewing tobacco, snuff, or dip?
A. Yes
B. No

Item 55 of NYTS. How many of your four closet friends smoke cigarettes?
A. None
B. One 
C. Two

D. Three

E. Four

F. Not sure

Item 56 of NYTS. How many of your four closest friends use chewing tobacco, snuff, or dip?
A. None
B. One
C. Two
D. Three
E. Four
F. Not sure

Item 57 of NYTS. Which statement best describes the rules about smoking inside your home?
A. Smoking is not allowed anywhere inside my home
B. Smoking is allowed in some places or at some times
C. Smoking is allowed anywhere in my home
D. There are no rules about smoking in my home

The questions asking about the adolescent's thoughts about tobacco:

Item 58 of NYTS. Do you think you will smoke a cigarette at anytime during the next year?
A. Definitely yes 

B. Probably yes
C. Probably not
D. Definitely not

Item 60 of NYTS. If one of your best friends offered you a cigarette would you smoke it?
A. Definitely yes
B. Probably yes
C. Probably not
D. Definitely not

Item 61 of NYTS. Do you think that you will try a cigarettes soon?
A. I have already tried smoking cigarettes
B. Yes
C. No

Item 64 of NYTS. Do you think it is safe to smoke for only a year or two, as long as you quit after that?
A. Definitely yes
B. Probably yes
C. Probably not
D. Definitely not

Questions asking about tobacco-use induced massages:

Some tobacco companies make items like sports gear, t-shirts, lighters, hats, jackets, and sunglasses that people can buy or receive free. 
Item 66 of NYTS. During the past 12 months, did you buy or receive anything that has a tobacco company name or picture on it?
A. Yes
B. No

Item 67 of NYTS. Would you ever use or wear something that has a tobacco company name or picture on it such as a lighter, $t$-shirt, hat or sunglasses?
A. Definitely yes
B. Probably yes
C. Probably not
D. Definitely not

Events adolescents may have attended or what they have seen or heard on the TV, radio, movies, billboards, signs, newspapers, magazines, stores, or the internet.

Item 69 of NYTS. During the past 30 days, how many times did you see anti-smoking messages on TV?
A. I did not watch TV in the past 30 days
B. None
C. 1 to 3 times in the past 30 days
D. 1 to 3 times per week
E. Daily or almost daily
F. more than once a day

Item 70 of NYTS. During the past 30 days, how many times did you hear anti-smoking messages on the radio? 

A. I did not listen to the radio in the past 30 days
B. None
C. 1 to 3 times in the past 30 days
D. 1 to 3 times per week
E. Daily or almost daily
F. more than once a day

Item 71 of NYTS. During the past 30 days, how many times did you see anti-smoking messages on the internet?
B. None
C. 1 to 3 times in the past 30 days
D. 1 to 3 times per week
E. Daily or almost daily
F. more than once a day

A. I did not use the internet in the past 30 days

Item 72 of NYTS. During the past 30 days, how many times have you seen anti-smoking messages on billboards or outdoor signs?
a. None in the past 30 days
b. 1 to 3 times in the past 30 days
c. 1 to 3 times per week
d. Daily or almost daily
e. more than once a day

Item 73 of NYTS. During the past 30 days, how many times did you see anti-smoking 
messages in magazines or newspapers?
A. I did not read magazines or newspapers
B. None in the past 30 days
C. 1 to 3 times in the past 30 days
D. 1 to 3 times per week
E. Daily or almost daily
F. more than once a day

Item 74 of NYTS. When you watch TV or go to movies, how often do you see actors using tobacco?
A. I don't watch TV or go to movies
B. Most of the time
C. Some of the time
D. Hardly ever
E. Never

Item 75 of NYTS. When you are using the internet, how often do you see ads for tobacco products?
A. I do not use the internet
B. Most of the time
C. Some of the time
D. Hardly ever
E. Never

Item 76 of NYTS. When you read newspapers or magazines, how often do you see ads or 
promotions for cigarettes and other tobacco products?
A. I do not read newspapers or magazines
B. All of the time
c. Most of the time
d. Some of the time
e. Hardly ever
f. Never

Item 77 of NYTS. When you go to a convenience store, supermarket, or gas station, how often do you see ads for cigarettes and other tobacco products or items that have tobacco company names or pictures on them?
A. I never go to convenience store, supermarket, or gas wstation
B. All of the time
c. Most of the time
d. Some of the time
e. Hardly ever
f. Never

Questions asking about if the adolescents were taught about tobacco in the classes.

Item 78of NYTS. During this school year, did you practice ways to say "No" to tobacco in and of your classes (for example, by role playing)?
A. Yes
B. No
C. Not sure 
Item 79 of NYTS. During this school year, were you taught in any of your classes the reasons why people your age smoke?
A. Yes
B. No
C. Not sure

Item 80 of NYTS. During this school year, were you taught in any of your classes that most people your age do not smoke cigarettes?
A. Yes
B. No
C. Not sure

Item 81 of NYTS. During this school your, were you taught in any of your classes about the dangers of tobacco use?
A. Yes
B. No
C. Not sure 


\begin{abstract}
Appendix F
Items from the Indiana Youth Tobacco Use Survey (IYTS):

Questions asking about attitudes toward smoking were adopted two sections of questions from the Indiana Youth Tobacco Use Survey (IYTS) including items regarding perceived peer acceptance to smoking and items regarding perceived benefit of smoking.

Items regarding perceived peer acceptance to smoking:

Do most people of your age think it is okay to smoke?
\end{abstract}
a. Definitely Yes
b. Probably Yes
c. Probably Not
d. Definitely Not 
Appendix G

The Assessment of Prototypes and Subjective Normative Social Images of Smokes consists of three parts:

1) The Assessment of Prototypes of Smokers:

What do you think about kids who smoke?

Kids who smoke are cool

yes no maybe

Kids who smoke are neat/exciting yes no maybe

Kids who smoke are popular/liked by other kids yes

no

maybe

Modified to 1. Do you think kids who smoke are cool?
a. Definitely
b. Probably Yes
c. Probably Not
d. Definitely not

2. Do you think kids who smoke are neat/exciting?
a. Definitely
b. Probably Yes
c. Probably Not
d. Definitely not

3. Do you think kids who smoke are popular/liked by other kids?
a. Definitely
b. Probably Yes 

c. Probably Not
d. Definitely not

2) The assessment of normative social images of smokers:

What your friends think about kids who smoke?

Kids who smoke are cool

Kids who smoke are neat/exciting

Kids who smoke are popular/liked by other kids yes

$$
\text { yes no maybe }
$$$$
\text { yes no maybe }
$$

no maybe

Modified to 4. What your friends think about kids who smoke; do they think kids who smoke are cool?
a. Definitely
b. Probably Yes
c. Probably Not
d. Definitely not

5. What your friends think about kids who smoke: do they think kids who smoke are neat/exciting?
a. Definitely
b. Probably Yes
c. Probably Not
d. Definitely not

6. What do your friends think about kids who smoke; do they think kids who smoke are popular/liked by other kids. 

a. Definitely
b. Probably Yes
c. Probably Not
d. Definitely not

3) The assessment of intention to smoke:

Do you think you would smoke when you grown up?
Response options: yes
no maybe

Do you think you would smoke when you are.... a teenager (for $4^{\text {th }}-6^{\text {th }}$ graders)

$$
\begin{aligned}
& \text { in high school (for } 7^{\text {th }}-8^{\text {th }} \text { graders) } \\
& \text { out of high school (for } 9^{\text {th }} \text { and } 10^{\text {th }}
\end{aligned}
$$

graders)

Response options: yes no maybe

Response options have been modified to:
a. Definitely
b. Probably Yes
c. Probably Not
d. Definitely not 


\section{Appendix H}

The Self-Esteem Questionnaire (SEQ):

The SEQ is comprised of six constructs of self-esteem and options of responses are rated on a 4-point scale ranging from strongly disagree, disagree, agree, and strongly agree, respectively.

Construct 1. Peer relations

1. I am popular with kids my own age as I want to be

7. I am as good as I want to be at making new friends.

13. I have as many close friends as I would like to have.

19. I an as well liked by other kids a I want to be.

25. I feel good about how well I get along with other kids.

30. I wish my friends like me more than they do.

35. I feel good about how much my friends like my ideas.

39. I feel OK about how much other kids like doing things with me.

Construct 2 School self-esteem

2. I am as good a student as I would like to be.

8. I am doing well on school work as I would like to.

14. I am good enough at math.

20. I am as good at reading and writing as I want to be.

26. I get grades that are good enough for me.

31. I feel OK about how good of a student I am.

36. I do as well on tests in school as I want to. 
40. I get too many bad grades on my report cards.

Construct 3. Family

3. I am happy about how much my family likes me.

9. I am too much trouble to my family.

15. I get in trouble too much at home.

21. I feel OK about how important I am to my family.

27. I get along as well as I would like to with my family.

32. My family pay enough attention to me.

37. I am happy with how much my family loves me.

41. I feel good about how much my family cares about my ideas.

Construct 4. Body image

4. I am happy with the way I look.

10. I like my body just the way it is.

16. I feel good about my height and weight.

22. I wish I looked a lot different.

Construct 5. Sport/Athletics

5. I am as good at sports/physical activities as I want to be.

11. I wish I was better at sports/physical activities.

17. I feel OK about how well I do when I participate in sports/physical activities.

23. I am happy about how many different kinds of sports/physical activities I am good at.

28. I wish it were easier for me to learn new kinds of sports/physical activities.

33. I participate in as many different kinds of sports/physical activities as I want to. 


\section{Construct 6. Global Self-Esteem}

6. I am happy with the way I can do most things.

12. I sometimes think I am a failure (a "loser").

18. I am happy with myself as a person.

24. I am the kind of person I want to be.

29. I often feel ashamed of myself.

34. I like being just the way I am.

38. I an as food a person as I want to be.

42. I wish I had more to de proud of. 


\section{Appendix I}

Sensation seeking Scales.

Experience seeking

1. I would like to explore strange places

2. I would like to take off on a trip with no pre-planed routes or timetables.

Boredom susceptibility

3. I get restless when I spend too much time at home

4. I prefer friends who are excitingly unpredictable.

Thrill and adventure seeking

5. I like to do frightening things.

6. I would like to try bungee jumping.

Disinhibition

7. I like wild parties.

8. I would live to have new and exciting experiences, even if they are illegal.

The instrument is a five-point scale labeled as strongly disagree, disagree, neither disagree nor agree, agree, and strongly agree, respectively. 